Aus der Abteilung Präventive Zahnmedizin, Parodontologie und Kariologie

(Komm. Direktor: Prof. Dr. med. dent. M. Hülsmann)

im Zentrum Zahn-, Mund- und Kieferheilkunde

der Medizinischen Fakultät der Universität Göttingen

\title{
Untersuchung neuer Techniken zur Entfernung von Kalziumhydroxid aus dem Wurzelkanalsystem gerader Wurzelkanäle
}

\author{
INAUGURAL - DISSERTATION \\ zur Erlangung des Doktorgrades \\ für Zahnheilkunde \\ der Medizinischen Fakultät \\ der Georg-August-Universität zu Göttingen
}

vorgelegt von

Anne-Kathrin Schmidt

aus

Bensheim

Göttingen 2011 
Dekan: Prof. Dr. med. C. Frömmel

I. Berichterstatter: Prof. Dr. med. dent. M. Hülsmann

II.Berichterstatter: Priv.-Doz. Dr. med. dent. W. Hahn

III. Berichterstatter/in:

Tag der mündlichen Prüfung: 


\section{Inhaltsverzeichnis}

1 Einleitung

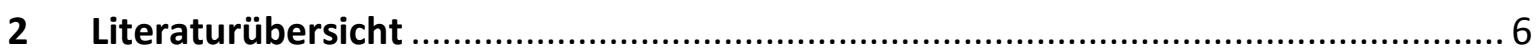

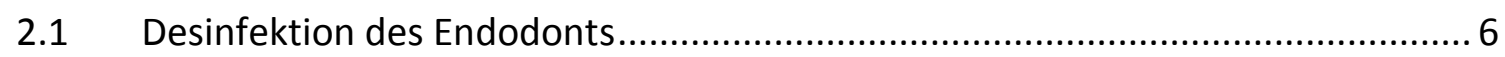

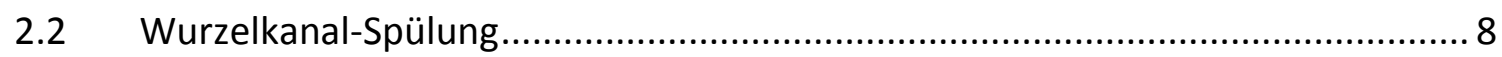

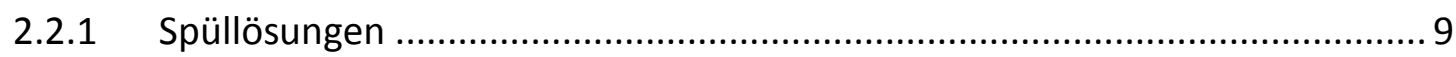

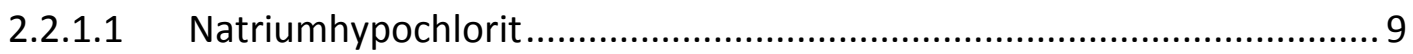

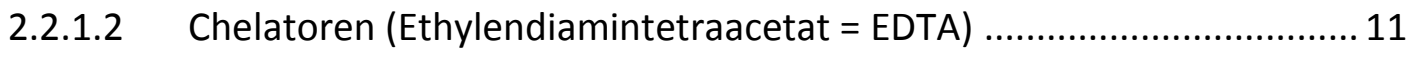

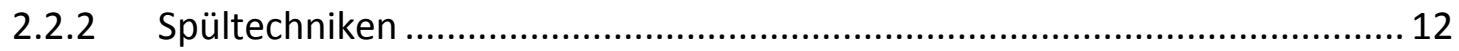

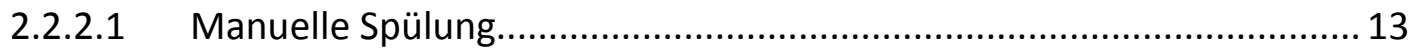

2.2.2.2 Hydrodynamische Spülung mit RinsEndo ${ }^{\circledR}$......................................... 16

2.2.2.3 Passive Ultraschallspülung ............................................................ 20

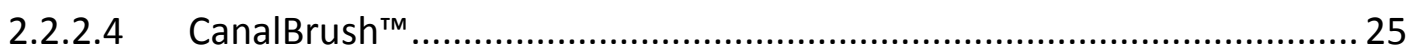

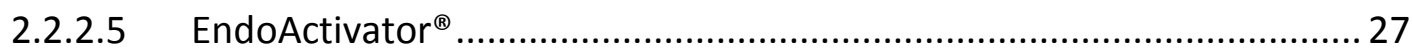

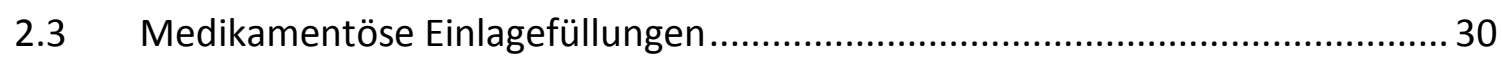

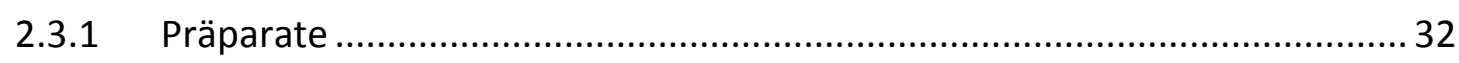

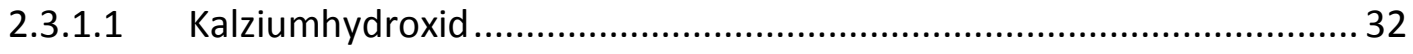

2.3.1.1.1 Historischer Überblick ................................................................. 32

2.3.1.1.2 Chemie und Wirkungsweise …...................................................... 33

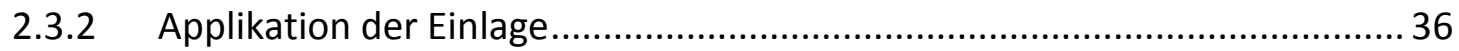

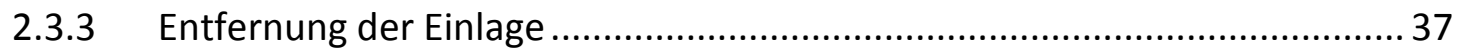

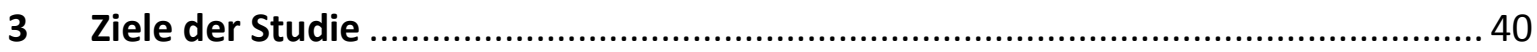

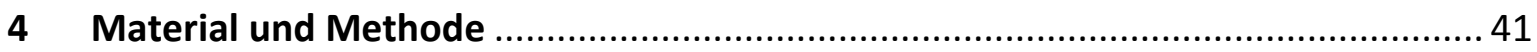

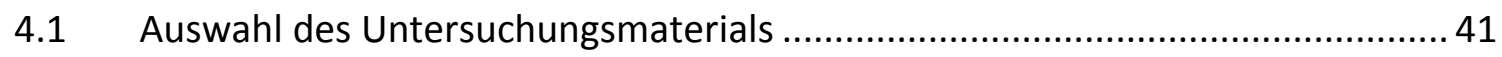

4.1.1 Herstellen der Wurzelhälften und Präparation der Gruben ........................ 42 


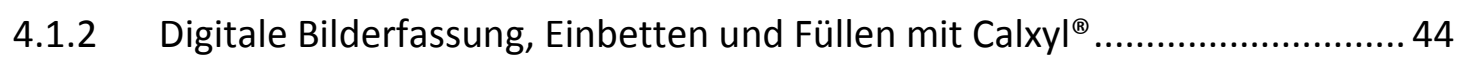

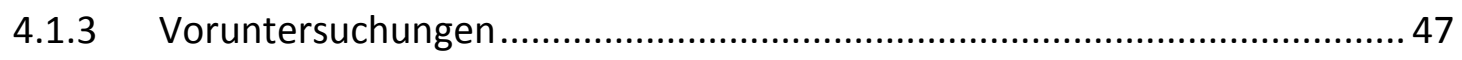

4.2 Verwendete Aktivierungsgeräte............................................................. 47

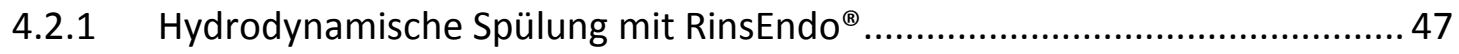

4.2.2 Mechanisch-aktivierte Spülung (CanalBrush $\left.{ }^{\mathrm{TM}}\right)$........................................ 48

4.2.3 Schall-aktivierte Spülung $\left(\right.$ EndoActivator $\left.^{\circledR}\right)$.............................................. 48

4.2.4 Ultraschall-aktivierte Spülung (Piezon Master 400) .................................... 48

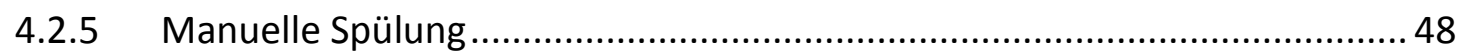

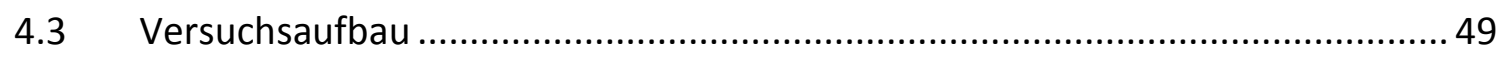

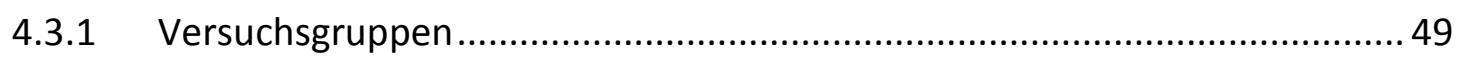

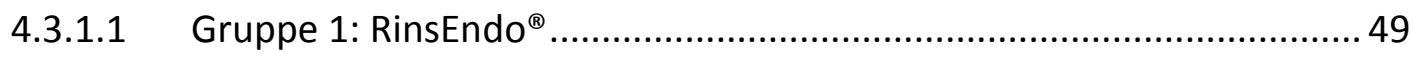

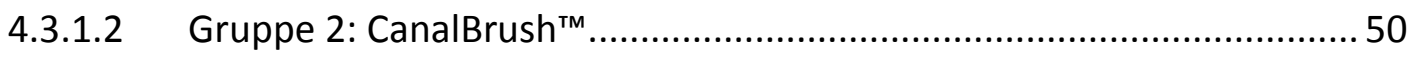

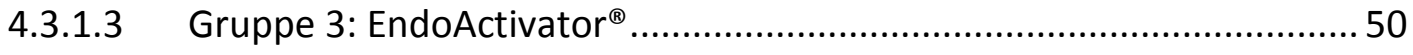

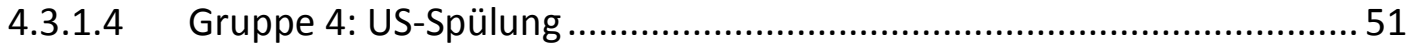

4.3.1.5 Gruppe 5: Handspülung (Kontrollgruppe) ........................................ 51

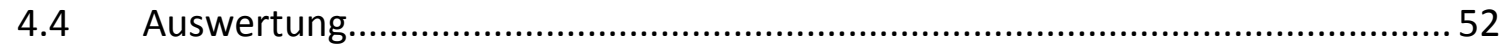

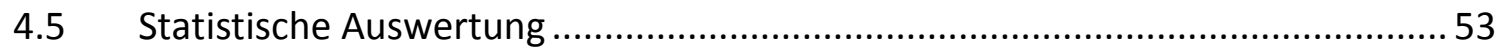

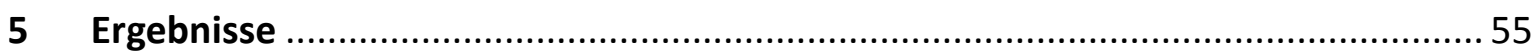

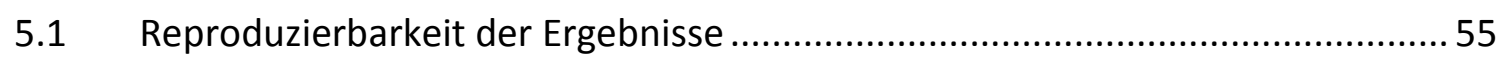

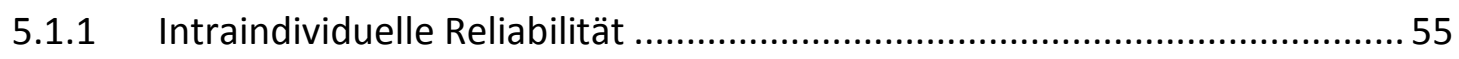

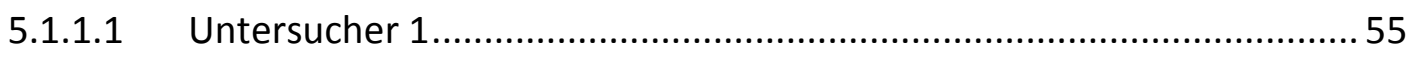

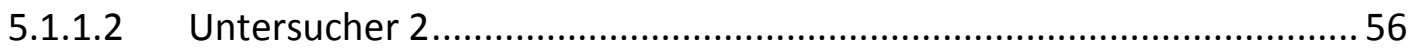

5.1.2 Interindividuelle Reliabilität .................................................................. 56

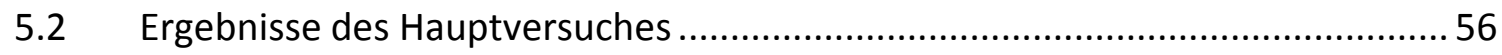

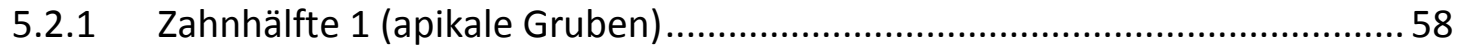

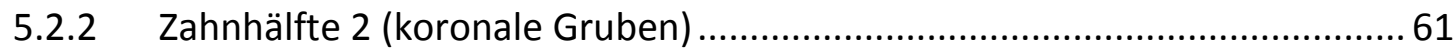




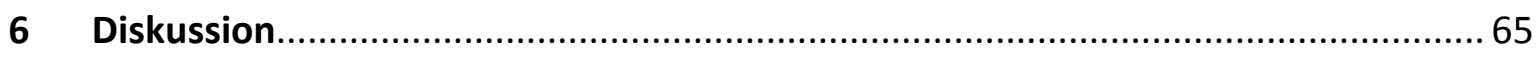

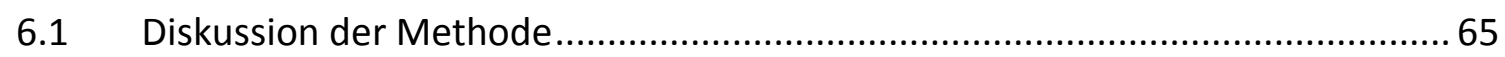

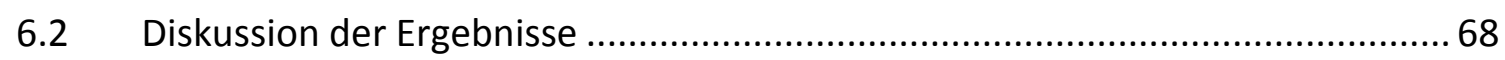

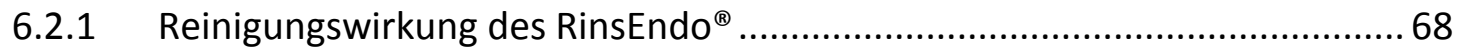

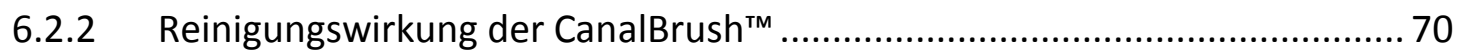

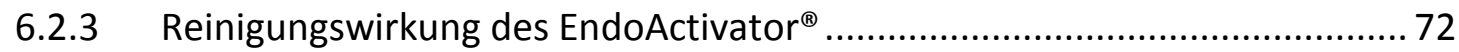

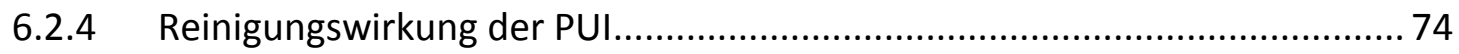

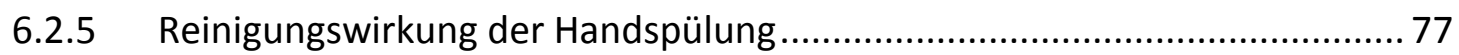

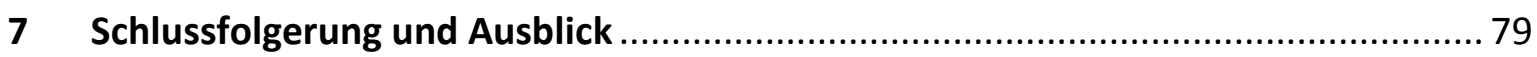

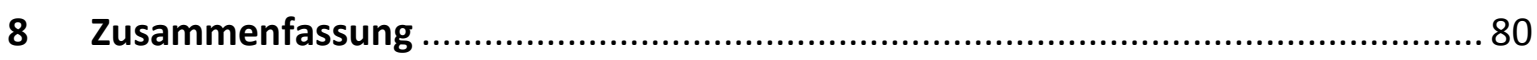

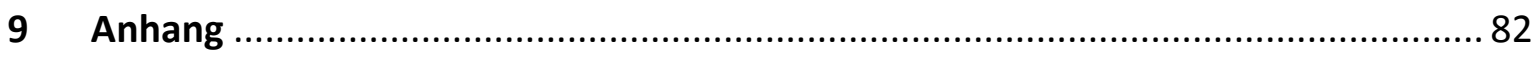

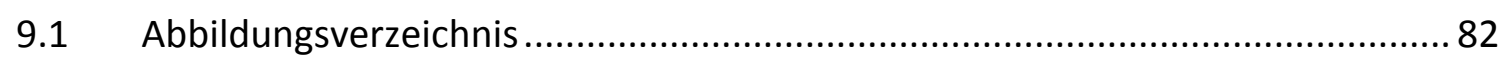

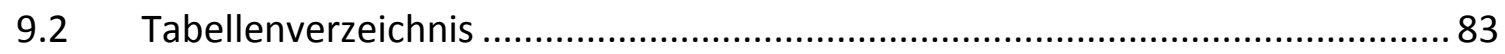

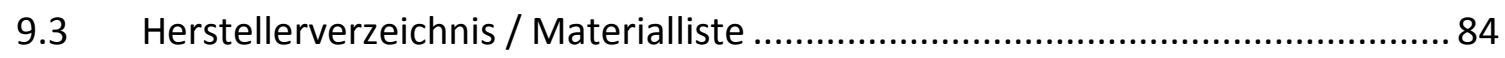

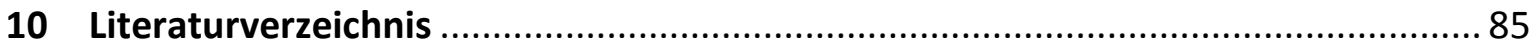




\section{Einleitung}

Ziele jeglicher konservierender zahnärztlicher Maßnahmen sind der Zahnerhalt und das Bewahren einer funktionsfähigen Kaueinheit. Inzwischen hat sich die Endodontie zu einem wissenschaftlich fundierten Spezialgebiet entwickelt, das sich mit der Morphologie, Physiologie und Pathologie des Pulpa-Dentin-Komplexes sowie den assoziierten klinischen Maßnahmen in Diagnostik, Prävention und Therapie beschäftigt.

Das langfristige Ziel jeder endodontischen Therapie ist es, den Zahn inklusive dessen Wurzel zu erhalten und als Infektionsquelle auszuschließen (Strindberg 1956). Seit langem ist bekannt, dass mikrobielle Infektionen die Ursache der meisten zu therapierenden endodontischen Pathologien sind. Viele bakterielle Infektionen des Körpers können von der allgemeinen körpereigenen Abwehr (oder in Kombination mit Antibiotika) eliminiert werden. Dies trifft für Infektionen des Wurzelkanalsystems leider nicht zu. Das ultimative Ziel der Wurzelkanalbehandlung ist es, den mikrobiellen Faktor (incl. Stoffwechselprodukten und Substratquellen) innerhalb der komplexen Wurzelkanalanatomie und im apikalen Periodont zu beherrschen (Nair et al. 2005), um eine Heilung zu ermöglichen (Haapasalo $\mathrm{M}$ et al. 2005).

Rein mechanisch ist die Entfernung nekrotischen, purulenten und infizierten Gewebes nur im Hauptkanal (bzw. den routinemäßig instrumentell zugänglichen Bereichen) möglich beachtet man dabei die komplexe Wurzelkanalanatomie, wird die limitierte Wirkung dieser Maßnahme deutlich (Byström und Sundqvist 1981; Ørstavik et al. 1991; Dalton et al. 1998). Mit Hilfe chemischer Spüllosungen werden auch Seitenkanälchen und nicht instrumentierte Bereiche des Wurzelkanalsystems erreicht - dies ist jedoch abhängig von der Applikationsmöglichkeit. Unterstützend zur Kontrolle der entzündlichen Situation und wenn aus Zeitgründen eine definitive Füllung nicht in der ersten Sitzung erfolgen kann, wird als Mittel der Wahl Kalziumhydroxid als medizinische Einlage verwendet. Man verspricht sich davon vor allem eine zusätzliche antimikrobielle Wirkung. Die Applikation von Kalziumhydroxid bis zum Foramen apicale ist auf vielfältige Weise möglich. Kritisch ist jedoch die Entfernung desselben: häufig bleiben Reste an der Wurzelkanalwand und in nicht instrumentierbaren Einziehungen zurück, die zu Undichtigkeiten und „leakages" der Wurzelkanalfüllung führen können. 
Da die natürliche Dentinstruktur mit den Dentintubuli Bakterien und deren Toxinen gute Überlebensmöglichkeiten bietet, könnte entlang eines „leakages“ die Infektion wieder aufflammen.

Mit Ausnahme der Oberkieferschneidezähne weisen nahezu alle Wurzelkanäle einen elliptisch-bandförmigen Kanalquerschnitt auf (Riitano 1981; Gulla et al. 1990). Die uns verfügbaren runden Präparationsinstrumente befördern zusätzlich Debris, Bakterienbestandteile und Rückstände von medikamentösen Einlagen in die nicht instrumentierbaren Bereiche. Daher ist es äußerst wichtig, sich genauer mit deren Reinigung zu beschäftigen und neue Techniken und Spülprotokolle zu entwickeln und zu erproben, die eine Verbesserung der Reinigung von Wurzelkanälen in der RoutineWurzelkanalbehandlung ohne großen Mehraufwand für den Zahnarzt ermöglichen. 


\section{Literaturübersicht}

\subsection{Desinfektion des Endodonts}

Generell ist die Desinfektion definiert als eine gezielte, selektive Keimabtötung mit dem Ziel, eine Übertragung von Infektionen durch unerwünschte Mikroorganismen zu verhindern (Muschol und Speer 1978), bzw. als eine Maßnahme, die durch Abtöten, Inaktivieren und Entfernen von Mikroorganismen eine Reduzierung der Keimzahl um mindestens fünf Zehnerpotenzen erreicht, damit von dem desinfizierten Material keine Infektion mehr ausgehen kann (Pschyrembel 2010). Eine Desinfektion kann mechanisch, z.B. durch Reiben, physikalisch durch Strahlen (z.B. UV-Strahlen) oder Hitze sowie chemisch durch Desinfektionsmittel durchgeführt werden. Die Wirkung der Desinfektionsmittel wird durch Proteinschädigung, Permeabilitätsveränderung der Zellmembran oder die Blockade von Enzymsystemen der Mikroorganismen erzielt.

Mikrobiologische Analysen von Wurzelkanälen mit infizierter, beziehungsweise nekrotischer Pulpa belegen deutlich, dass es sich in der Regel um bakterielle Infektionen handelt. Man findet sowohl anaerobe Bakterien, vor allem gramnegative Spezies der Genera Porphyromonas, Prevotella, Fusobacterium und Campylobacter, grampositive Anaerobier der Genera Peptostreptococcus, Eubacterium und Pseudoramibacter sowie fakultative und mikroaerophile Streptokokken als auch Pilze (Sundqvist 1992; Lana et al. 2001; Peters LB et al. 2002b). Die Anzahl der Mikroorganismen im Wurzelkanal beträgt in der Regel zwischen $10^{3}$ und $10^{8}$ koloniebildende Einheiten (Colony Forming Unit $=$ CFU) (Kantz und Henry 1974; Fabricius et al. 1982; Sundqvist et al. 1989). Die Größe der apikalen Knochendestruktion korreliert signifikant mit der Anzahl von Mikroorganismen im Wurzelkanal (Byström et al. 1987; Siqueira und Rôças 2008). In obturierten Wurzelkanälen mit persistierender Infektion lassen sich andere Spezies isolieren. In mehreren Studien wurde eine hohe Prävalenz von Enterokokken und Streptokokken gefunden; dabei ist Enterococcus faecalis der am häufigsten isolierte Erreger (Molander et al. 1998; Sundqvist et al. 1998; Pinheiro et al. 2003a). In anderen Studien in größeren Mengen isolierte Spezies waren Peptostreptokokken, Actinomyces (Hancock et al. 2001; Pinheiro et al. 2003b) und Lactobazillen (Molander et al. 1998). Aufgrund der Fähigkeit der Mikroorganismen zur Dentinadhäsion und Penetration in Dentintubuli (Waltimo et al. 
2000) sowie zur Ausbildung von Biofilmen (Sen et al. 1997; Distel et al. 2002) wird die Desinfektion des Wurzelkanalsystems erschwert. Die Erkenntnis, dass es sich bei der Infektion des endodontalen Systems um einen Biofilm (Def.: ein- oder mehrzellige Schicht von Zellen, die in eine extrazelluläre Matrix eingebettet sind) handeln kann, ist bedeutend für die Auswahl der Behandlungsstrategien. Gulabivala (2005) postuliert, dass diese bei der ersten Behandlung ausreichend effektiv sein sollten, um eine Dominanz der Infektion durch überlebende resistente Mikroorganismen zu verhindern.

Die in Laborversuchen ermittelte antimikrobielle Effizienz von Desinfektionslösungen gegen einzelne Bakterienspezies kann nur mit Einschränkung auf die Wirkung gegenüber Biofilmen übertragen werden. Die in einen Biofilm eingebundenen Mikroorganismen können resistent sein gegenüber der Wirtsabwehr und antimikrobieller Therapie (Svensäter und Bergenholtz 2004). Persistierende Mikroorganismen werden daher auch für die Misserfolge einer Wurzelkanalbehandlung verantwortlich gemacht (Molander et al. 1998; Sundqvist et al. 1998).

In zahlreichen Studien wurde der Effekt der verschiedenen Behandlungsschritte einer Wurzelkanalbehandlung auf die mikrobielle Flora im infizierten Wurzelkanal untersucht. In einigen Arbeiten wird die alleinige Reduktion durch die mechanische Präparation bewertet (Gulabivala 2005). Byström und Sundqvist (1981) konnten bei Zähnen mit infizierter Pulpanekrose und apikaler Läsion zeigen, dass sich die Zahl der Mikroorganismen im Wurzelkanalsystem nach mechanischer Instrumentierung und Spülung mit Kochsalzlösung signifikant um den Faktor 100 bis 1000 verringerte. Doch selbst nach wiederholter Präparation an fünf aufeinander folgenden Behandlungstagen enthielten 7 der 15 Wurzelkanäle immer noch anzüchtbare Mikroorganismen (Byström und Sundqvist 1981). Ørstavik et al. (1991) konnten diesen limitierten antimikrobiellen Effekt bestätigen. In ihrer Studie wiesen 14 der behandelten 23 Zähne ein positives Kulturergebnis auf. Auch Dalton et al. (1998) fanden in $72 \%$ der Versuchszähne kultivierbare Mikroorganismen. Ebenso konnten Siqueira et al. (1999) nach Infektion von Wurzelkanälen mit Enterococcus faecalis durch Präparation unter Verwendung maschineller und manueller Präparationstechniken und der Spülung mit Kochsalzlösung nur eine ca. 90\%ige Reduktion, jedoch keine vollständige Elimination der Bakterien erreichen. 
Bei der reinen Instrumentierung wird ungefähr ein Drittel der Wurzelkanaloberfläche nicht bearbeitet. Durch die instrumentelle Bearbeitung entsteht eine Schmierschicht („,smear layer“) (Sen et al. 1995b; Koçkapan 1995), die ebenfalls bakteriell kontaminiert ist und eine effektive Desinfektion der Dentintubuli verhindert.

Es wird deutlich, dass die alleinige mechanische Präparation des Wurzelkanalsystems nicht in der Lage ist, die Infektion desselben vollständig zu eliminieren. Daher ist der zusätzliche Einsatz antimikrobiell wirksamer Substanzen mit dem Ziel einer verbesserten Reinigung insbesondere der nicht instrumentierten Bereiche unbedingt notwendig (Peters OA 2004; Paqué et al. 2009).

Der Zerstörung des Biofilms sollte hierbei ein beträchtlicher Stellenwert zugewiesen werden. Dabei sind die Aktivierung der Spülflüssigkeiten und die mechanische Wirkung neuer Aktivierungssysteme bedeutend und müssen weiterhin Bestandteil der Forschung sein.

\subsection{Wurzelkanal-Spülung}

Die Spülung des Wurzelkanalsystems mit antibakteriell wirksamen und gewebeauflösenden Substanzen stellt einen integralen Bestandteil der chemomechanischen Wurzelkanalpräparation dar (Barthel et al. 2006). Sie unterstützt die Reinigung vor allem jenseits der Areale, die durch instrumentelle Bearbeitung erreicht werden (Svec und Harrison JW 1977; Gulabivala und Stock 2005). Es ergeben sich folgende Anforderungen und Ziele, die durch eine Spülung des Wurzelkanals mit einer Spüllösung verfolgt werden (Hülsmann 1997; Harrison JW 1984; Koçkapan 2003; Hülsmann 2006; Zehnder 2006):

- Desinfektion des Wurzelkanalsystems durch Auflösung des Biofilms und antimikrobielle Wirkung gegen anaerobe und fakultative Mikroorganismen

- Inaktivierung bakterieller Toxine (Lipopolysaccharide)

- Auflösung und Entfernung organischen und anorganischen Kanalinhaltes

- Unterstützung der mechanischen Präparation und Abtransport der Dentinspäne

- Gleitwirkung für die Wurzelkanalinstrumente 
- Auflösen und Entfernen der Schmierschicht, bzw. Verhinderung der Bildung derselben

- gute Gewebeverträglichkeit und niedrige Zytotoxizität.

Die ideale Wurzelkanalspüllösung sollte alle beschriebenen Bedingungen erfüllen, um zum endodontischen Erfolg zu führen (Zehnder 2006). Aufgrund der Vielzahl der an die Spüllösung gestellten Anforderungen und Ziele gibt es jedoch keine Substanz, die all diese erfüllen könnte. Daher ist eine Kombination verschiedener Agenzien sinnvoll (Hülsmann 2006; Hülsmann und Schäfer 2007). Diese sollten so eingesetzt werden, dass sie ihre volle Wirkung entfalten können und sich nicht gegenseitig beeinträchtigen (Zehnder 2006).

\subsubsection{Spüllösungen}

Es steht eine große Auswahl verschiedener Spüllösungen und -agenzien zur Verfügung. An dieser Stelle wird vertiefend auf die in der Endodontie häufig verwendeten und auch in dieser Studie eingesetzten Spüllösungen eingegangen.

\subsubsection{Natriumhypochlorit}

Die endodontische Anwendung des Natriumhypochlorits ( $\mathrm{NaOCl}$ ) wurde erstmals von Coolidge (1919) empfohlen. $\mathrm{NaOCl}$ gilt heute als Standardspüllösung für die Reinigung und Desinfektion des Wurzelkanalsystems (Hülsmann und Schäfer 2007). Verwendet wird es in Konzentrationen von $0,5 \%$ bis $5,25 \%$. NaOCl dissoziiert in wässriger Lösung zu Natrium $\left(\mathrm{Na}^{+}\right)$- und Hypochloritionen $\left(\mathrm{OCl}^{-}\right)$. Der $\mathrm{pH}$-Wert der in der Endodontie verwendeten Lösungen liegt bei etwa 12 , somit liegt das verfügbare Chlor fast vollständig als Hypochlorit vor (Zehnder 2006). Dieses chloriert Protein-Endgruppen und fragmentiert Peptidketten. Dabei entstehen Chloramine, die weiter abgebaut werden können. Diese Eigenschaft erklärt die Iytische Wirkung auf Mikroorganismen, Gewebe und die organische Dentinmatrix. $\mathrm{NaOCl}$ ist als einzige Spülflüssigkeit in der Lage, sowohl nekrotisches als auch vitales Pulpagewebe effizient aufzulösen (Hand et al. 1978; Andersen et al. 1992; Naenni et al. 2004). Hinsichtlich der Fähigkeit, nekrotisches Gewebe aufzulösen, ist bereits eine 1\%ige Lösung anderen üblichen Spüllösungen, wie z.B. Wasserstoffperoxid, Zitronensäure oder Chlorhexidin, signifikant überlegen (Naenni et al. 
2004). Es ist jedoch in keiner der empfohlenen Konzentrationen in der Lage, die Schmierschicht vollständig aufzulösen, sondern löst nur deren organische Anteile (Baumgartner und Cuenin 1992).

In verschiedenen Studien konnte eine sehr gute antimikrobielle Wirkung gegen zahlreiche endodontisch relevante Keime (Byström und Sundqvist 1983, 1985; Shuping et al. 2000; Waltimo et al. 2005) ermittelt werden. Waltimo et al. (1999) fanden ebenso eine Abtötung von Candida albicans in vitro. Dies konnte von Radcliffe et al. (2004) bestätigt werden. Hinsichtlich der Wirksamkeit gegenüber Endotoxinen (Lipopolysaccharide aus der Zellwand gramnegativer Bakterien) konnte jedoch nur eine geringfügige (Buck et al. 2001) bzw. keine (Tanomaru et al. 2003; de Oliveira et al. 2007) Inaktivierung festgestellt werden. Auch bezüglich des Problemkeims Enterococcus faecalis liegen keine eindeutigen Studienergebnisse vor. So wird von einer konzentrationsabhängigen Wirksamkeit in vitro berichtet (Gomes et al. 2001), aber auch von 100\%iger Keimelimination im Einzel-SpeziesBiofilm-Modell (Spratt et al. 2001), sowie von einer vollständigen polymikrobiellen Biofilm-Auflösung durch $\mathrm{NaOCl}$ (Clegg et al. 2006). Bryce et al. (2009) fanden für $\mathrm{NaOCl}$ die größte Effektivität bei der Zerstörung von Einzel- und Dual-Spezies-Biofilmen.

Die antimikrobielle Wirksamkeit in vivo ist jedoch deutlich geringer (Siqueira et al. 2007a, b, c) und scheint weniger abhängig von der verwendeten Konzentration zu sein (Siqueira et al. 1998). Dies lässt sich durch die Versuchsbedingungen in vitro erklären, die weder die komplexe Struktur des Wurzelkanalsystems noch die Morphologie der Infektion berücksichtigen. Ebenfalls kann die Wirksamkeit von $\mathrm{NaOCl}$ in vivo durch das Vorhandensein von Dentinspänen und Serumproteinen verringert sein (Haapasalo HK et al. 2000; Portenier et al. 2001).

Eine Konzentrationssteigerung des $\mathrm{NaOCl}$ hat scheinbar keine allzu große Relevanz bezüglich der antibakteriellen Wirksamkeit (Byström und Sundqvist 1985; Siqueira et al. 2000; Sena et al. 2006). Vielmehr sollen zur Gewährleistung der antimikrobiellen Effektivität der regelmäßige Austausch und die Verwendung großer Volumina entscheidender sein (Siqueira et al. 2000). Ebenso können hoch konzentrierte Lösungen nach Extrusion in das periapikale Gewebe schwerste Nebenwirkungen auslösen (Hülsmann und Hahn 2000; Witton et al. 2005). Daher wird eine Anwendung niedrig konzentrierter (0,5-1\%) Lösungen bei einer Volumensteigerung empfohlen (Zehnder 2006). Eine deutliche Wirkungsverstärkung bezüglich der Auflösung vitaler Gewebeanteile 
kann ebenso durch Erwärmen der Lösungen unmittelbar vor der Anwendung erreicht werden. So zeigt eine $1 \%$ ige $\mathrm{NaOCl}$-Lösung bei $45{ }^{\circ} \mathrm{C}$ den gleichen gewebeauflösenden Effekt wie eine $5,25 \%$ ige bei $20^{\circ} \mathrm{C}$; bei gleichen Konzentrationen führt eine Temperaturerhöhung von $20^{\circ} \mathrm{C}$ auf $45^{\circ} \mathrm{C}$ zu einer Steigerung der antibakteriellen Wirksamkeit um den Faktor 100 (Sirtes et al. 2005). Bei der Wahl der Konzentration ist zu berücksichtigen, dass $\mathrm{NaOCl}$ in Abhängigkeit von seiner Konzentration einen negativen Einfluss auf die Dentineigenschaften hat (Marending und Zehnder 2007).

Zukünftige Spülmethoden werden daher wahrscheinlich eher darauf abzielen, $\mathrm{NaOCl}$ in seiner Wirkung zu unterstützen, als es komplett zu ersetzen (Ørstavik 2003).

\subsubsection{Chelatoren (Ethylendiamintetraacetat = EDTA)}

Infolge der mechanischen Präparation des Wurzelkanals entstehen an den bearbeiteten Abschnitten der Wurzelkanalwand amorphe irreguläre Auflagerungen. Diese Schmierschicht besteht aus einem Gemisch von zurückgebliebenem Dentinabrieb, Resten des Pulpagewebes, koagulierten Proteinen und Blutzellen, demnach aus organischen als auch anorganischen Substanzen (Yamada et al. 1983; Koçkapan 1995). Bei einem Zahn mit infizierter Pulpa enthält sie auch Bakterien. Sie sorgt für einen Verschluss der Tubuliöffnungen und Seitenkanäle bis zu einer Tiefe von $40 \mu \mathrm{m}$ (Sen et al. 1995b; Koçkapan 2003; Gulabivala 2005). Oberflächliche, ca. 1-5 $\mu$ m dicke Ablagerungen bilden eine allgemeine Diffusionsbarriere und setzten dadurch die Permeabilität des Dentins um 25-30\% herab. In infizierten Fällen können diese Ablagerungen von Bakterien besiedelt sein und die antimikrobiellen Effekte von medikamentösen Einlagen in Dentintubuli verzögern oder verhindern (Sen et al. 1995b). Nach der Wurzelkanalfüllung sind Bakterien über die verbliebene Schmierschicht als Substratquelle in der Lage, das Wurzelkanalsystem wieder vollständig zu besiedeln (Drake et al. 1994). Die Entfernung der Schmierschicht stellt daher einen wichtigen Schritt zur Desinfektion des Wurzelkanalsystems dar (Torabinejad et al. 2002; Haapasalo M et al. 2005). Die Spülung mit $\mathrm{NaOCl}$ führt selbst in Konzentrationen von 5,25\% nicht zu einer Auflösung der Schmierschicht (Baumgartner und Cuenin 1992). Eine wirkungsvolle Entfernung der Schmierschicht kann nur durch den Einsatz von Säuren oder Chelatoren gelingen, bleibt jedoch unvollständig (Koçkapan 2003). EDTA unterstützt den Lösungsprozess durch 
Chelatbildung mit Schwermetallionen, die normalerweise als Brückenbildner zwischen den einzelnen Bakterien fungieren (Gulabivala und Stock 2005).

Ebenso wird das Erschließen von Seitenkanälen für desinfizierende Agenzien hierdurch erleichtert (Byström und Sundqvist 1985; Ørstavik und Haapasalo M 1990) und die Adaptation und Dichtigkeit der Wurzelkanalfüllung an die Kanalwand verbessert (Shahravan et al. 2007). Eine effiziente Entfernung der Schmierschicht mit 17\%igem EDTA wurde bereits nach einer Minute Spülzeit erreicht (Crumpton et al. 2005). Bei längerer Kontaktzeit sind andernfalls ausgeprägte peritubuläre und intratubuläre Dentinerosionen die Folge, vor allem bei kombinierter Benutzung mit $\mathrm{NaOCl}$ (Niu et al. 2002; Calt und Serper 2002). Zudem kann der inhibierende Effekt des Dentins auf antibakterielle Spüllösungen durch Vorbehandlung mit Chelatoren deutlich reduziert werden (Portenier et al. 2002). Dies könnte die verbesserte antibakterielle Wirksamkeit der Kombination von $\mathrm{NaOCl}$ und EDTA erklären (Byström und Sundqvist 1985). Die Spülung mit Chelatoren hat ebenso einen Einfluss auf die Dentinhärte. Mehrere Studien zeigten nach Verwendung von 17\%igem EDTA eine signifikante Verringerung der Dentinhärte nach einminütigem (Saleh und Ettman 1999) bzw. nach 15 minütigem Einsatz (Ari et al. 2004).

Trotzdem wurde die große Wirksamkeit der Kombination von $\mathrm{NaOCl}$ und EDTA als Abschlussspülung nach der Präparation des Wurzelkanalsystems zur Beseitigung der mikrobiellen Infektion und zur Entfernung der Schmierschicht mehrfach beschrieben und empfohlen (Hülsmann et al. 2003, Gulabivala et al. 2005; Zehnder 2006; Rödig et al. 2010a).

\subsubsection{Spültechniken}

Die Wurzelkanalspülung sollte im Idealfall in alle Verzweigungen und nicht instrumentierbaren Bereiche des endodontischen Systems penetrieren. Dabei ist es für die Spüllösung aufgrund des sogenannten „vapor-lock“-Effekts oft schwierig, den apikalen Anteil des Wurzelkanals zu erreichen (Pesse et al. 2005; Schoeffel 2008).

In der Vergangenheit wurden mehrfach Versuche unternommen, Apparate zur Erleichterung des Spülvorgangs zu entwickeln (Koçkapan 2003). Zumeist handelte es sich dabei um kombinierte Spül-Saug-Vorrichtungen oder -kanülen. Keines dieser Systeme konnte sich jedoch etablieren und der Spülvorgang als solcher geriet aus dem Blickfeld 
der Forschung, so dass die manuelle Spülung des Wurzelkanals mittels Einwegspritze und -kanüle noch heute das Standardverfahren der endodontischen Behandlung darstellt (Peters OA 2004). Vielmehr wurden hauptsächlich die verschiedenen Spüllösungen und -protokolle diskutiert. Die Erkenntnis, dass Reinigungs- und Desinfektionsmaßnahmen abhängig sind von der chemischen und der mechanischen Wirkung der Spüllösung (Siqueira et al. 1999), die mechanische Reinigungswirkung der konventionellen Handspülung relativ gering ist und große Unterschiede zwischen verschiedenen Anwendern bestehen (Boutsioukis et al. 2007), führte dazu, dass in den letzten Jahren zahlreiche manuelle und maschinelle Hilfsmittel und Systeme entwickelt wurden, die entweder die Applikation der Spüllösung und/oder die mechanische Aktivierung der Flüssigkeit ermöglichen (Rödig 2010). Dazu gehören verschiedene KanülenModifikationen, Bürstchen, Schall (Sabins et al. 2003), Ultraschall (Cunningham et al. 1982a, b; Sabins et al. 2003) und Wechsel-Druck-Systeme. Zu der letzten Gruppe gehören beispielsweise das RinsEndo ${ }^{\circledR}$ (Braun et al. 2005; Muselmani et al. 2005a), Endo-Vac (Fukumoto et al. 2006; Nielsen und Craig Baumgartner 2007) und andere Variationen intrakanalärer Aspiration (Lussi et al. 1993; Walters et al. 2002).

\subsubsection{Manuelle Spülung}

Die konventionelle Spülung beinhaltet das Verteilen der Spüllösung in einem Wurzelkanal mit Hilfe einer herkömmlichen Spritze und Applikationsnadeln unterschiedlichen Durchmessers $(0,23-0,4 \mathrm{~mm})$. Dies kann sowohl passiv, d.h. statisch an einem Applikationsort im Wurzelkanal, als auch aktiviert mit kleinen vertikalen Bewegungen der Kanüle stattfinden. Um die Gefahr des Ablösens der Spülkanüle während des Gebrauchs zu verhindern, sollten Einwegspritzen mit Luer-Lock-Verbindung benutzt werden (Manogue et al. 2005; Lumley et al. 2006).

Die Gestaltung der Kanülenöffnung ist unterschiedlich. Einige geben die Flüssigkeit an ihrem äußersten Ende ab, bei anderen ist das Ende verschlossen und die Flüssigkeit kann seitlich entweichen.

Ein Vorteil der Handspülung ist die vergleichbar leichte Kontrolle der Eindringtiefe der Nadel und der Menge der abgegebenen Spüllösung (van der Sluis et al. 2006). Trotzdem ist die mechanische Wirkung, die von normalen Spritzenspülungen erreicht wird, relativ 
schwach. Die Reinigung des gesamten Wurzelkanals resultiert in einer besseren Sauberkeit weiter koronal gelegener Kanalanteile im Vergleich zum apikalen Drittel (Abou-Rass und Piccinino 1982; Albrecht et al. 2004). Ram (1977) konnte zeigen, dass bei der Spülung mit einer Kanüle die Spülflüssigkeit nur $1 \mathrm{~mm}$ tiefer als das Nadelende in den Kanal eindringt. Durch erhöhten Spüldruck kann eine bis zu $2 \mathrm{~mm}$ tiefer gehende Wirkung erzielt werden (Ram 1977). Ein Problem ergibt sich bei größeren Nadeldurchmessern oder gekrümmten Kanälen. Dort reicht die Nadelspitze oft nur in das koronale bzw. bei weitlumigen Kanälen bis in das mittlere Kanaldrittel (Chow 1983). Entscheidend für das Vordringen der Spülflüssigkeit bis in die apikalen Kanalbereiche ist daher die Eindringtiefe der Nadel. Die ist zum einen abhängig von dem Durchmesser der verwendeten Spülkanüle als auch von der apikalen Präparationsgröße des Wurzelkanals. Durch die Herstellung dünnerer Nadeln kann ein tiefer reichender und effizienterer Flüssigkeitsaustausch und damit verbundenes verbessertes Debridement erreicht werden (Chow 1983; Sedgley et al. 2005; van der Sluis et al. 2006; Hsieh et al. 2007).

Schon Grossmann (1943) erkannte die Notwendigkeit der Erweiterung des Wurzelkanals. Ram (1977) forderte einen apikalen Präparationsdurchmesser der ISO-Größe 40, um effektiv spülen zu können. Diese Forderung wurde in mehreren Studien bestätigt (Wu und Wesselink 1995; Albrecht et al. 2004; Usman et al. 2004; Falk und Sedgley 2005). Khademi et al. (2006) halten eine Mindestpräparationsgröße von 30/.06 erforderlich, um mit einer 27-„,gauge“-Kanüle eine ausreichende Reinigungswirkung im Apikalbereich zu erzielen. Auch in gekrümmten Kanälen war die Spülung nach Präparation bis 46/.04 signifikant effektiver als nach Präparation bis 27/.04, obwohl sich auch dort die 30-„gauge“-Kanüle bis $1 \mathrm{~mm}$ vor Arbeitslänge vorschieben ließ (Nguy und Sedgley 2006). Zu große Aufbereitungsdurchmesser scheinen jedoch Turbulenzen in der Spüllösung hervorzurufen, die ein Herausspülen von Debris und Mikroorganismen verhindern können (Hsieh et al. 2007). Je tiefer die Nadel inseriert ist, desto höher ist die mechanische Effektivität. Mehrere In-vitro-Studien zur Entfernung von Dentin- (Brown und Doran 1975) und Gelpartikeln (Chow 1983) aus simulierten Wurzelkanälen und von radioopakem Dentindebris (Abou-Rass und Piccinino 1982) und Mikroorganismen (Kahn et al. 1995) aus Wurzelkanälen extrahierter Zähne belegen dies. Auch Sedgley et al. (2004) konnten eine signifikant bessere rein mechanische Wirkung der Spülung mit 
Wasser bezüglich der Bakterienelimination bei einer Eindringtiefe von $1 \mathrm{~mm}$ vor dem Apex als bei einer Distanz von $5 \mathrm{~mm}$ feststellen.

In einer kürzlich veröffentlichten Studie wurde die Strömungsdynamik anhand eines computerunterstützten Fluss-Dynamic-Modells detailliert untersucht. Hier erreichte die Flüssigkeit nach Austritt aus einer seitlich geöffneten Spülnadel eine Distanz von 1-1,5 mm (in Abhängigkeit der Flussgeschwindigkeit) über das Nadelende hinaus (Boutsioukis et al. 2009). In einer Folgestudie wurde für eine an der Spitze geöffnete Spülnadel ein tieferes Eindringen der Flüssigkeit ab einem Aufbereitungsdurchmesser von 35/.06 beobachtet (Boutsioukis et al. 2010). Generell wird eine Nadelposition $1 \mathrm{~mm}$ kürzer als die endodontische Arbeitslänge gefordert (Abou-Rass und Piccinino 1982; Zehnder 2006; Boutsioukis et al. 2009).

Je näher das Nadel-Ende zum apikalen Gewebe positioniert ist, desto höher ist jedoch auch das Risiko der transapikalen Extrusion der Spüllösung (Ram 1977; Chow 1983). Daher differenzieren Boutsioukis et al. (2010) in ihrer Studie die Nadelposition in Abhängigkeit vom Nadeldesign. Für seitlich geöffnete Nadeln schließen sie sich der Meinung an, dass diese $1 \mathrm{~mm}$ vor Arbeitslänge positioniert werden sollte, bei an der Spitze geöffneten Nadeltypen sollte der Abstand auf 2-3 mm vergrößert werden. Um einer Extrusion der Spüllösung über den Apex hinaus vorzubeugen und einen koronalwärts gerichteten Debristransport zu erreichen, sollte generell ein Verklemmen der Kanüle im Wurzelkanal vermieden werden (Gulabivala und Stock 2005). Einige Autoren empfehlen zur grundsätzlichen Minderung des Extrusionsrisikos die Verwendung von Kanülen mit seitlicher Austrittsöffnung (Gulabivala 2005; Manogue et al. 2005).

Die Reinigungswirkung ist vor allem vom Strömungsprofil der Spülflüssigkeit abhängig. Während der Handspülung ist es schwierig, die Fließrate der Spüllösung zu standardisieren und zu kontrollieren (Boutsioukis et al. 2007).

Die Fließrate und der daraus resultierende Flüssigkeitsaustausch haben direkten Einfluss auf den Flüssigkeitsstrom am Nadelende (Boutsioukis et al. 2007). Durch den kleineren Durchmesser der Kanülen verlangsamt sich der Spülvorgang und für die Applikation ist ein größerer Stempeldruck erforderlich. Zudem finden sich signifikant niedrigere Fließgeschwindigkeiten (Boutsioukis et al. 2007). Ebenso kann das Lumen feiner Kanülen 
durch Kristallisation von $\mathrm{NaOCl}$ zusätzlich verengt bzw. verschlossen werden (Moser und Heuer 1982).

\subsubsection{Hydrodynamische Spülung mit RinsEndo ${ }^{\circledR}$}

Das RinsEndo ${ }^{\circledR}$ (Dürr Dental, Bietigheim-Bissingen, Deutschland) ist ein System zur hydrodynamischen Wurzelkanalspülung, das 2005 erstmals vorgestellt wurde. Das System besteht aus einem Handstück, einer Einmalkanüle und einer konventionellen Einmalspritze beliebiger Größe mit Luer-Lock-Anschluss (Abb. 1). Die RinsEndo ${ }^{\circledR}$-Kanüle ist $12 \mathrm{~mm}$ lang und weist einen äußeren Durchmesser von 0,45 mm auf. Auf den letzten 7 $\mathrm{mm}$ ist sie halboffen gestaltet. Nach der Montage am Handstück wird sie durch Drehen gesichert. Das Handstück besteht aus einem Titangehäuse mit Turbinenanschluss, Frequenzgenerator und Mischkammer. Es kann an Turbinenkupplungen der Firmen KaVo Sirona, und $\mathrm{W} \& \mathrm{H}$ angeschlossen und über den Fußschalter der Behandlungseinheit bedient werden. Im Bereich der Handstückbasis befindet sich die für eine Einmalspritze vorgesehene Halterung.

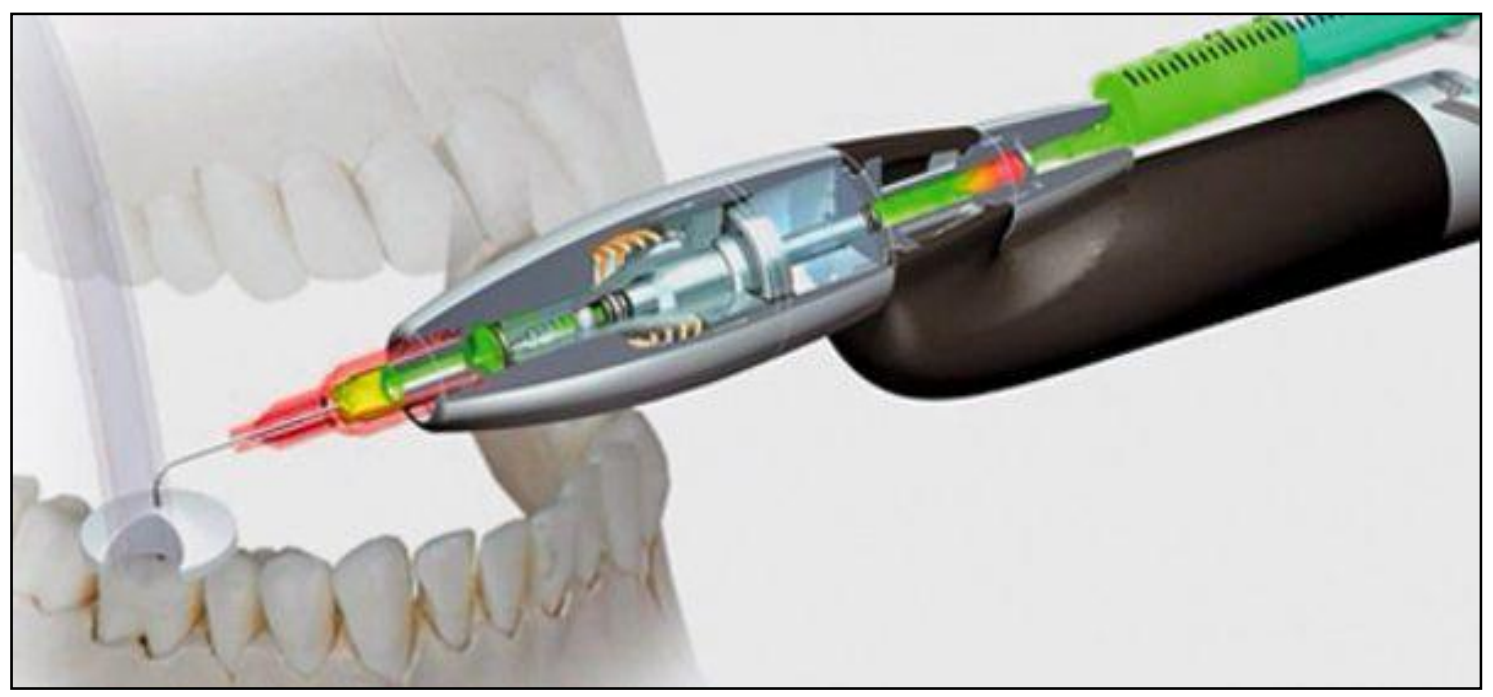

Abb. 1: Schematische Darstellung des RinsEndo ${ }^{\circledR}-S y s t e m s$ der Fa. Dürr Dental (Dürr Dental 2011)

Die zugrunde liegende Technologie beruht auf einem Druck-Saug-Zyklus. Ein pneumatisch betriebener Frequenz-Generator saugt jeweils $65 \mu$ l einer Spüllösung oszillierend mit einer Frequenz von 1,6 Hz aus einer aufgesteckten Spritze an und befördert diese über eine Kanüle in den Wurzelkanal. Während der Saugphase werden verbrauchte Lösung 
und Luft durch die Kanüle zurückgesaugt und in der Mischkammer automatisch mit frischer Spüllösung versetzt. Saug- und Druckzyklus wechseln sich etwa 100mal pro Minute ab.

Die technischen Daten des RinsEndo ${ }^{\circledR}$-Gerätes werden vom Hersteller wie folgt angegeben:

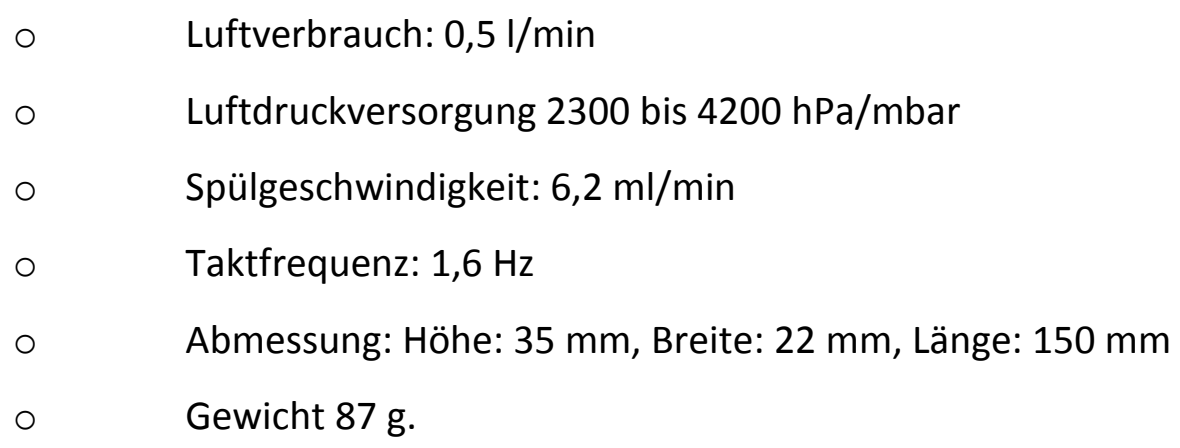

Nach Herstellerangaben dürfen nur folgende Spüllösungen in den angegebenen Konzentrationen verwendet werden:

$\begin{array}{lll}\circ & \mathrm{NaOCl} & 1 \%-3 \% \\ \circ & \mathrm{H}_{2} \mathrm{O}_{2} & 3 \%-5 \% \\ \circ & \mathrm{CHX} & 0,2 \%-2 \% \\ \circ & \text { EDTA } & <10 \% \\ \circ & \text { Citrat } & <17 \% .\end{array}$

Nach dem Aufsetzen des RinsEndo ${ }^{\circledR}$-Handstückes auf die Turbinenkupplung werden die Wasser- und die Lichtleitung automatisch geschlossen, so dass ein steriles Arbeiten möglich ist. Um den Spülvorgang vorzubereiten, wird die Spülkanüle mit dem vom Hersteller mitgelieferten Protector versehen, dieser schützt vor Spritzern und dient als Längenstopp; gleichzeitig verfügt er über eine Öffnung für den Speichelsauger, mit dem die Spüllösung zahnnah abgesaugt werden kann. Die mit Spüllösung befüllte Spritze wird auf das RinsEndo ${ }^{\circledR}$ Handstück aufgesteckt. Die Einführung der Kanüle bis in das koronale Kanaldrittel reicht nach Herstellerangaben aus, um den apikalen Bereich zu reinigen (Dürr 
Dental 2011). Der resultierende Druck im apikalen Kanaldrittel sei durch die an der Spitze halbseitig offene Kanüle auf 0,3 bar begrenzt, bei anderen Techniken steige der ausgeübte Druck üblicherweise auf mehr als 1 bar. Über die Effektivität und Anwendungssicherheit dieses neuen Applikationssystems liegen bislang nur wenige vergleichbare Studien vor. Braun et al. (2005) untersuchten die Wirkung von RinsEndo ${ }^{\circledR}$ in ersten Studien histologisch an Wurzelquerschnitten sowie an Wurzelspaltpräparaten bezüglich der Entfernbarkeit pulpalen Gewebes unter dem Rasterelektronenmikroskop: Wurzelkanäle, die bis zur Größe ISO 40 präpariert wurden, konnten mit dem RinsEndo ${ }^{\circledR}$ System signifikant besser gereinigt werden als mit konventioneller Handspülung. Muselmani et al. (2005b) und Muselmani (2007) untersuchten die Desinfektionswirkung von RinsEndo ${ }^{\circledR}$ im Vergleich zur konventionellen Spülung unter Verwendung von $\mathrm{NaOCl}$ $(2,5 \%)$ oder CHX-Lösung (1\%) an extrahierten Zähnen, die experimentell mit den Indikatorkeimen E. faecalis und C. albicans infiziert worden waren. Die Wurzelkanäle zeigten sowohl nach konventioneller als auch nach hydrodynamischer Spülung eine signifikante Reduktion beider Testkeime, $\mathrm{NaOCl}$ war bei der Eliminierung von $\mathrm{C}$. albicans effektiver, $\mathrm{CHX}$ zeigte mit RinsEndo ${ }^{\circledR}$ eine tendenziell bessere Wirksamkeit. Die Autoren vermuten eine synergistische Unterstützung der Keimzahlreduktion durch die PumpSaug-Wirkung des RinsEndo ${ }^{\circledR}$. Im mittleren Wurzeldrittel war RinsEndo ${ }^{\circledR}$ signifikant, im apikalen Drittel tendenziell der herkömmlichen Spritzen-Handspülung in der Entfernung von Debris überlegen, im koronalen Kanaldrittel nicht. Bei der Entfernung der Schmierschicht zeigten sich beide Techniken als gleichwertig.

Hauser et al. (2007) untersuchten die zirkuläre und apikale Penetrationstiefe einer über das RinsEndo ${ }^{\circledR}$-System applizierten mit Fuchsin eingefärbten 2\%igen $\mathrm{NaOCl}$-Lösung in das Wurzelkanaldentin sowie die mögliche apikale Extrusion der Spüllösung. Nach Spülung von Kanälen, die bis zur Größe ISO 30 präpariert wurden, zeigten sich signifikant höhere Eindringtiefen des markierten $\mathrm{NaOCl}$ in die zirkulären Dentinstrukturen als nach herkömmlicher Handspülung. Ebenso zeigte sich eine signifikant höhere Spültiefe. Die Gefahr der apikalen Extrusion von Spüllösung war bei der Anwendung von RinsEndo ${ }^{\circledR}$ mit $80 \%$ gegenüber $13 \%$ bei manuell gespülten Präparaten deutlich erhöht. Desai und van Himel (2009) bestätigen mit ihrer Studie zur Sicherheit mehrerer Spülsysteme die Gefahr der Extrusion von Spülflüssigkeiten bei der Verwendung des RinsEndo ${ }^{\circledR}$. 
Heistein (2007) berichtete ausschließlich positiv über seine Erfahrungen mit RinsEndo ${ }^{\circledR}$ in der klinischen Anwendung am Patienten. Bei 512 Einsätzen des Systems sei es in nur drei Fällen zu Schmerzen gekommen, was er jedoch auf Messfehler beim Festlegen der Arbeitslänge zurückführt. RinsEndo ${ }^{\circledR}$ führe zu saubereren Kanälen bezüglich der Entfernung pulpalen Gewebes, Debris und Kalziumhydroxids bei erleichterter Anwendung im Vergleich zur manuellen Spülung mit Spritze und Kanüle.

In einer weiteren Studie von McGill et al. (2008) wurde anhand eines Ex-vivoBiofilmmodells an Spaltpräparaten die antimikrobielle Effektivität untersucht. Nach der Spülung (2,5\%-NaOCl) mit unterschiedlichen Nadeleindringtiefen in geraden Kanälen, die bis 40/.08 präpariert wurden, schnitt RinsEndo ${ }^{\circledR}$ signifikant besser ab als die statische manuelle Spülung. Allerdings schnitt RinsEndo ${ }^{\circledR}$ Im Vergleich zur Aktivierung der Spülung mit einem gut passenden Guttaperchastift signifikant schlechter ab. In dieser Studie konnte ein signifikanter Einfluss der Nadelposition in koronal-apikaler Richtung bezüglich der Kollagenfreiheit festgestellt werden.

Caron et al. (2010) untersuchten die Effektivität von RinsEndo ${ }^{\circledR}$ bezüglich der Entfernung der "smear layer" in Kombination mit EDTA und $\mathrm{NaOCl}$ bei der Abschlussspülung gekrümmter Kanäle. Die Kanalwände im mittleren Drittel waren nach Spülung mit RinsEndo ${ }^{\circledR}$ signifikant sauberer als nach Handspülung, aber gleichwertig zur Aktivierung mit einem Guttaperchastift und dem EndoActivator ${ }^{\circledR}$. Im apikalen Drittel waren der EndoActivator ${ }^{\circledR}$ und die Guttaperchastift-Aktivierung dem RinsEndo ${ }^{\circledR}$ und der Handspülung signifikant überlegen. In zwei Studien wurde die Entfernung von Debris untersucht. Rödig et al. (2010c) untersuchten die Entfernung aus Gruben und halbkugelförmigen Kavitäten, die in die Wurzelkanalwand präpariert worden waren, bei unterschiedlichen Präparationsdurchmessern (30/.02, 40/.03, 50/.02). RinsEndo ${ }^{\circledR}$ erzielte in allen Gruppen signifikant bessere Ergebnisse als die Handspülung. Allerdings war die passive Ultraschallspülung dem RinsEndo ${ }^{\circledR}$ signifikant überlegen, nur bei einem Aufbereitungsdurchmesser von 30/.02 konnte keine Signifikanz festgestellt werden. Vivan et al. (2010) untersuchten mit Handinstrumenten apikal bis zur ISO-Größe 40 präparierte Kanäle, wobei nach jedem Instrument mit RinsEndo ${ }^{\circledR}$ oder manuell (NaviTip „gauge“ 30) mit Kochsalzlösung gespült wurde. Die Wurzelkanäle wurden der Länge nach gespalten und in drei Ebenen (koronal, mittel und apikal) unter dem Elektronenmikroskop bewertet. 
Es konnten keine signifikanten Unterschiede zwischen den zwei Techniken festgestellt werden.

In ihrer abschließenden Bewertung sind alle Studien zu RinsEndo ${ }^{\circledR}$ bislang sehr zurückhaltend. Eine umfangreiche Studie zur Entfernung von Kalziumhydroxid aus dem Wurzelkanal liegt bisher nicht vor. Wirksamkeit und Arbeitssicherheit sollten in weiteren Studien untersucht werden, bevor eine Empfehlung für die Anwendung des Verfahrens in der Praxis gegeben werden kann.

\subsubsection{Passive Ultraschallspülung}

Richman beschrieb 1957 erstmals die Ultraschallanwendung in der Endodontie (Wiggins und Ottino 2004), zuvor wurde Ultraschall bereits lange in der Parodontologie eingesetzt (Gu et al. 2009).

Die Generatoren der Ultraschallgeräte wandeln elektrische Energie mittels Magnetostriktion oder Piezoelektrizität in Ultraschallwellen um. Die Frequenz der erzeugten Wellen liegt jenseits der menschlichen Hörschwelle $(20 \mathrm{kHz})$ zwischen 25 und 40 Kilohertz (Jiang et al. 2010b). Die dadurch aktivierten Feilen oder Instrumente werden in hochfrequente Schwingungen versetzt (van der Sluis 2006). Eine Anwendung der Ultraschallsysteme zur Wurzelkanalpräparation konnte sich aufgrund gravierender Mängel in der Formgebung insbesondere bei gekrümmten Kanälen und verschiedener Probleme bezüglich der Arbeitssicherheit nicht durchsetzen (Hülsmann und Hahn 2000).

Als Passive Ultraschallspülung (passive ultrasonic irrigation= PUI) wird sie dann beschrieben, wenn die Feile so geführt wird, dass sie keinen Wandkontakt hat und friktionsfrei in der Spüllösung steht (Walmsley 1987; Walmsley et al. 1989). Durch die Ultraschallaktivierung entstehen akustische Mikroströmungen in der Spüllösung (Ahmad et al. 1987; Lumley et al. 1991), wobei das Strömungsmuster mit dem charakteristischen Muster von Schwingungsknoten und -bäuchen (Abb. 2) entlang der gesamten Feile korrespondiert (van der Sluis et al. 2007a). Die größte transversale Schwingungsamplitude entsteht im Bereich der Instrumentenspitze. 

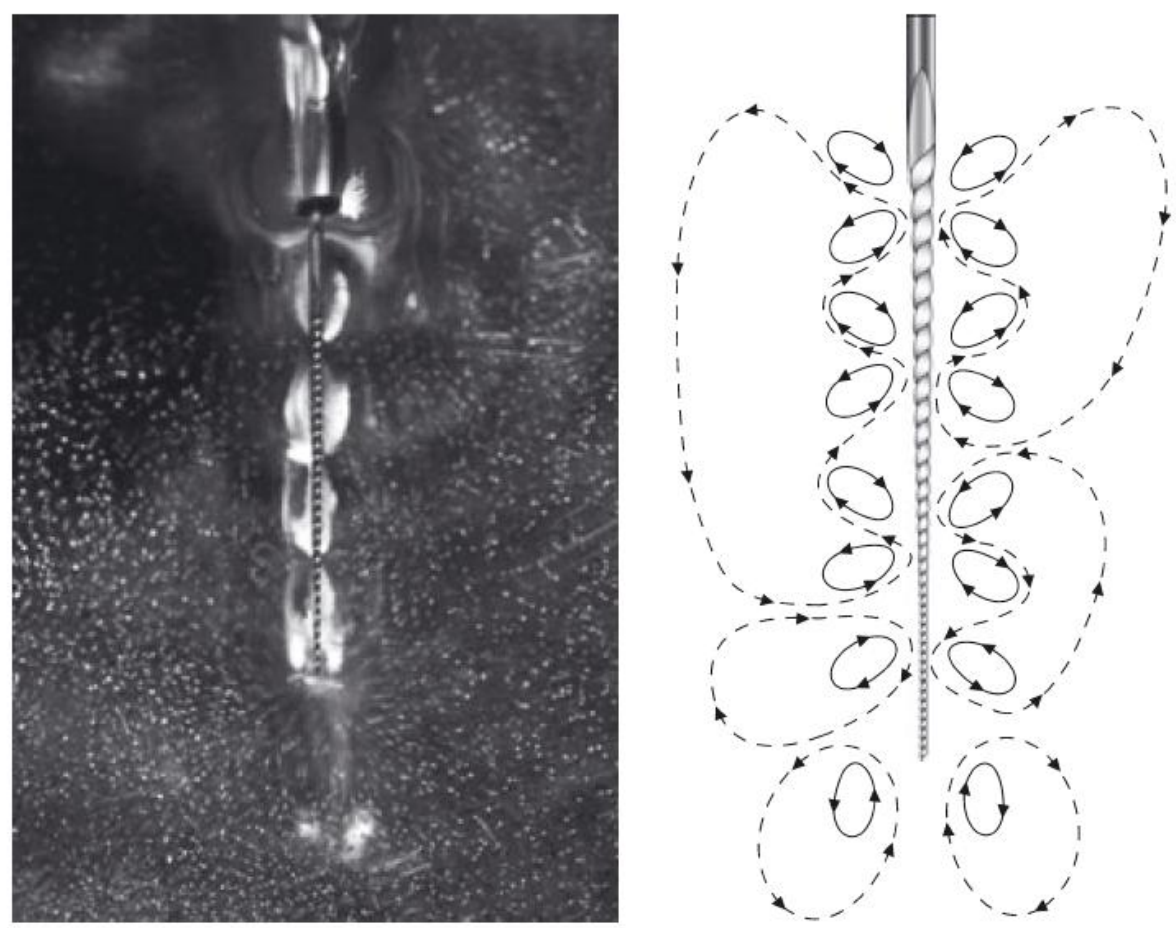

Abb. 2: Acoustic streaming entlang der Feile in Wasser (links) und als Schema (rechts) (aus: van der Sluis et al. 2007a, S. 418)

Die dünnen Feilen oder glatten Drähte der ISO-Größen 10 bis 20 werden 2-3 mm kürzer als die errechnete Arbeitslänge in den Wurzelkanal eingebracht, sitzen daher apikal nicht auf und können im Wurzelkanal frei oszillieren (van der Sluis 2006). Kann das Instrument im Wurzelkanal nicht frei schwingen, werden Wirkung und Stärke der akustischen Mikroströmung reduziert (Ahmad et al. 1992). Für eine Feile der ISO-Größe 15 müsste der Kanal daher mindestens bis zur ISO-Größe 40 erweitert werden, um maximale Schwingungsamplituden (von $135 \mu \mathrm{m}$ ) zu ermöglichen (Ahmad et al. 2009). Ebenso kann es bei Einsatz des Ultraschalls mit Drahtfeilen zu einem ungewollten Dentinabtrag an der Kanalinnenwand kommen, die im schlimmsten Fall zu einer Perforation führen kann. Daher wird empfohlen, die Ultraschallspülung erst nach ausreichender Präparation einzusetzen (van der Sluis 2006), möglichst glatte Feilen zu verwenden (Sabins et al. 2003; van der Sluis et al. 2005b) und diese beim Einsatz in gekrümmten Wurzelkanälen vorzubiegen (Lumley und Walmsley 1992).

Die Zufuhr der Spülflüssigkeit kann sowohl über das Ultraschallgerät selbst als auch über die vorherige Applikation per Spritze und Kanüle in den Kanal erfolgen. Um einem frühzeitigen Feilenbruch vorzubeugen, sollte die Feile immer erst in der Flüssigkeit aktiviert werden. 
Verbunden mit dem charakteristischen Strömungsprofil entlang der Feile ist die Entstehung von Kavitationen. Es bilden sich submikroskopische Bläschen und durch den sich ständig verstärkenden Flüssigkeitswirbel kommt es zur Implosion dieser Bläschen. Dadurch entsteht ein Vakuum, das sofort durch den großen hydrodynamischen Druck mit der vorhandenen Flüssigkeit und mit dem nekrotischen Gewebe auch aus den Ramifikationen und Dentinkanälchen gefüllt wird. Bezüglich der Auswirkungen dieses Phänomens bestehen verschiedene Ansichten. Nach Ahmad et al. (1987) und Stock (1991) scheinen Kavitationseffekte gering und auf den Bereich der Instrumentenspitze begrenzt zu sein. Roy et al. (1994) konnten eine transiente Kavitation ebenfalls nur im Bereich der Instrumentenspitze beobachten. In einem Glasmodell eines Wurzelkanals konnten diese Strömungs- und Kavitationseffekte für die $\mathrm{PUI}$ mit $\mathrm{NaOCl}$ bestätigt werden. $\mathrm{Ob}$ diese ausreichen, um den Biofilm im Wurzelkanal mechanisch zu zerstören, ist fraglich. In vitro konnte dieses durch akustische Kavitation erreicht werden (van der Sluis 2006). In einer neueren Studie wurde kein Unterschied bezüglich der Entfernung von Debris und „smear layer" festgestellt (Ahmad et al. 2009). Nur Feilen, die über das normal empfohlene Energielevel hinaus aktiviert wurden, führten zu Kavitationen im Bereich der Instrumentenspitze, konnten jedoch Debris und „smear layer“ nicht besser entfernen als die normal schwingenden Feilen (Ahmad et al. 2009).

Insbesondere in der Kombination von PUI mit $\mathrm{NaOCl}$ als Spüllösung ist die Reinigungswirkung bezüglich der Entfernung nekrotischen und vitalen Gewebes, der Schmierschicht und Dentindebris signifikant besser als bei Verwendung von Wasser (Cheung und Stock 1993; Lee et al. 2004a; van der Sluis et al. 2006). Dies betrifft auch die Reinigung instrumentell nicht zugänglicher Kanalareale (z.B. Isthmi) (Peters OA 2004).

Die durch Ultraschallaktivierung erzielte Erwärmung der Spüllösung kann bei Verwendung von Natriumhypochlorit zu einer Wirkungsverstärkung bei der Auflösung von organischem Material führen (Sirtes et al. 2005; Al-Jadaa et al. 2009). Ahmad (1990) konnte in vitro nur eine unbedeutende Temperaturerhöhung feststellen. Zeltner et al. (2009) berichten jedoch von einer signifikanten Temperaturerhöhung zuvor eingebrachter Spüllösung durch die Ultraschallaktivierung im koronalen $\left(7,7^{\circ} \mathrm{C}\right)$, mittleren $\left(7,5^{\circ} \mathrm{C}\right)$ und 
apikalen $\left(4,2^{\circ} \mathrm{C}\right)$ Kanalabschnitt. Bei kontinuierlicher Flüssigkeitszufuhr bleibt die Erwärmung jedoch aus.

Bezüglich der Bakterienelimination findet man für PUI ebenfalls signifikant bessere Ergebnisse im Vergleich zur Handspülung (Sjögren und Sundqvist 1987). In einer Studie an experimentell infizierten Zähnen bei Hunden zeigte sich diese Wirkungsverbesserung jedoch nicht (DeNunzio et al. 1989). Ebenfalls konnten Siqueira et al. (1997) in vitro zwischen manueller Agitation von Natriumhypochlorit und Ultraschallaktivierung keinen signifikanten Unterschied hinsichtlich der Reduktion von E. faecalis finden. Ultraschall selbst zeigt nur einen geringen bakteriziden Effekt, in Kombination mit Natriumhypochlorit jedoch eine starke antimikrobielle Wirkung (Ahmad 1990).

Auch nach PUI-Anwendung bleibt eine Schmierschicht zurück (Cheung und Stock 1993; Lumley et al. 1993), die nur durch den zusätzlichen Einsatz entsprechender chemischer Agenzien wie EDTA aufgelöst und entfernt werden kann (Cameron 1995). Sabins et al. (2003) bewerteten die Reinigungseffektivität einer kurzzeitigen Schall- oder Ultraschallaktivierung einer 5,25\%igen $\mathrm{NaOCl}$-Lösung nach Handpräparation extrahierter oberer Molaren durch Bestimmung des verbliebenen Debris im Apikalbereich. Die Aktivierung mittels Ultraschall für 30 Sekunden führte zu einer signifikant besseren Reinigung als die mittels Schall, wobei beide Verfahren der manuellen Spülung deutlich überlegen waren. Mehrere in-vitro-Studien befassten sich mit der Entfernung von Debris aus simulierten Extensionen in künstlichen Wurzelkanälen und in Wurzelkanälen extrahierter Zähne. Die Ultraschallspülung zeigte sich effektiver als die konventionelle Spülung (Lee et al. 2004a) und ein glattes Instrument zur Schwingungsübertragung war genauso wirksam wie eine KFeile (van der Sluis et al. 2005a). Mit zunehmender Konizität verbesserte sich tendenziell die Reinigungswirkung der PUI (Lee et al. 2004b; van der Sluis et al. 2005b). Im Gegensatz zu NaOCl konnte mit Wasser als Spüllösung keine effektive Reinigung erreicht werden, obwohl auch hier eine strömungsmechanische Entfernung zu erwarten war, da die durch Ultraschall induzierten Strömungsphänomene gleich sein sollten (van der Sluis et al. 2006).

In einer In-vivo-Studie untersuchten Gutarts et al. (2005) histologisch die Reinigungseffizienz der ultraschallaktivierten Spülung nach kombinierter manuell-maschineller Präparation in menschlichen Unterkiefermolaren nach Extraktion der Zähne. Dabei resultierte die einminütige ultraschallaktivierte Spülung mit Natriumhypochlorit in 
signifikant saubereren Kanalwänden und Isthmen, was die Ergebnisse früherer Studien an Unterkiefermolaren bestätigt (Haidet et al. 1989; Archer et al. 1992).

Daraus kann gefolgert werden, dass mit PUI die Spülflüssigkeit das Potential hat auch uninstrumentierte Kanalareale zu erreichen.

Aktivierungszeiten der PUI-Geräte von 1 Minute scheinen ausreichend zu sein, um eine deutlich verbesserte Reinigungswirkung zu erzielen (Gutarts et al. 2005; van der Sluis et al. 2006), die empfohlenen Anwendungszeiten variieren zwischen 10 Sekunden und 3 Minuten (in Abhängigkeit von der Technik).

Bei der Spültechnik konnten mehrere Autoren zeigen, dass die Ultraschallspülung der Handspülung mit Spritze und Kanüle überlegen ist (van der Sluis et al. 2005b; Kenee et al. 2006). Es ist jedoch festzustellen, dass auch mit Hilfe von Ultraschall Kalziumhydroxid nicht vollständig aus dem Wurzelkanal entfernt werden konnte. 


\subsubsection{CanalBrush ${ }^{\mathrm{Tm}}$}

Im April 2008 wurde die CanalBrush ${ }^{\text {TM }}$ (Coltène/Whaledent, Langenau, Deutschland) eingeführt. Es handelt sich um ein aus Polypropylen gefertigtes Bürstchen, das in einen HG-Schaft eines Winkelstücks inseriert werden kann und die im Wurzelkanal befindliche Spüllösung aktiviert (Abb. 3). Dieses Bürstchen besteht aus einem zentralen Stift, dessen Arbeitssteil durchschnittlich 17,1 mm lang ist (Länge insgesamt: $41 \mathrm{~mm}$ ) (Salman et al. 2010) und dessen Durchmesser durchschnittlich $0,22 \mathrm{~mm}$ an der Spitze und 0,6 $\mathrm{mm}$ am Ende des Arbeitsteils beträgt. In Abständen von 0,4 mm sitzen jeweils $30 \mathrm{im} 90^{\circ}$ Winkel abstehende, um $180^{\circ}$ versetzte, 0,4 bis $0,5 \mathrm{~mm}$ lange Bürstenhaarpaare am zentralen Stift. Der apikale Millimeter ist nicht mit Bürstenhaaren besetzt (Plotino et al. 2009).

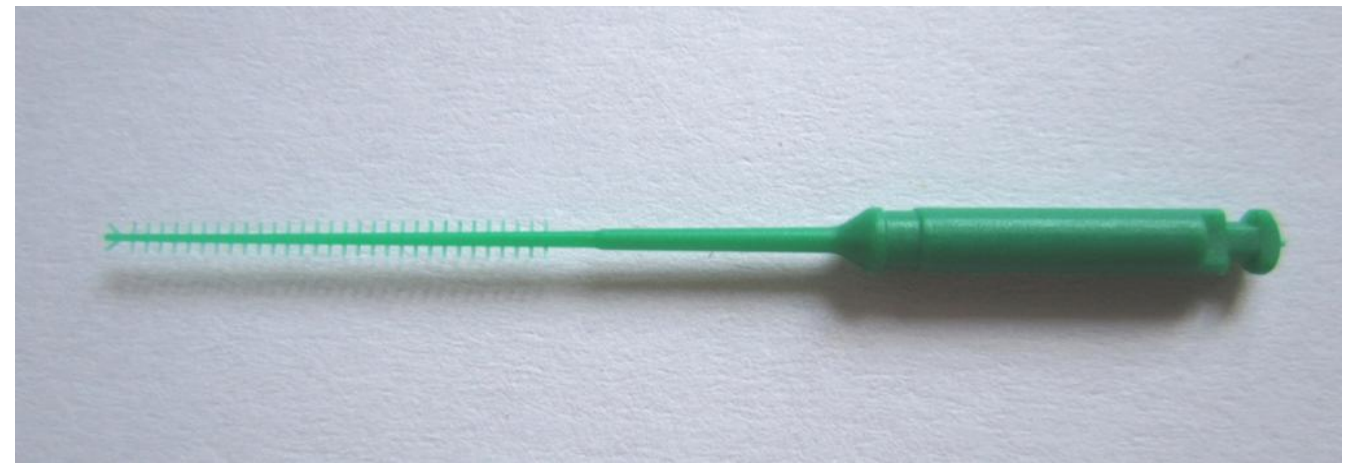

Abb. 3: CanalBrush ${ }^{\mathrm{TM}}$

Inzwischen gibt es die CanalBrush ${ }^{\mathrm{TM}}$ in drei verschieden Größen $(S, M, L)$. Der Einsatz dieses helixartigen Bürstchens im Wurzelkanal kann sowohl manuell oder in einem Winkelstück bei bis zu 600 Umdrehungen pro Minute erfolgen. Laut Herstellerangaben ist sie bei max. $134{ }^{\circ} \mathrm{C}$ autoklavierbar. Das Bürstchen soll laut Hersteller in Kombination mit Spüllösungen bzw. zur Aktivierung derselben und zur Applikation von Zement und Adhäsiven zur Stiftinsertion einsetzbar sein.

In der Literatur sind bisher nur wenige Studien bezüglich der Effektivität und der Einsatzmöglichkeiten der CanalBrush ${ }^{\mathrm{TM}}$ in der Endodontie verfügbar.

Über den früheren Einsatz von Bürstchen findet man ebenfalls recht wenig Literatur. In den 1990ern berichteten Keir et al. (1990) von einer Endobrush (C\&S Microinstruments Ltd, Markham, Ontario, Canada). Sie besteht aus gewundenen Drähten mit Nylonborsten an einem Griff. Dieses spiralförmige Bürstchen wurde mit $90^{\circ}$-Drehungen und 2-3-mm- 
Auf- und Abbewegungen manuell im Kanal eingesetzt und bezüglich der Entfernung von Debris überprüft. Im Vergleich zur normalen Instrumentierung wurden die Kanäle signifikant besser gereinigt. Allerdings konnte die Endobrush aufgrund ihres Durchmessers nicht auf Arbeitslänge eingebracht werden, was zur apikalen Kompaktierung des Debris führte (Keir et al. 1990).

Ein Bürstchen-ähnliches Spülinstrument wurde von Al-Hadlaq et al. (2006) untersucht. Die NaviTipFx ist eine 30-„gauge“-NaviTip-Spülnadel, die mit kleinen Bürstenhärchen überdeckt wurde (Abb. 4). Im Vergleich zur konventionellen Spülung mit einer NaviTip wurde das koronale Drittel der instrumentierten Kanalwände signifikant besser gereinigt. Die Unterschiede im apikalen und mittleren Drittel waren statistisch nicht signifikant.

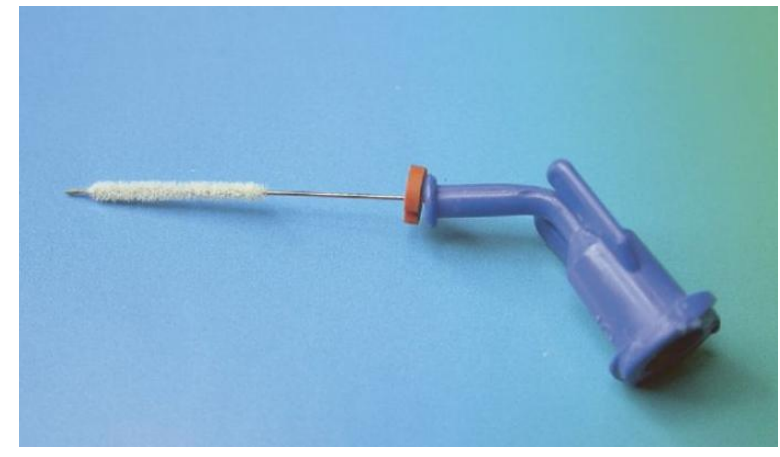

Abb. 4: NaviTipFx (aus: Al-Hadlaq et al. 2006, S. 1182)

In einem veröffentlichten Abstract von Weise et al. (2007) wurde die Entfernbarkeit von Debris aus Gruben und halbmondförmigen Kavitäten verglichen, die in gekrümmte Kanäle präpariert worden waren. Es wurde kein signifikanter Unterschied bezüglich der Effektivität zwischen Ultraschall, Schall und der CanalBrush ${ }^{\text {TM }}$ gefunden. Lediglich der Vergleich zur Handspülung fiel signifikant aus.

Garip et al. (2010) fanden bezüglich der Entfernung der „smear layer" beim Einsatz der CanalBrush $^{\text {TM }}$ bei 600 Umin $^{-1}$ zusätzlich zur Abschlussspülung mit EDTA zwar sauberere Kanäle im mittleren und apikalen Kanaldrittel, jedoch war der Unterschied nicht signifikant. Im koronalen Drittel konnte kein Unterschied festgestellt werden.

Plotino et al. (2009) untersuchten an standardisierten runden, ovalen und gekrümmten Kanälen die Frakturanfälligkeit und Abnutzung der Bürstchen. In ihren Versuchen frakturierte kein Instrument und es löste sich kein seitliches Bürstenhaar. Die Abnutzung der lateralen Bürstchenhaare nahm mit der Dauer der Beanspruchung zu. 
Salman et al. (2010) variierten die Anwendung der CanalBrush ${ }^{\mathrm{TM}}$ indem sie das Bürstchen in einen modifizierten Kopf einer elektrischen Schallzahnbürste (Philips SoniCare Elite, Philips, Amsterdam, Niederlande) eingliederten. Die somit Schall-aktivierte CanalBrush ${ }^{\mathrm{TM}}$ ( $50 \mathrm{~Hz}, 31.000$ Stöße pro Minute) wurde zusätzlich zur Abschlussspülung mit EDTA für 30 Sekunden auf Arbeitslänge aktiviert. Die Spülung mit dieser Apparatur erzeugte bezüglich der Entfernung des Debris in allen Dritteln der Wurzelkanäle signifikant sauberere Kanalwände; ebenso konnte mehr „smear layer“ entfernt werden, allerdings nicht signifikant mehr als bei der Handspülung mit EDTA ohne Aktivierung. Eine kürzlich publizierte Studie von Taşdemir et al. (2011) beschäftigte sich mit der Entfernung von Kalziumhydroxid aus Wurzelkanälen. Die Auswertung erfolgte über die prozentuale Bedeckung der gesamten Wurzelkanaloberfläche. Die Spülung mit $\mathrm{NaOCl}$ und einer bei 600 Umdrehungen pro Minute für 30 Sekunden eingesetzten CanalBrush $^{\mathrm{TM}}$ erzielte signifikant sauberere Kanäle als die reine Handspülung mit $\mathrm{NaOCl}$ bzw. EDTA. Der Vergleich zur Ultraschallspülung fiel nicht signifikant aus.

\subsubsection{EndoActivator ${ }^{\circledR}$}

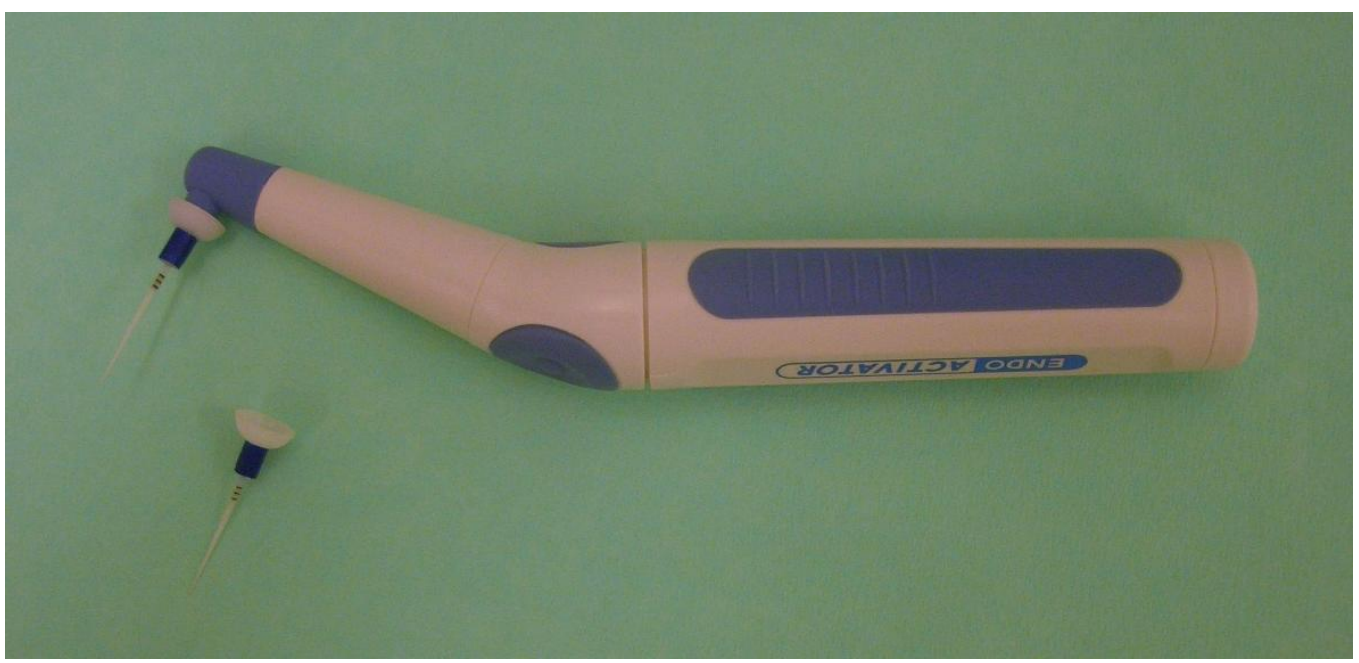

Abb. 5: EndoActivator ${ }^{\circledR}$

Der EndoActivator ${ }^{\circledR}$ (Dentsply Tulsa Dental, Tulsa, USA) wurde 2007 von C. Ruddle entwickelt (Ruddle 2007). Er ist ein batterie-betriebenes (2 AA-Batterien) Handstück (Abb. 5) mit einem Antriebsmotor, der über drei verschiedene Einstellungen: 2000, 6000 und $10000 \mathrm{cpm}$ (cycles per minute $=$ Schwingungen pro Minute) verfügt. Dieser überträgt mit 
Hilfe einer aus Polymer bestehenden Spitze Schallwellen auf die statische Spülflüssigkeit. Die zum Einmalgebrauch gedachten Polymerspitzen sind aus dem medizinischen Polymer Delron gefertigt und liegen in den drei farbmarkierten Größen Small (15/02), Medium (25/04) und Large (35/04) vor. Der erste Wert gibt den Spitzenquerschnitt $1 \mathrm{~mm}$ vor der Instrumentenspitze an, der zweite Wert bezeichnet die Konizität des Instruments, also 2\% oder 4\%. Die Spitzen sind $22 \mathrm{~mm}$ lang und bei 18, 19 und $20 \mathrm{~mm}$ mit Längenmarkierungen versehen. Das Aufstecken des Ansatzes erfolgt nach dem Überziehen der Hygienehülle über das Handstück, das so vor Kontamination geschützt ist. Das Handstück ist nicht autoklavierbar und nicht wasserdicht. Laut Hersteller sollte der EndoActivator ${ }^{\circledR}$ ohne Kontakt zur Kanalwand in $2 \mathrm{~mm}$ Abstand vom Kanalende im mit Spülflüssigkeit gefüllten Kanal angewendet werden. Dabei sollte er erst aktiviert werden, wenn die Spitze in geeigneter Position in den Kanal eingeführt wurde. Die Spitze sollte dort vertikal 2-3 mm pumpend bewegt werden. Der Hersteller empfiehlt eine wiederholte Anwendung von 3060 Sekunden. Die Aktivierung mit Schall unterscheidet sich von der Ultraschallaktivierung insofern, dass Schall mit einer niedrigeren Frequenz von 1-6 kHz arbeitet und kleinere Scherspannungen produziert (Ahmad et al. 1987).

Laut $\mathrm{Gu}$ et al. (2009) wurde über die Anwendung von Schall-Instrumenten in der Endodontie erstmals von Tronstad et al. (1985) berichtet. Diese verwendeten eine schallbetriebene K-Feile zur Entfernung von Debris und „smear layer“. Sabins et al. (2003) berichten von der Anwendung einer „Rispisonic-file“ zur Debris-Entfernung. Mehrere Studien untersuchten in vitro die Entfernbarkeit von Bakterien mit Schall-Unterstützung (Townsend und Maki 2009; Brito et al. 2009; Shen et al. 2010; Pasqualini et al. 2010). Bezüglich der Entfernung aus simulierten gekrümmten Kanälen wurde kein signifikanter Unterschied zwischen Ultraschall- und Schall- (EndoActivator ${ }^{\circledast}$ ) Aktivierung für 30 Sekunden festgestellt (Townsend und Maki 2009). Brito et al. (2009) konnten ebenfalls keinen signifikanten Unterschied zwischen Nadelspülung (NaviTip), EndoActivator ${ }^{\circledR}$ und EndoVac bei 60 -sekündiger Aktivierung und Spülung mit $\mathrm{NaOCl}$ und EDTA bezüglich der Reduktion von Enterococcus faecalis feststellen. In der Studie von Pasqualini et al. (2010) erreichte ein 30-sekündiger EndoActivator ${ }^{\circledR}$ Einsatz in Kombination mit 5\%-NaOCl eine signifikante Reduktion von Enterococcus faecalis im Vergleich zur alleinigen Spritzenspülung. Ebenso erkannten Shen et al. (2010), dass die alleinige Verwendung von Schall- oder Ultraschall keinen Einfluss auf die Biofilm-Struktur und die Vitalität von 
Bakterien hat. Allerdings unterstützen diese Systeme CHX-Lösungen bei der BakterienElimination, wobei längere Aktivierungszeiten zu besseren Ergebnissen führen. Auch Huffaker et al. (2010) fanden in ihrer In-vivo-Studie keinen signifikanten Unterschied zwischen der Handspülung und Aktivierung mit dem EndoActivator ${ }^{\circledast}$ bezüglich der Bakterienelimination.

Paragliola et al. (2010) untersuchten den EndoActivator ${ }^{\circledast}$ im Vergleich zur Aktivierung mit einem Guttapercha-Point und Ultraschall bezüglich der Eindringtiefe von gefärbtem $\mathrm{NaOCl}$ in Dentintubuli bei einer Anwendungszeit von 20 Sekunden. Die Ultraschallaktivierung erzeugte die größten Eindringtiefen, gefolgt von der Schallaktivierung. Die Gutta-Percha-Aktivierung erzielte die gleichen Eindringtiefen wie die Kontrollgruppe ohne jegliche Aktivierung. Auch mit der Entfernung der „smear-layer“ und Debris beschäftigten sich einige Forschungsgruppen. Uroz-Torres et al. (2010) berichten von keinem signifikanten Unterschied bezüglich der „smear layer"-Entfernung im Vergleich zwischen Handspülung mit Max-I-Probe und EndoActivator ${ }^{\circledast}$ mit verschiedenen Spüllösungen. Einzig der Einsatz von EDTA resultierte in signifikanten Unterschieden im Vergleich zur reinen $\mathrm{NaOCl}$-Spülung, wobei die Ergebnisse im koronalen Drittel besser waren als die in den mittleren und apikalen Kanalanteilen. Auch Rödig et al. (2010b) konnten eine bessere Entfernung der „smear layer" in den koronalen Kanalanteilen erreichen, wobei hier der EndoActivator ${ }^{\circledR}$ signifikant effektiver war als die Ultraschallaktivierung $(p=0.028)$ und die CanalBrush $^{\text {TM }}(p=0.025)$. Im apikalen Anteil wurden keine Unterschiede bezüglich der Schmierschicht festgestellt. Debris konnte ebenfalls koronal besser entfernt werden als apikal, wobei kein Unterschied zwischen den Gruppen (Handspülung, Ultraschall, EndoActivator $^{\circledR}{ }$, CanalBrush ${ }^{\mathrm{TM}}$ ) festgestellt werden konnte. Diese Ergebnisse stimmen mit denen von Klyn et al. (2010) bezüglich der Debris-Entfernung überein.

In einer Studie wurde die Entfernbarkeit von Kalziumhydroxid mittels Micro-Scan untersucht. Die Kombination von rotierender Instrumentierung und der insgesamt 60sekündigen Aktivierung von Ultraschall erzielte eine signifikant höhere Reinigungswirkung in gekrümmten Kanälen als die Aktivierung mit Schall (Wiseman et al. 2011). Zur Entfernbarkeit von Kalziumhydroxid aus weitlumigen geraden Kanälen bzw. aus lateralen Ausläufern liegen bisher keine Publikationen vor. 


\subsection{Medikamentöse Einlagefüllungen}

Bei der Wurzelkanalbehandlung steht die Beseitigung der bakteriellen Infektion des Wurzelkanalsystems im Vordergrund. Es ist bekannt, dass Mikroorganismen sowohl bei der Ätiologie der Pulpitis, der infizierten Nekrose als auch der apikalen Parodontitis eine Schlüsselrolle spielen (Kakehashi et al. 1965). Den größten desinfizierenden, bzw. antibakteriellen Effekt haben die Präparation und die Spülung des Wurzelkanals mit desinfizierenden Agenzien (chemomechanische Wurzelkanalpräparation). Diese reduzieren die Anzahl der im Wurzelkanal befindlichen Bakterien deutlich (Law und Messer 2004). Byström und Sundqvist (1981) und Byström et al. (1985) konnten eindeutig nachweisen, dass durch eine mechanische Reinigung des Wurzelkanals in Kombination mit Natriumhypochlorit als Spüllösung in etwa der Hälfte der untersuchten Zähne intrakanaläre Mikroorganismen nicht vollständig eliminiert werden konnten. Gleichzeitig ist hinlänglich bekannt, dass der Erfolg einer Wurzelkanalbehandlung mit dem Grad der mikrobiellen Besiedlung des Endodonts korreliert (Byström et al. 1987; Sjögren et al. 1997). Auf rein mechanischem Weg ist es jedoch praktisch unmöglich, alle Keime und jeglichen Debris zu beseitigen, da die infizierten Hohlräume nicht nur aus den Hauptkanälen bestehen. Dies gilt ebenso für die von Meyer (1970) beschriebenen zahllosen Verzweigungen eines Wurzelkanals, die Nebenkanälchen und die Ramifikationen des apikalen Deltas. Zurückgebliebene Mikroorganismen finden sich auch in pulpanahen Dentinkanälchen (Gutiérrez et al. 1990; Sen et al. 1995a). Diese stellen ein bedeutendes Reservoir dar, von dem eine Infektion oder Reinfektion während oder nach der endodontischen Behandlung ausgehen kann (Oguntebi 1994). Sind keine Mikroorganismen im Wurzelkanal vorhanden, wie z.B. bei einer Vitalexstirpation, wird empfohlen, die Wurzelkanalbehandlung inklusive Füllung in einer Sitzung zu beenden. Hierbei wird das Risiko einer Neu- oder Reinfektion mit hoher Wahrschein-lichkeit ausgeschlossen. Kann eine endodontische Behandlung nicht in einer Sitzung beendet werden, z.B. aus Zeitgründen, oder liegt eine Infektion des Endodonts vor, sollte zwischen den Behandlungssitzungen eine medikamentöse Einlage erfolgen, um die Zahl der im Wurzelkanal verbliebenen Mikroorganismen auf ein Minimum zu reduzieren, beziehungsweise diese und ihre Toxine zu zerstören, sowie organisches Gewebe aufzulösen (Sundqvist 1994). Hierbei sollten Präparate Anwendung finden, die einerseits 
eine ausgeprägte und lang andauernde desinfizierende Wirkung gegen die verschiedenen Bakterienspezies im infizierten Kanal aufweisen und dies möglichst tief in die Dentintubuli hinein. Andererseits sollten sie dabei keinerlei Irritation auf das periapikale Gewebe entfalten oder gar systemische Reaktionen verursachen.

In jüngster Zeit wird kontrovers diskutiert, ob prinzipiell auf eine temporäre medikamentöse Einlage verzichtet werden kann. Die Resultate der aussagekräftigen Studien sind widersprüchlich, die Studien unterscheiden sich jedoch erheblich im Studiendesign. Es ist also noch ungeklärt, ob eine temporäre Einlage die Erfolgsquote der Wurzelkanalbehandlungen verbessert. Peters LB et al. (2002a) konnten beim Wiedereröffnen des Zahnes eine Woche nach der medikamentösen Einlage mit $\mathrm{Ca}(\mathrm{OH})_{2}$ mehr Bakterien in Kanal nachweisen als vor Beginn der Wurzelbehandlung. In Tierversuchen von Katebzadeh et al. (1999) waren jedoch die histologischen Ergebnisse nach medikamentöser Wurzelkanaleinlage signifikant besser $(p<0,05)$. Auch in klinischen Studien von Sjögren et al. (1997), Trope et al. (1999) und Katebzadeh et al. (2000) erwiesen sich die klinischen Erfolgsraten nach medikamentöser Einlage als signifikant besser. Die klinischen Nachuntersuchungen nach einem Jahr ergaben, dass mehrzeitige Behandlungen signifikant erfolgreicher waren als ein „one-visit-treatment". In einem kürzlich publizierten Review-Artikel wurde zusammenfassend kein Unterschied zwischen ein- und mehrzeitiger Behandlung bei infizierten Zähnen festgestellt (Su et al. 2011). Athanassiadis et al. (2007) beschreiben für medikamentöse Einlagefüllungen folgende Ziele:

- Eliminierung von Mikroorganismen, die während der chemomechanischen Präparation nicht zerstört wurden

- Reduktion der periradikulären Entzündungsprozesse

- Induktion von Hartgewebsbildung im Periapex

- Schmerzlinderung

- Beherrschung entzündlicher Wurzelresorptionen nach Trauma

- Verhinderung einer Reinfektion des Wurzelkanalsystems durch Bildung einer chemomechanischen und physikalischen Barriere

- Neutralisierung von Endotoxinen im Dentin

- Desinfektion bei Pulpanekrose und in Revisionsfällen

- Gewebeauflösung. 


\subsubsection{Präparate}

Mit der Behandlung der Pulpaerkrankungen und ihrer Folgen beschäftigen sich Menschen schon lange. Pierre Fauchard schrieb 1728 das erste zahnärztliche Lehrbuch, worin er die Verwendung von Nelkenöl, Ingwer, Opium und einer Mixtur von Urin und Branntwein zur Desinfektion vorschlug (Spielman 2007). Anfang des vergangenen Jahrhunderts wurde ein großes Spektrum unterschiedlich wirkender Medikamente eingeführt, wie Arsen, Paramonochlorphenol, Paramonochlorphenolkampfer, Kampferphenol, schwefelhaltige Lösungen, Formaldehyde, Trikresolformalin und unzählige andere Mittel (Preiswerk 1901). Aufgrund des Missverhältnisses zwischen deren Toxizität und der antimikrobiellen Effizienz (Spångberg und Langeland 1973; Spångberg et al. 1979) werden diese Präparate heute nicht mehr verwendet. Heute gilt Kalziumhydroxid als das am geringsten toxische, aber effizienteste Wurzelkanalmedikament (Zehnder et al. 2003).

\subsubsection{Kalziumhydroxid}

\subsection{Historischer Überblick}

Kalziumhydroxid wurde 1920 von B. W. Herrmann als biologisches Wurzelfüllmaterial in die Zahnheilkunde eingeführt (Löst et al. 1992). Die ersten Artikel über die erfolgreiche vital-erhaltende Therapie der Pulpa mit Kalziumhydroxid erschienen zwischen 1934 und 1941. Frank (1966) beschrieb, dass bei Verwendung von Kalziumhydroxid bei devitalen Zähnen mit unvollständigem Wurzelwachstum eine weitere Wurzelbildung oder apikale Hartsubstanzbarriere induziert werden konnte.

Kalziumhydroxid etablierte sich und wurde als intermediäre medikamentöse und antibakterielle Einlage in der Endodontie eingesetzt (Fava und Saunders 1999) und mit dem Ausheilen periradikulärer Läsionen verbunden (Sjögren et al. 1990). Heute kann Kalziumhydroxid als das am häufigsten verwendete Medikament für medikamentöse Einlagen in der klinischen Praxis betrachtet werden (Itoh et al. 1999). 


\subsection{Chemie und Wirkungsweise}

Die Wirkung des Kalziumhydroxids beruht auf der Freisetzung von Kalzium $\left(\mathrm{Ca}^{2+}\right)-$ und Hydroxyl $\left(\mathrm{OH}^{-}\right)$-lonen in wässrigen Lösungen. Das Trägermedium der Kalziumhydroxidzubereitung bestimmt die Geschwindigkeit der Dissoziation (Siqueira und Lopes 1999). Die dissoziierten lonen können in die Dentintubuli penetrieren (Komabayashi et al. 2009). Dies ist jedoch abhängig von den vorher verwendeten Spüllösungen (Saif et al. 2008). Die Kalziumionen binden Kohlendioxidionen, die Bakterien für ihre anaerobe Atmung benötigen (Saif et al. 2008). Die Hydroxylionen induzieren einen Anstieg des pH-Wertes, welcher abhängig von ihrer Konzentration durch irreversible enzymatische Reaktionen eine antibakterielle Wirkung auslöst (Byström et al. 1985). Tronstad et al. (1981) konnten nach vierwöchiger $\mathrm{Ca}(\mathrm{OH})_{2}$-Einlage einen erhöhten $\mathrm{pH}$-Wert selbst in peripheren Anteilen des Wurzelkanals nachweisen. Dieser lag zwischen 8,0 und 10,0 im Vergleich zu den nicht behandelten Zähnen ( $\mathrm{pH}$-Wert dort zwischen 6,4 und 7). Das unmittelbar an den Wurzelkanal angrenzende Dentin wies einen pH-Wert von 11,1-12,2 auf.

Nach einer Einlagedauer von einer Woche ist Kalziumhydroxid in der Lage, den pH-Wert im inneren Dentinbereich auf pH 9 anzuheben (Siqueira und Lopes 2002). Sjögren et al. (1991) verglichen die Wirkung einer 10-minütigen mit der einer 7-tägigen $\mathrm{Ca}(\mathrm{OH})_{2}$-Einlage in vivo. Die Applikation für eine Woche führte hier in allen Fällen zur Keimfreiheit, die 10minütige Einlage zeigte vergleichbare Ergebnisse wie 0,5\%iges $\mathrm{NaOCl}$. Möglicherweise fanden Nerwich et al. (1993) eine Erklärung für die erforderliche Langzeitexposition mit Kalziumhydroxid: Nach der Applikation von $\mathrm{Ca}(\mathrm{OH})_{2}$ dauerte es 1-7 Tage, bis der pH-Wert an der Wurzeloberfläche zu steigen begann. Nach zwei Wochen wurde zervikal ein pHWert von 9,3, apikal von 9,0 erreicht. Nerwich et al. (1993) sprechen von einer Pufferwirkung des Apatits des Dentins sowohl gegenüber Säuren als auch Basen. Daher wird vermutlich für $\mathrm{Ca}(\mathrm{OH})_{2}$ eine längere Expositionszeit benötigt, um in allen Arealen einen $\mathrm{pH}$-Anstieg hervorzurufen.

Der pH-Wert-Anstieg kann verschiedene Effekte hervorrufen, unter anderem die Schädigung der mikrobiellen Membran, die Denaturierung struktureller Proteine und Enzyme, sowie die Spaltung der DNA (Estrela et al. 1995a, 1995b; Siqueira und Lopes 2002; Athanassiadis et al. 2007).

Molander et al. (1999) konnten in einer In-vivo-Studie keine verbesserten antimikrobiellen Eigenschaften feststellen, wenn $\mathrm{Ca}(\mathrm{OH})_{2}$ statt 7 Tagen über zwei Monate im 
Wurzelkanal verweilte. Ørstavik und Haapasalo M (1990) kamen in ihrer In-vitro-Studie zu der Erkenntnis, dass mit E. faecalis infiziertes Dentin eine mindestens 10 -tägige $\mathrm{Ca}(\mathrm{OH})_{2^{-}}$ Exposition benötigt, um die Keime abzutöten. Harrison AJ et al. (2010) konnten nach einer einwöchigen Kalziumhydroxideinlage in $83 \%$ der Proben eine vollständige Entfernung von Enterococcus faecalis nachweisen. Evans et al. (2002) zeigten, dass Enterococcus faecalis gegen Kalziumhydroxid resistent zu sein scheint. Kayaoglu et al. (2009) wiesen nach, dass Kollagen, die Hauptkomponente des Dentins, die Resistenz von E. faecalis gegenüber Kalziumhydroxid erhöhen konnte. In der Studie von Badr et al. (2011) konnte Kalziumhydroxid E. faecalis nur bei direktem Kontakt inhibieren. Kalziumhydroxid ist gegen ein sehr breites Spektrum endodontisch relevanter Mikroorganismen wirksam, jedoch wirkt es nicht gegen alle Keime gleichermaßen gut. Einige Mikroorganismen (Enterokokken, Pilze) scheinen den erreichten pH-Wert zu tolerieren. Sathorn et al. (2007) konnten in einem Reviewartikel zusammenfassend ebenfalls eine eingeschränkte Effektivität des Kalziumhydroxids auf Bakterienkulturen schlussfolgern. Verschiedene Autoren beschrieben zudem die Neutralisierung bakterieller Endotoxine (durch Hydrolisierung deren Lipid-A-Bestandteils) durch $\mathrm{Ca}(\mathrm{OH})_{2}$ in vitro (Barthel et al. 1997; Safavi und Nichols 1993) und in vivo (Nelson-Filho et al. 2002; Tanomaru et al. 2003). Endotoxine sind Lipopolysaccharide, die bei der Vermehrung und beim Absterben von Bakterien frei werden (Barthel et al. 1997).

$\mathrm{Ca}(\mathrm{OH})_{2}$ hat ebenso eine physikalische Wirkung, indem es durch das Ausfüllen des Wurzelkanals den Bakterien den Raum und die Substrate für Wachstum und Vermehrung entzieht (Athanassiadis et al. 2007). Aufgrund der Partikelgröße von ca. 0,5 $\mu \mathrm{m}$ bis $2,5 \mu \mathrm{m}$ kann Kalziumhydroxid ebenfalls in offene Dentintubuli (2-5 $\mu \mathrm{m}$ weit) penetrieren und dort dissoziieren (Komabayashi et al. 2009). 
Das Medikament wird nicht ausschließlich zur Desinfektion im Rahmen der Wurzelkanalbehandlung verwendet, sondern auch eingesetzt

- zur direkten Überkappung oder der Amputation der exponierten Pulpa (Tronstad und Mjör 1972; Haskell et al. 1978; Fuks et al. 1982, 1987; Schröder 1985; Cvek 1978)

- nach Perforationen des Wurzelkanals (Tidmarsh 1979; Biggs et al. 1988)

- zur Apexifikation der Wurzelspitze von Zähnen mit nicht abgeschlossenem Wurzelwachstum nach Trauma (Heithersay 1970, 1975; Cvek 1972, 1974; Gilbert 1983).

Es scheint inzwischen gesichert, dass die dabei einsetzende Hartgewebsbildung in erster Linie auf die antibakterielle Wirkung zurückzuführen ist. Die Annahme, dass das für die Hartgewebsbildung benötigte Kalzium aus dem $\mathrm{Ca}(\mathrm{OH})_{2}$ stamme, wurde inzwischen widerlegt (Sciaky und Pisanti 1960). Hanlon et al. (1998) untersuchten das Potential verschiedener Biomaterialien, wie z.B. mineralisches Trioxidaggregat (MTA), $\mathrm{Ca}(\mathrm{OH})_{2}$, Kalziumsulfat, Kalziumphosphat und Hydroxylapatit zur Stimulierung der Knochenneubildung. Sie konnten zeigen, dass alle Kalzium-enthaltenden Materialien im Vergleich zu den Kontrollgruppen eine deutlich bessere Mineralisation hervorriefen.

Ebenso wie $\mathrm{NaOCl}$ ist $\mathrm{Ca}(\mathrm{OH})_{2}$ in der Lage, nekrotisches Gewebe aufzulösen. Türkün und Cengiz (1997) konnten zeigen, dass eine Vorbehandlung nekrotischen Gewebes mit $\mathrm{Ca}(\mathrm{OH})_{2}$ zu einer verbesserten Löslichkeit in 0,5\%igem $\mathrm{NaOCl}$ führt. Ebenso untersuchten Wadachi et al. (1998) die gewebeauflösende Eigenschaft von $\mathrm{Ca}(\mathrm{OH})_{2}$ und $\mathrm{NaOCl}$. $\mathrm{Ca}(\mathrm{OH})_{2}$ war nach 7-tägiger Applikation bezüglich der Gewebeauflösung signifikant überlegen gegenüber einer 1- bzw. 3-tägigen Applikation. Die Kombination beider Agenzien war signifikant besser bezüglich der Gewebeauflösung als die Applikation der Agenzien alleine. Die Ergebnisse einer Studie von Hasselgren et al. (1988) bestätigten diese Beobachtungen. 


\subsubsection{Applikation der Einlage}

Nach Deveaux et al. (2000) sind antibakterielle Behandlungen am effektivsten, wenn das antibakterielle Agens in direktem Kontakt mit den Mikroorganismen steht. Dies kann am sichersten gewährleistet werden, wenn die medikamentöse Einlage alle endodontischen Hohlräume temporär vollständig und homogen ausfüllt (Sigurdsson et al. 1992). Hierbei sollte eine Extrusion über das Foramen apicale vermieden werden.

Die optimale Technik für das Einbringen der Kalziumhydroxid-Paste wird in der Literatur kontrovers diskutiert. Es werden verschiedene Techniken empfohlen.

Das Einrotieren mithilfe eines Lentulos wird von mehreren Autoren bevorzugt (Dumsha und Gutmann 1985; Sigurdsson et al. 1992; Rivera und Williams 1994; Staehle et al. 1997; Torres et al. 2004; Peters $\mathrm{Cl}$ et al. 2005). Allerdings besteht bei der Anwendung eines Lentulos in engen und gekrümmten Kanälen das Risiko einer Instrumentenfraktur. Ebenso findet man Empfehlungen für das Einrotieren mittels eines McSpadden-Kompaktors (Kleier et al. 1985; Teplitsky 1986). Die Applikation mit einer Injektionskanüle bei Verwendung injizierbarer Präparate findet in den letzten Jahren immer mehr Anhänger (Braun und Nolden 1999). Dies ist eine weniger risikoreiche Applikationsform. Allerdings stellen hierbei die Kanalkrümmung und der Präparationsdurchmesser die limitierenden Faktoren dar (Sigurdsson et al. 1992). Mit zunehmender Präparationsgröße verbessert sich die Qualität der Einlage (Braun und Nolden 1999). Staehle et al. (1997) konnten in bis zur ISO-Größe 50 aufbereiteten Wurzelkanälen eine homogenere und blasenfreiere Füllung mit dem Spritzensystem im Vergleich zum Einrotieren mittels Lentulo feststellen. Die Verwendung von K-Feilen zum Einbringen von $\mathrm{Ca}(\mathrm{OH})_{2}$-Suspensionen schnitt in den meisten Studien am schlechtesten ab, vor allem im apikalen Wurzelanteil (Sigurdsson et al. 1992; Staehle et al. 1997). Deveaux et al. (2000) schlossen in ihre Versuche auch die Verwendung des Pasteinject-Instruments mit ein. Damit ließen sich im Vergleich zu dem Gutta-Condensor, in Ultraschallhandstücke montierten K-Feilen und in ein Schallvibrationshandstück montierterten Meca-Shaper signifikant bessere Ergebnisse erzielen. Der Unterschied zum Einrotieren mit einem Lentulo war jedoch nicht signifikant.

Auch zur Nachkondensation werden verschiedene Möglichkeiten erwähnt. Braun und Nolden (1999) konnten mithilfe des Nachkondensierens mit einem Wattepellet eine verbesserte Qualität (Eindringtiefe und Homogenität) der Kalziumhydroxideinlage 
nachweisen. Ähnliche Ergebnisse wurden bei der Verwendung von Papierspitzen (Staehle et al. 1997) oder Pluggern (Webber et al. 1981; Kleier et al. 1985) erreicht.

Die Qualität bzw. Dichte der Kalziumhydroxid-Einlage ist von weiteren Faktoren abhängig. So sind bei der Auswahl und Bewertung der entsprechenden Technik die Kanalkrümmung, der Präparationsdurchmesser und der Trocknungsgrad des Kanals zu berücksichtigen (Peters $\mathrm{Cl}$ et al. 2005).

Das blasenfreie und homogene Einbringen von Kalziumhydroxid kann besonders bei weitlumigen Kanälen röntgenologisch überprüft werden. In der Regel besitzt Kalziumhydroxid eine ähnliche Röntgenopazität wie Dentin. Diese kann durch den Zusatz von Bariumsulfat, wie es z.B. in dem Präparat Calxyl ${ }^{\circledR}$ (OCO Präparate GmbH, Dirmstein, Deutschland) enthalten ist, erhöht und damit die radiologische Darstellung deutlich verbessert werden (Webber et al. 1981).

\subsubsection{Entfernung der Einlage}

Vor einer definitiven Füllung des Wurzelkanalsystems sollte die vollständige Entfernung der medikamentösen Einlage angestrebt werden. Somit kann einer Kompromittierung der Wandständigkeit der Wurzelkanalfüllung beim Zurückbleiben von Einlageresten an der Wurzelkanalwand vorgebeugt werden (Rödig und Hülsmann 2006). Aufgrund der Wasserlöslichkeit kann Kalziumhydroxid durch Körperflüssigkeiten aufgelöst werden und dadurch ein „leakage“ entstehen. Rückstände von Kalziumhydroxid reduzierten die Bonding-Stärke eines Kunststoff-basierten Sealers am Wurzelkanaldentin (Barbizam et al. 2008) und interferierten mit der Haftung eines Silikon-basierten Sealers (Contardo et al. 2007). Ebenso wurde von Kim und Kim (2002) gezeigt, dass bei der Verwendung von Zinkoxideugenol-Sealern in Kombination mit Guttapercha-Füllungen apikale Undichtigkeiten entstehen. Schon Margelos et al. (1997) und Calt und Serper (1999) erkannten eine unvollständige Penetration des Sealers in Dentintubuli durch die Bildung von Kalziumeugenolat, wenn Kalziumhydroxidrückstände vorhanden waren.

Die Entfernung von Kalziumhydroxid aus dem Wurzelkanalsystem wurde in einigen Studien mit unterschiedlichen Spüllösungen und Techniken untersucht.

Die übliche Methode zur Entfernung einer medikamentösen Einlage ist die Verwendung von Spüllösungen in Kombination mit Handinstrumenten bis auf Arbeitslänge (Rödig et al. 
2010d). Die Spülung mit Natriumhypochloritlösungen alleine wurde als nicht effizient bewertet, um Kalziumhydroxid zu entfernen (Kenee et al. 2006; Salgado et al. 2009). EDTA oder Zitronensäure als Spüllösungen scheinen Kalziumhydroxid besser zu entfernen als $\mathrm{NaOCl}$ (Rödig et al. 2010d). Kuga et al. (2010) konnten dies in ihrer Studie mit rasterelektronenmikroskopischer Auswertung nicht bestätigen.

EDTA-Lösungen von 17\% können Kalziumhydroxid in wässrigem Milieu effektiv entfernen, in öligem Milieu ist 10\%ige Zitronensäure EDTA überlegen (Nandini et al. 2006). EDTA soll in der Lage sein, Kalziumhydroxid zu neutralisieren und somit eine chemische Interaktion mit dem Wurzelfüllmaterial verhindern (Margelos et al. 1997). Die Kombination von ETDA-Spülungen gefolgt von einer Natriumhypochlorit-Abschlussspülung führte zu signifikant besserer (Margelos et al. 1997) bzw. vollständiger (Calt und Serper 1999) Entfernung von Kalziumhydroxid. Vermutet wird eine bessere Herausbeförderung der gebildeten Komplexe mit dem $\mathrm{NaOCl}$ aus dem Kanal. In anderen Studien wurden jedoch unter Verwendung von EDTA und $\mathrm{NaOCl}$ wenige bis viele Kalziumhydroxidrückstände gefunden (Lambrianidis et al. 1999; Kenee et al. 2006). Eine jüngere Studie fand bessere Ergebnisse bei der Verwendung von EDTA-T (Kombination von Chelator und 0,2\% Laurylsodium-sulphat-detergent) im Vergleich zu NaOCl, EDTA-C und Zitronensäure (Salgado et al. 2009).

Ebenso konnte ein Einfluss des Trägermediums der Kalziumhydroxidzubereitung auf die Entfernbarkeit der medikamentösen Einlage festgestellt werden. Zubereitungen mit öligen und viskösen Medien lassen sich im Gegensatz zu wässrigen Lösungen schwerer entfernen (Lambrianidis et al. 1999; Hosoya et al. 2004; Nandini et al. 2006).

In geraden Kanälen konnten Salgado et al. (2009) zeigen, dass das Rekapitulieren mit der Masterapikalfeile in Kombination mit der Wurzelkanalspülung die Kalziumhydroxidentfernung im Vergleich zur Spülung alleine verbesserte.

Vor allem in gekrümmten Kanälen muss beim Entfernungsversuch der medikamentösen Einlage die Möglichkeit einer Veränderung der Wurzelkanalanatomie (Begradigung, Stufenbildung, Überpräparation) beachtet werden. Dies wurde von Goldberg et al. (2004) untersucht. Hierbei wurde deutlich, dass die Entfernung der Einlage aus gekrümmten Wurzelkanälen mit Stahlinstrumenten ein hohes Risiko der Begradigung birgt. Unter Verwendung rotierender Nickel-Titan-Instrumente scheint die Kalziumhydroxid- 
entfernung aus gekrümmten Kanälen ohne Veränderung der Kanalanatomie besser möglich zu sein (Kenee et al. 2006).

Durch eine Aktivierung und Durchmischung der Spülflüssigkeit scheint die medikamentöse Einlage besser entfernbar zu sein. Einige Studien beschäftigten sich mit verschiedenen Aktivierungsverfahren in Kombination mit Spüllösungen.

Kenee et al. (2006) verglichen vier Techniken der $\mathrm{Ca}(\mathrm{OH})_{2}$ Entfernung: Spülung mit $\mathrm{NaOCl}$, Spülung mit $\mathrm{NaOCl}+$ Masterapikalfeile (MAF), $\mathrm{NaOCl}+\mathrm{EDTA} ; \mathrm{NaOCl}+$ rotierende MAF, $\mathrm{NaOCl}+\mathrm{PUI}$. Mit keiner der angewandten Techniken gelang eine vollständige Entfernung. Zusätzlich zu einer intensiven Spülung erwies sich der Gebrauch eines rotierend eingesetzten Instruments oder der passiven Ultraschallspülung als vorteilhaft. Ebenfalls konnten Lambrianidis et al. (2006) mit keinem der angewendeten Spülprotokolle die Einlage effektiv entfernen. Vor allem im apikalen Drittel blieben signifikant mehr Rückstände. Diese konnten durch Verwendung einer Patency-Feile verringert werden (Lambrianidis et al. 2006).

Die passive Ultraschallaktivierung mit $\mathrm{NaOCl}$ (2\%) war effektiver bezüglich der Kalziumhydroxidentfernung aus in den Wurzelkanal eingelassenen Gruben als die Handspülung mit $\mathrm{NaOCl}(2 \%)$ oder Wasser (van der Sluis et al. 2007b).

Wiseman et al. (2011) untersuchten in einer mikrotomographischen Untersuchung die Entfernung von Kalziumhydroxid aus gekrümmten Kanälen mit 3mal 20-sekündiger Ultraschall- und Schallaktivierung in Kombination mit rotierender Instrumentierung. Bei Verwendung von Ultraschall konnte signifikant mehr Kalziumhydroxid entfernt werden.

Bei Taşdemir et al. (2011) wurde $\mathrm{Ca}(\mathrm{OH})_{2}$ aus geraden Kanälen entfernt. Sowohl die CanalBrush $^{\text {TM }}$ als auch PUI in Kombination mit $\mathrm{NaOCl}$ entfernten signifikant mehr Kalziumhydroxid als die Spülung alleine.

Die Datenlage über neue Spültechniken bezüglich der Kalziumhydroxidentfernung ist sehr lückenhaft. Meistens wurden diese in Kombination mit chemisch wirkenden Spüllösungen verwendet, sodass über die rein mechanische Wirkungsweise der Spültechnik bzw. des Gerätes keine eindeutigen Aussagen gemacht werden können. 


\section{$3 \quad$ Ziele der Studie}

Ziel der vorliegenden Studie ist es, verschiedene traditionelle und neuartige Spültechniken zur Entfernung von Kalziumhydroxid aus dem Wurzelkanal zu untersuchen. Differenziert wird hierbei zwischen der Wirksamkeit der Methoden in apikalen und koronalen Wurzelkanaldritteln. Ebenso werden die verschiedenen Systeme miteinander verglichen.

Untersucht werden:

$>\quad$ Die passive Ultraschallspülung (PUI)

$>\quad$ Die hydrodynamische Spülung mit dem RinsEndo ${ }^{\circledR}$-Gerät

$>\quad$ Die schallgestütze Spülung mit vibrierendem Polymerstab (EndoActivator ${ }^{\circledR}$ )

$>\quad$ Die Reinigung mithilfe eines Plastikbürstchens (CanalBrush ${ }^{\mathrm{TM}}$ )

$>\quad$ Die traditionelle manuelle Spülung mit einer konventionellen Spritze.

Die Ergebnisse werden mit den in der Literatur beschriebenen Daten verglichen und diskutiert. 


\section{Material und Methode}

In der vorliegenden Studie wurde die Entfernung von Kalziumhydroxid aus standardisierten Gruben im Wurzelkanal mit Hilfe von fünf verschiedenen Techniken (Ultraschall, EndoActivator ${ }^{\circledR}$, CanalBrush $^{\top \mathrm{M}}$, RinsEndo ${ }^{\circledR}$ und Handspülung) untersucht. Das Versuchsdesign lehnt sich an das von Lee et al. (2004a) an, welches auch in anderen Studien übernommen wurde (van der Sluis et al. 2005a, b).

\subsection{Auswahl des Untersuchungsmaterials}

Für die Versuche wurden 110 humane einwurzelige mittlere und seitliche OberkieferFrontzähne sowie Eckzähne und Prämolaren mit rundem Wurzelquerschnitt und gerader Wurzel ausgewählt. Die Mindestlänge musste $19 \mathrm{~mm}$ betragen und das Wurzelwachstum abgeschlossen sein. Des Weiteren durften die Zähne keine kariösen oder resorptiven Zerstörungen oder Wurzelfüllungen aufweisen. Die Querschnittsgröße der Wurzelkanäle an der apikalen Konstriktion sollte zu Beginn der Instrumentierung kleiner sein als ein Handinstrument der ISO-Größe 35. Zähne, die diese Kriterien nicht erfüllten, wurden von vornherein aus der Untersuchung ausgeschlossen.

Nach der Extraktion der Zähne, die aus unbekannten Gründen alio loco erfolgt war und in keinem kausalen Zusammenhang mit dieser Studie stand, wurden die Zähne in Aqua dest. gelagert. Die Zähne wurden gesäubert und anhaftende Weich- und Hartgewebe von der Wurzeloberfläche entfernt. Nachfolgend wurde eine koronale Zugangskavität präpariert, die Kronenpulpa entfernt und die Wurzelkanaleingänge dargestellt. Die Wurzelkanäle wurden mit Handinstrumenten auf Gängigkeit geprüft. Anschließend konnte mit Hilfe von Reamern (Vereinigte Dentalwerke, München, Deutschland) annäherungsweise der Kanaldurchmesser ermittelt werden. Die Wurzellänge wurde vom Apex bis zur SchmelzZement-Grenze gemessen und betrug 19-24 mm. Um eine einheitliche Länge zu schaffen, wurden alle Zähne von koronal mit diamantierten Schleifern unter Wasserkühlung auf 19 mm gekürzt.

Die Präparation der Wurzelkanäle erfolgte per Hand mit Reamern und Hedströmfeilen (Vereinigte Dentalwerke, München, Deutschland) bei einer Arbeitslänge von $18 \mathrm{~mm}$ bis zur ISO-Größe 50. Nach jeder Feilengröße wurde mit 2 ml 1\%-NaOCl per Hand mit Spritze und einer 30-,,gauge“-NaviTip-Kanüle gespült wie bei Taşdemir et al. (2011) beschrieben. 
Die Abschlussspülung erfolgte pro Kanal mit $5 \mathrm{ml}$ 17\%-EDTA. Im Anschluss wurden die Kanäle mit Papierspitzen der ISO-Größe 50 getrocknet.

\subsubsection{Herstellen der Wurzelhälften und Präparation der Gruben}

Ein Guttaperchastift der ISO-Größe 50 (Vereinigte Dentalwerke, München, Deutschland) wurde in die Wurzelkanäle eingebracht und zwei zirkuläre und zwei vertikale Rillen mit einer diamantierten Trennscheibe (Horico, Berlin, Deutschland) in die Zähne gefräst. Die Guttapercha diente der besseren Einschätzung des Abstands zum Kanallumen, das nicht eröffnet werden durfte. Die horizontalen zirkulären Rillen dienten der Retention der später eingebetteten Zähne gegen vertikal angreifende Kräfte.

Anschließend wurden die Zähne entlang der Längsrillen mit Hilfe eines kleinen Wachsmessers (Aesculap, Tuttlingen, Deutschland) in zwei Hälften gespalten. Mit einer Lupenbrille wurde bei 2,5facher Vergrößerung und unter einem Auflichtmikroskop (Motic Ergonomic Trinokular Zoom Stereo Mikroskop, Motic Deutschland GmbH, Wetzlar, Deutschland) bei 20facher Vergrößerung überprüft, ob die Zahnhälften wieder spaltfrei zusammengesetzt werden können. Zähne, die nicht spaltfrei zusammengesetzt werden konnten, wurden von der Studie ausgeschlossen.

Im Folgenden wurde der Handgriff eines Fingerspreaders der Größe medium (Vereinigte Dentalwerke, München, Deutschland) abgetrennt und die Spitze mit einer diamantierten Trennscheibe (Horico, Berlin, Deutschland) auf 0,2 mm Breite reduziert. Der präparierte Fingerspreader wurde in den Nadelhalter eines Ultraschallgeräts (Piezon Master 400, EMS, Nyon, Schweiz) eingesetzt.

Mit Hilfe dieses Instrumentes wurden wie bei Lee et al. (2004a) bei niedriger Stärke unter Wasserkühlung $4 \mathrm{~mm}$ lange, 0,2 $\mathrm{mm}$ breite und 0,5 $\mathrm{mm}$ tiefe Kavitäten in die Kanalwände präpariert. Diese wurden in einer Wurzelhälfte im apikalen Wurzeldrittel im Bereich von 2-6 mm Abstand zum Apex, in der jeweils gegenüberliegenden Hälfte der Wurzel im koronalen Wurzeldrittel in einem Abstand von 10-14 mm zum Apex präpariert. Dies ist schematisch in Abbildung 6 dargestellt. Die Ausmaße der Kavität entsprechen bei der mechanischen Präparation nicht zu erfassenden Bereichen (Wu et al. 2003). Im Anschluss 
wurden die Zahnhälften mit einer Zahnbürste (Meridol, Gaba GmbH, Lörrach, Deutschland) gründlich von Debris befreit.

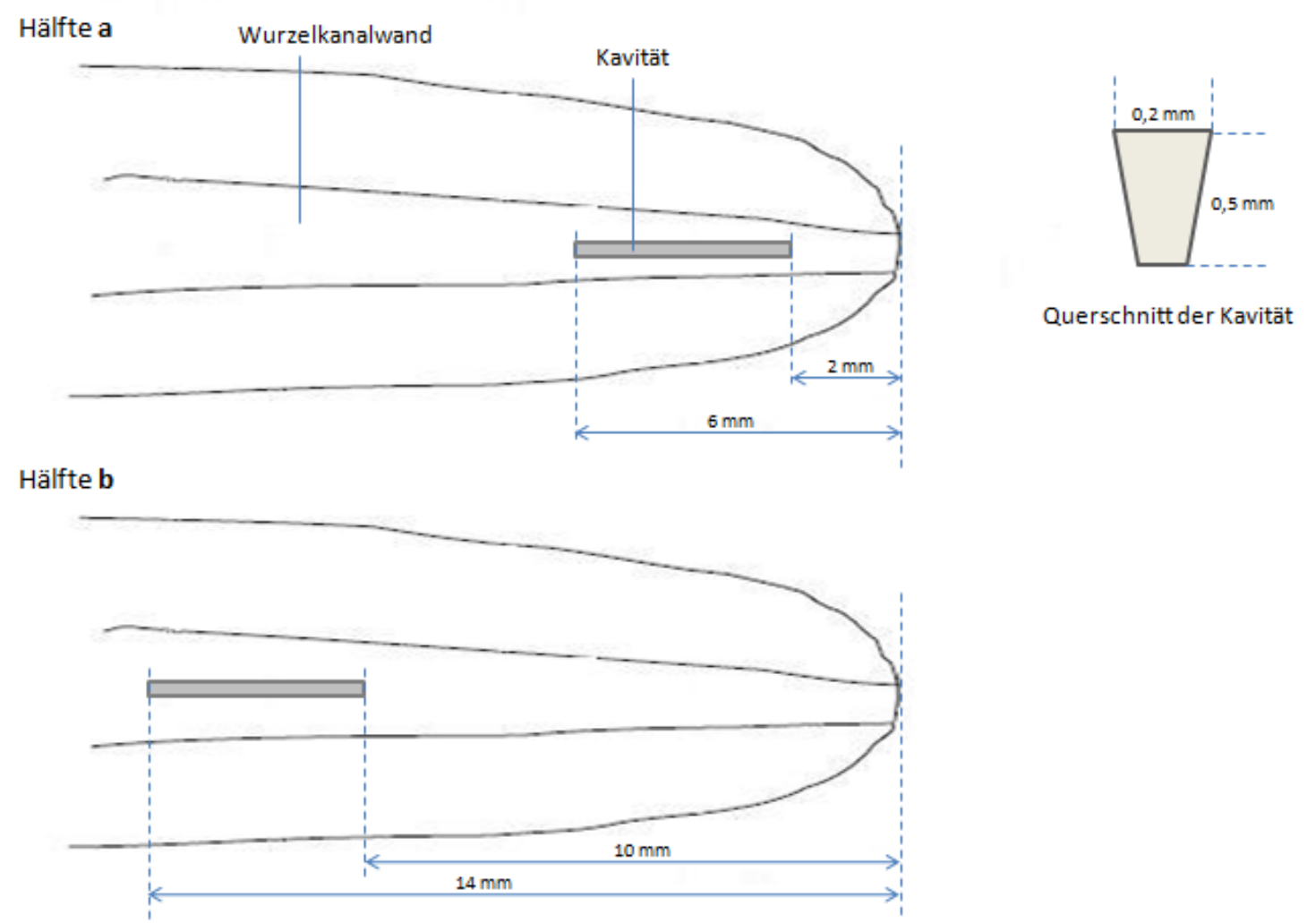

Abb. 6: Schematische Darstellung der Kavitätenpräparation innerhalb der gespaltenen Wurzelkanäle. In einer Hälfte wurde die Kavität von $2 \mathrm{~mm}$ bis $6 \mathrm{~mm}$, in der anderen von $10 \mathrm{~mm}$ bis $14 \mathrm{~mm}$ Entfernung vom Apex präpariert. 


\subsubsection{Digitale Bilderfassung, Einbetten und Füllen mit Calxy $\left.\right|^{\circledR}$}

Um das Ausmaß der Kalziumhydroxidrückstände in den Kavitäten nach Beendigung des Spülvorgangs besser auswerten zu können, wurden von beiden Zahnhälften mit präparierten Kavitäten (Beispiel Abb. 7 und 9) und von den Kavitäten selbst (Beispiel Abb. 8 und 10) digitale Bilder erstellt.

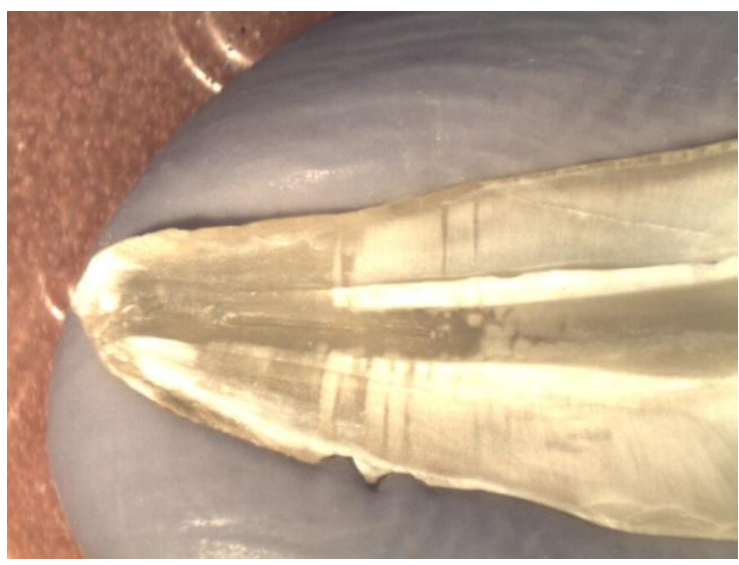

Abb. 7: Übersicht einer Zahnhälfte mit apikaler Kavität

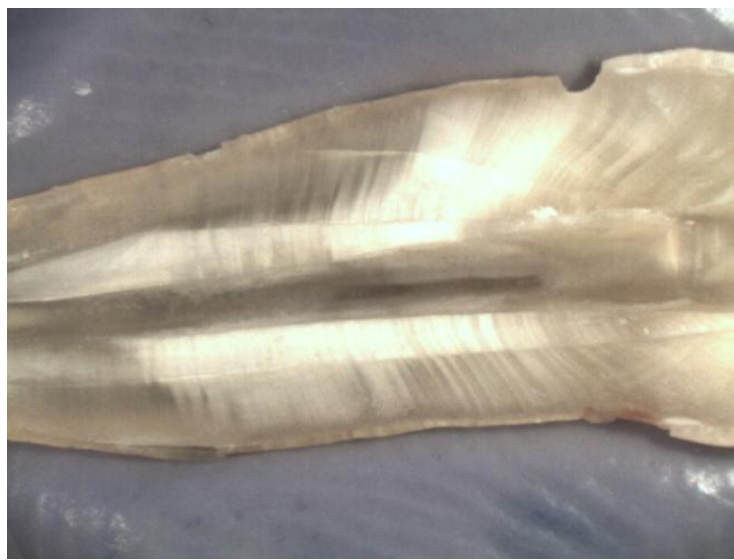

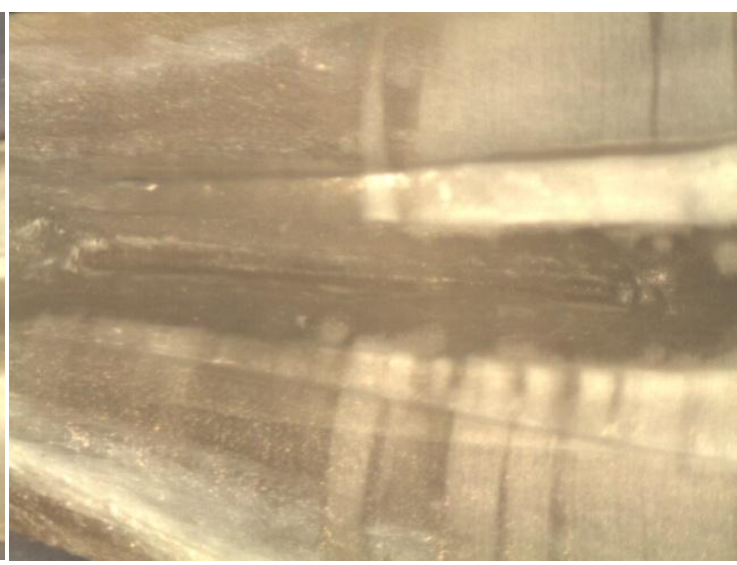

Abb. 8: Vergrößerte apikale Kavität

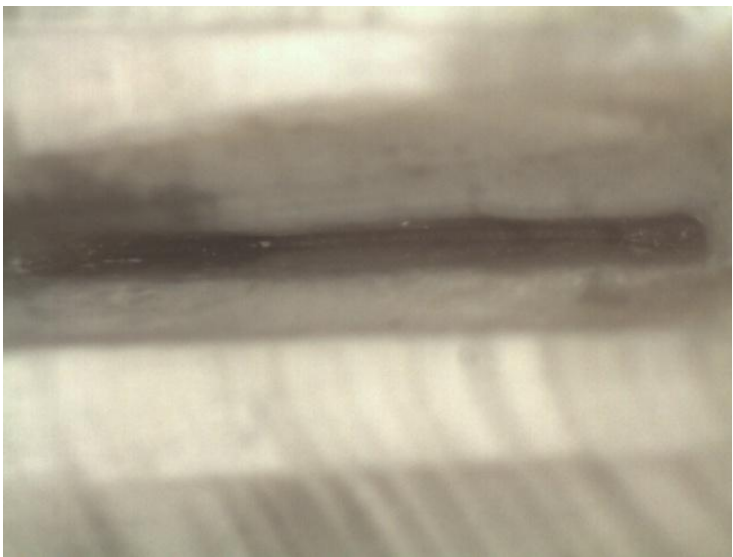

Abb. 9: Übersicht einer Zahnhälfte mit koronaler Kavität Abb. 10: Vergrößerte koronale Kavität

Die Bilderfassung erfolgte mit einem Auflichtmikroskop (MOTIC Ergonomic Trinokular Zoom Stereo Mikroskop, Motic Deutschland $\mathrm{GmbH}$, Wetzlar, Deutschland) bei 1040facher Vergrößerung mittels einer Digitalkamera (Moticam 1300, Motic Deutschland $\mathrm{GmbH}$, Wetzlar, Deutschland) bei einer Bildauflösung von 1,3 Megapixel. Um gleiche Winkel der Aufnahmen und einen identischen Bildabstand der Bilder vor und nach dem Spülen zu schaffen, wurden Schlüssel aus Abformmasse auf Silikonbasis (Flexitime ${ }^{\circledR}$, Heraeus Kulzer $\mathrm{GmbH}$, Hanau, Deutschland) angefertigt. Die Abformmasse wurde angemischt und die Zahnhälfte während der Aushärtezeit in dem noch formbaren Silikon 
so ausgerichtet, dass die Kavität unter dem Mikroskop optimal einsehbar war. Ebenso wurden die Mikroskopeinstellungen über den gesamten Versuchszeitraum eingefroren. Die Kavitäten wurden mit Hilfe eines Fingerspreaders (Vereinigte Dentalwerke, München), wie er auch zum Anlegen der Kavität genutzt wurde, mit Calxyl ${ }^{\circledR}$ (OCO Präparate $\mathrm{GmbH}$, Dirmstein/Pfalz, Deutschland) unter dem Mikroskop bei 30facher Vergrößerung gefüllt und eine digitale Aufnahme jeder gefüllten Kavität bei $40 f a c h e r$ Vergrößerung angefertigt (Abb.11).

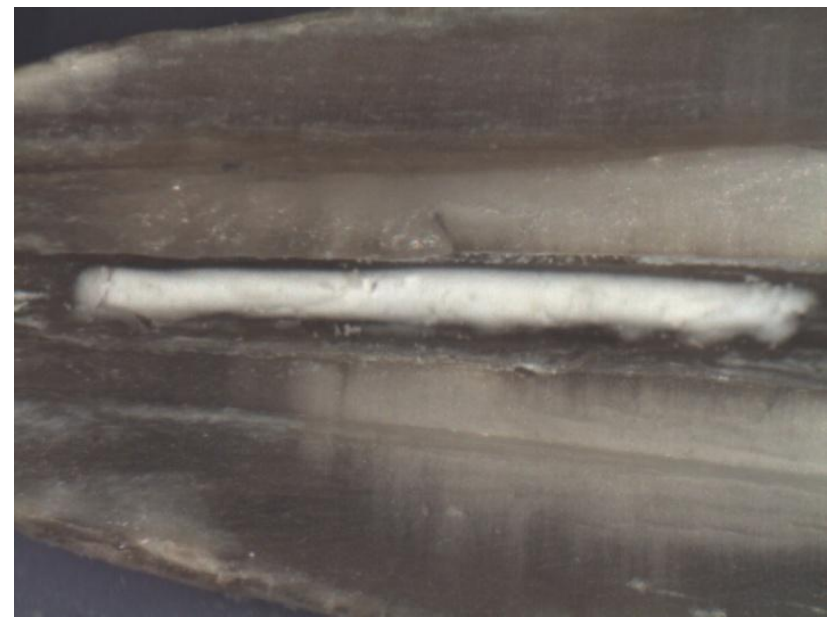

Abb. 11: Mit Kalziumhydroxid gefüllte Kavität bei 40facher Vergrößerung

Sofort im Anschluss wurden die entsprechenden Zahnhälften unter mikroskopischer Kontrolle spaltfrei zusammensetzt und mit Cervikal- (Geo Cervikalwachs, Renfert GmbH, Hilzingen, Deutschland) und Klebewachs (Hartklebewachs Deiberit, Siladent Dr. Böhme \& Schöps $\mathrm{GmbH}$, Goslar, Deutschland) fixiert. Hierbei wurde auch das Foramen apicale mit Klebewachs verschlossen, um das Ausströmen der Spülflüssigkeit zu verhindern und invivo-Konditionen zu simulieren (Schoeffel 2007). Dabei wurde ein Guttaperchastift bis auf Arbeitslänge in den Kanal eingebracht, um das Eintreten von Wachs in den Apex zu verhindern (Paragliola et al. 2010). Die Guttapercha wurde entfernt, nachdem das Wachs eingebracht war. Die so zusammengesetzten Zähne wurden einzeln mit einem Abformmaterial auf Silikonbasis (Silaplast, Dentax GmbH \& Co. KG, Ettlingen, Deutschland) in Plastikröhrchen von ca. $17 \mathrm{~mm}$ Höhe eingebettet, wie bei McGill et al. (2008) beschrieben. Die Plastikröhrchen wurden zuvor mit einer diamantierten Trennscheibe aus einem Plastikrohr in einheitlicher Länge abgetrennt. Der herausragende Zahnanteil wurde zirkulär mit Klebewachs mit der Hohlform verbunden. Mit einem in ein 
Winkelstück eingespannten Pasteinject der ISO-Größe 40 (Micro-Mega, Besançon, Frankreich) wurden die Wurzelkanäle mit Calxyl-Paste gefüllt. Das Pasteinject hatte sich in Studien von Deveaux et al. (2000) und Oztan et al. (2002) als besonders geeignetes Instrument zur Applikation von röntgenopakem $\mathrm{Ca}(\mathrm{OH})_{2}$ in den Wurzelkanal herausgestellt.

Am Wurzelkanaleingang wurde ein kleines Wattekügelchen eingebracht. Mit diesem konnte das Calxyl ${ }^{\circledR}$ kompaktiert werden, wie es von Braun und Nolden (1999) empfohlen wurde. Die Trepanationsöffnungen wurden mit Cavit ${ }^{\circledast}$ (3M ESPE, Neuss, Deutschland) in 2 mm Schichtstärke verschlossen und die Proben für 7 Tage bei $37{ }^{\circ} \mathrm{C}$ und $100 \%$ iger Luftfeuchtigkeit im Inkubator (Climacell 111, MMM Medcenter GmbH, München, Deutschland)

$\mathrm{KBF}$, Binder $\mathrm{GmbH}$, Tuttlingen, Deutschland) gelagert. Um sicher zu gehen, dass die Kanäle vollständig gefüllt waren, wurden vor der Aufbewahrung im Brutschrank Zahnfilme (Abb. 12) von allen gefüllten und eingebetteten Zähnen mit einem dentalen Röntgengerät (Heliodent DS D3302, Sirona Dental Systems GmbH, Bensheim, Deutschland) bei einer Belichtungszeit von 0,06 Sekunden, $7 \mathrm{~mA}$ und 60 kvDc erstellt. Nicht vollständig gefüllte Kanäle wurden erneut gefüllt und wiederum einer Röntgenkontrolle unterzogen.

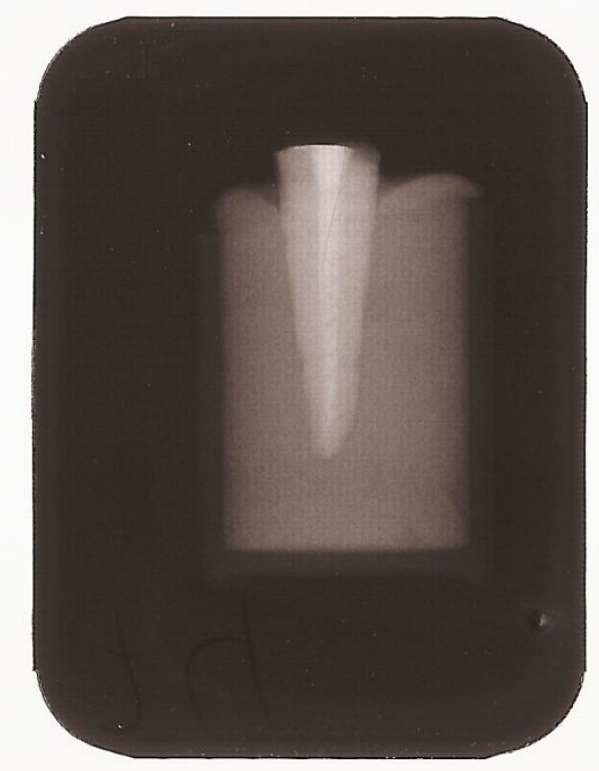




\subsubsection{Voruntersuchungen}

Zur Sicherung des standardisierten experimentellen Vorgehens wurden zunächst Voruntersuchungen an zehn Zähnen durchgeführt. Diese dienten vor allem der Überprüfung der Herstellerangaben der verschiedenen Spülinstrumente und Materialien. Ebenso konnten so die Spüldauer und Spülflüssigkeitsmenge angepasst werden, um standardisierte Bedingungen für die Versuche zu schaffen und Fehlerquellen im Vorfeld zu identifizieren und gegebenenfalls zu beseitigen. Bezüglich der Flüssigkeitsmenge musste sich an dem nicht einstellbaren Verbrauch des RinsEndo ${ }^{\circledR}$-Systems orientiert werden. Dieses zieht 6,2 ml neue Spüllösung pro Minute aus der angesteckten Spritze ein. Daher wurde die Flüssigkeitsmenge auf 3,2 ml pro 30 Sekunden festgelegt. Die Spüldauer wurde in Anlehnung an die von Lee et al. (2004a) in einer In-vitro-Studie definierte Spüldauer auf 3 Minuten festgelegt. So ergab sich eine Gesamtspülmenge von 19,2 $\mathrm{ml}$ bei jeder verwendeten Spültechnik.

Bei den Vorversuchen wurde ebenso deutlich, dass nicht alle Kalziumhydroxid-Pasten deutlich röntgenopak sind - daher wurde das Fertigpräparat Calxyl ${ }^{\circledR}$ ausgewählt. Dieses ist wiederum so beschaffen, dass es sehr schwierig mit Injektionskanülen in den Wurzelkanal eingebracht werden kann, da es schnell austrocknet und die Kanüle verstopft. Es schien daher geeigneter, die Paste mithilfe eines Pasteinjects bis apikal zu befördern.

\subsection{Verwendete Aktivierungsgeräte}

\subsubsection{Hydrodynamische Spülung mit RinsEndo ${ }^{\circledR}$}

Das RinsEndo ${ }^{\circledR}$-Gerät wurde, wie vom Hersteller beschrieben, zur hydrodynamischen Wurzelkanalspülung eingesetzt. Die Druckluftversorgung der Behandlungseinheit wurde auf 3,5 bar eingestellt, was innerhalb des empfohlenen Bereichs von 2,3 bis 4,2 bar liegt. Da der Flüssigkeitsverbrauch des Gerätes 6,2 $\mathrm{ml}$ pro Minute beträgt, wurde eine $5 \mathrm{ml}$ Luer-Spritze mit 3,1 ml Aqua dest. befüllt und das RinsEndo ${ }^{\circledR}$ über 30 Sekunden aktiviert. Die maximale Eindringtiefe der RinsEndo ${ }^{\circledR}$-Kanüle betrug $16 \mathrm{~mm}$. 


\subsubsection{Mechanisch-aktivierte Spülung (CanalBrush ${ }^{\mathrm{TM}}$ )}

Zur mechanisch aktivierten Spülung wurde die CanalBrush ${ }^{\mathrm{TM}}$ verwendet. Dieses Bürstchen wurde in einen HG-Schaft eines Winkelstücks eingegliedert und bei einer Umdrehungszahl von $600 \mathrm{Umin}^{-1} \mathrm{im}$ Wurzelkanal bei einer maximalen Eindringtiefe von $16 \mathrm{~mm}$ eingesetzt. Da die mechanische Widerstandskraft der CanalBrush $^{\mathrm{TM}}$ ebenfalls bewertet werden sollte, wurde für jeden Wurzelkanal ein neues Bürstchen verwendet. Während der Aktivierung über 30 Sekunden wurden mit einer Handspritze 3,1 ml Aqua dest. zugeführt.

\subsubsection{Schall-aktivierte Spülung (EndoActivator ${ }^{\circledR}$ )}

Die Schall-Aktivierung der Spüllösung erfolgt mit dem EndoActivator ${ }^{\circledR}$ (Densply Tulsa Dental, Tulsa, USA). Dieser wurde so eingestellt, dass die Spüllösung mit einer Frequenz von $10.000 \mathrm{cpm}$ (cycles per minute) aktiviert wurde. Auf das Handstück wurde ein Ansatz der Größe Large (35/.04) aufgesteckt. Da die Ansätze zum Einmalgebrauch bestimmt sind, wurde für jeden Versuchszahn ein neuer Ansatz verwendet. Während der Aktivierung über 30 Sekunden wurden mit einer Handspritze 3,1 ml Aqua dest. zugeführt.

\subsubsection{Ultraschall-aktivierte Spülung (Piezon Master 400)}

Zur Ultraschall-Aktivierung der Spüllösung wurde das Piezon Master 400 (Fa. EMS, Nyon, Schweiz) verwendet. Es arbeitet in einem Frequenzbereich zwischen 27 und $30 \mathrm{kHz}$. Das Gerät wurde, wie vom Hersteller empfohlen, bei minimaler Leistungseinstellung in der Betriebsart „Endo“ angewendet. In das Handstück wurde eine Feile der ISO-Größe 15 eingesetzt. Diese wurde nach Bearbeitung von fünf Versuchszähnen ausgetauscht.

Die Spülmenge wurde vor Beginn der Versuche auf 3,1 ml pro Minute eingestellt. Diese Einstellung wurde am entsprechenden Drehschalter farblich mit einem Faserstift markiert und während der Versuche regelmäßig kontrolliert.

\subsubsection{Manuelle Spülung}

Für die manuelle Applikation der Spüllösung wurden 5-ml-Einmalspritzen und NaviTipSpülnadeln mit einem äußeren Durchmesser von 0,3 mm = 30 „gauge“ (Ultradent, 
München, Deutschland) verwendet. Es wurde grundsätzlich auf $17 \mathrm{~mm}$ Länge gespült. Zur Kontrolle wurde die Länge mit einem Gummistopper an der Spülkanüle markiert. Um einen Flüssigkeitsstrom von 6,2 $\mathrm{ml}$ pro Minute zu erreichen, wurden 3,1 ml Aqua dest. in die Spritze aufgezogen und über jeweils 30 Sekunden die Zeit gestoppt.

Die manuelle Spülung fand zusätzlich zur Kontrollgruppe auch in den Gruppen solcher Aktivierungsgeräte statt, die auf eine unabhängige Flüssigkeitszufuhr angewiesen sind (CanalBrush $^{\mathrm{T}}$, EndoActivator $^{\circledR}$ ).

\subsection{Versuchsaufbau}

Die 100 Zähne wurden randomisiert in fünf Gruppen aufgeteilt. Die Lagerung der Zähne im Brutschrank erfolgte in wieder verschließbaren Kuntststoffbehältern, die mit Aqua dest. befüllt wurden.

Nach Ablauf der 7 Tage wurden die Proben aus dem Brutschrank entnommen.

Das Cavit, welches zur koronalen Abdeckung diente, wurde entfernt und anschließend die Kalziumhydroxidpaste mithilfe der verschiedenen Spültechniken anhand des jeweiligen Spülprotokolls (s. 4.3.1.1 - 4.3.1.5) bestmöglich beseitigt.

\subsubsection{Versuchsgruppen}

\subsubsection{Gruppe 1: RinsEndo ${ }^{\circledR}$}

20 Zähne

\section{Spülprotokoll:}

- während der Präparation Spülung mit $2 \mathrm{ml} \mathrm{NaOCl}$ nach jeder Instrumentengröße

- 6 Zyklen: Spülung 30 Sekunden mit RinsEndo ${ }^{\circledR}$ bei einem durchschnittlichen Aqua dest.-Verbrauch von $6,2 \mathrm{ml} / \mathrm{min}$, also $3,1 \mathrm{ml}$ pro 30 Sekunden

- während eines Zyklus 10 vertikal pumpende Bewegungen von 2-3 mm im Kanal

- Eindringtiefe der RinsEndo ${ }^{\circledR}$ Spülkanülenspitze: $2 \mathrm{~mm}$ kürzer als Arbeitslänge, also maximal $16 \mathrm{~mm}$

- Abschlussspülung mit $3 \mathrm{ml}$ Aqua dest. 


\subsubsection{Gruppe 2: CanalBrush ${ }^{\mathrm{TM}}$}

20 Zähne

Spülprotokoll:

- während der Präparation Spülung mit $2 \mathrm{ml} \mathrm{NaOCl}$ nach jeder Instrumentengröße

- 6 Zyklen:

○ Spülung mit 3,1 $\mathrm{ml}$ Aqua dest. in 30 Sekunden mit 5-ml-Spritze und 30„gauge“-NaviTip-Kanüle

- Aktivierung der CanalBrush ${ }^{\mathrm{TM}}$ mit 600 Umdrehungen pro Min für 30 Sekunden

- Eindringtiefe der CanalBrush ${ }^{\mathrm{Tm}}: 2 \mathrm{~mm}$ kürzer als Arbeitslänge, also maximal $16 \mathrm{~mm}$

- Abschlussspülung mit $3 \mathrm{ml}$ Aqua dest.

\subsubsection{Gruppe 3: EndoActivator ${ }^{\circledR}$}

20 Zähne

Spülprotokoll:

- während der Präparation Spülung mit $2 \mathrm{ml} \mathrm{NaOCl}$ nach jeder Instrumentengröße

- 6 Zyklen:

○ Spülung mit 3,1 $\mathrm{ml}$ Aqua dest. in 30 Sekunden mit 5-ml-Spritze und 30„gauge"-NaviTip-Kanüle

○ Aktivierung des EndoActivator ${ }^{\circledR}$ mit 10.000 cpm für 30 Sekunden mit der Spitze large (35/.04)

$\circ$ dabei 10 vertikal pumpende Bewegungen von 2-3 mm im Kanal

- $\quad$ Eindringtiefe des EndoActivator ${ }^{\circledR}: 2 \mathrm{~mm}$ kürzer als Arbeitslänge, also maximal $16 \mathrm{~mm}$

- Abschlussspülung mit $3 \mathrm{ml}$ Aqua dest. 


\subsubsection{Gruppe 4: US-Spülung}

20 Zähne

\section{Spülprotokoll:}

- während der Präparation Spülung mit $2 \mathrm{ml} \mathrm{NaOCl}$ nach jeder Instrumentengröße

- 6 Zyklen: Spülung mit 3,1 ml Aqua dest. in 30 Sekunden bei passiver Aktivierung des PiezonMaster 400 mit einer Feile der ISO-Größe 15

- $\quad$ Eindringtiefe des Ultraschallspitze $2 \mathrm{~mm}$ kürzer als Arbeitslänge, also maximal $16 \mathrm{~mm}$

- Abschlussspülung mit $3 \mathrm{ml}$ Aqua dest.

\subsubsection{Gruppe 5: Handspülung (Kontrollgruppe)}

20 Zähne

\section{Spülprotokoll:}

- während der Präparation Spülung mit $2 \mathrm{ml} \mathrm{NaOCl}$ nach jeder Instrumentengröße

- 6 Zyklen: Spülung mit 3,1 ml Aqua dest. in 30 Sekunden mit 5-ml-Spritze und 30-„gauge“-NaviTip-Kanüle

- während eines Zyklus 10 vertikal pumpende Bewegungen von 2-3 mm im Kanal

- $\quad$ Eindringtiefe der NaviTip Spülkanülenspitze: $1 \mathrm{~mm}$ kürzer als Arbeitslänge, also maximal $17 \mathrm{~mm}$

- Abschlussspülung mit $3 \mathrm{ml}$ Aqua dest. 


\subsection{Auswertung}

Nach Abschluss des Spülvorgangs wurden die Wurzelkanäle mit Papierspitzen der ISOGröße 50 getrocknet und die Wurzelhälften getrennt. Wiederum wurden digitale Bilder der einzelnen Kavitäten mit Hilfe der entsprechenden Silikonschlüssel und der Digitalkamera (Moticam 1300, Motic Deutschland GmbH, Wetzlar, Deutschland) bei 30facher Vergrößerung und einer Bildauflösung von 1,3 Megapixeln angefertigt.

Vor der Bewertung wurden die Proben von einer unabhängigen Person zufällig verschlüsselt, so dass es für die beiden Untersucher nicht ersichtlich war, zu welcher Gruppe der Zahn bzw. die Zahnhälfte gehörte.

Die Menge des in der Kavität verbliebenen Kalziumhydroxids wurde von zwei kalibrierten Zahnärzten bewertet. Die Kalibrierung der beiden Untersucher für das von Lee et al. (2004a) entwickelte Scoresystem fand unter dem Mikroskop bei 40-facher Vergrößerung statt. Gemeinsam wurden zunächst 50 Zahnhälften bewertet und besprochen. Einige Tage später wurden erneut 50 Zahnhälften angesehen, bewertet und über abweichende Bewertungen diskutiert. Im Folgenden wertete jeder Untersucher alle 200 Zahnhälften bzw. die in ihnen befindlichen Kavitäten zweimal aus. Dabei konnten die digitalen Bilder der Kavitäten vor und nach der Spülung des Kanals zu Hilfe genommen werden. Die Auswertung fand an ein und demselben Bildschirm unter gleichen Lichtbedingungen statt. Zwischen der jeweils ersten und zweiten Auswertung lag ein zeitlicher Abstand von einer Woche. 
Das verwendete Bewertungsystem besteht aus den folgenden Scores:

0: die Kavität ist leer (Abb. 13)

1: $\quad$ weniger als die Hälfte der Kavität ist mit Kalziumhydroxid gefüllt (Abb. 14)

2: mehr als die Hälfte der Kavität ist mit Kalziumhydroxid gefüllt (Abb. 15)

3: die Kavität ist vollständig mit Kalziumhydroxid gefüllt (Abb. 16)

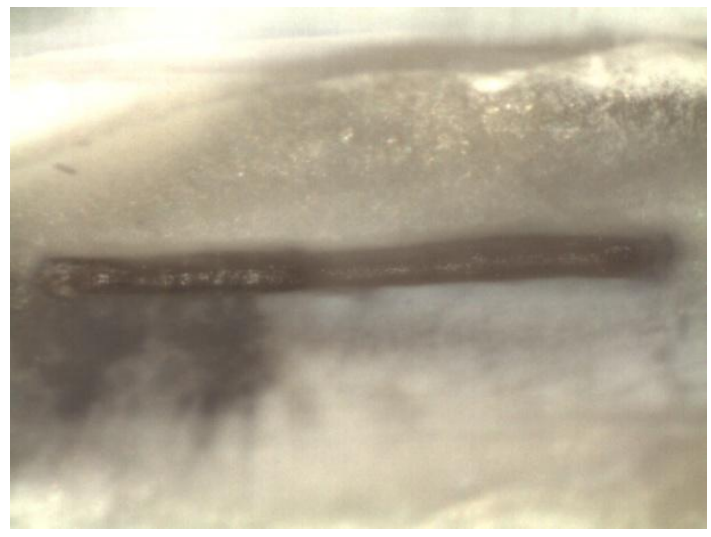

Abb. 13: Score 0 (40fache Vergrößerung)

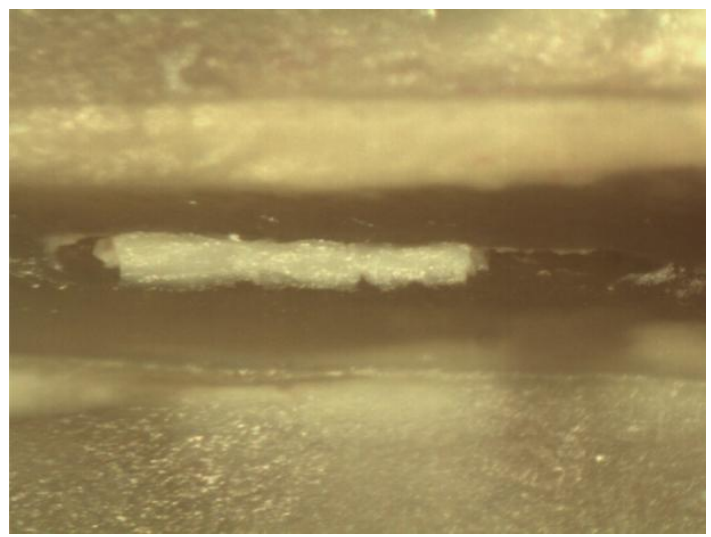

Abb. 15: Score 2 (40fache Vergrößerung)

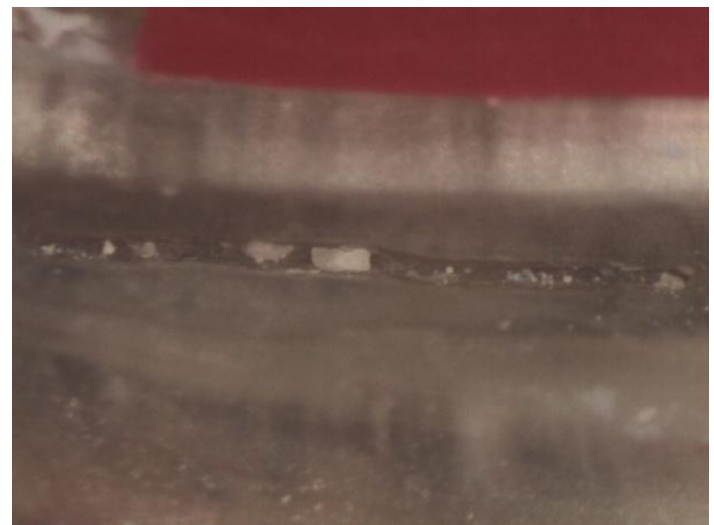

Abb. 14: Score 1 (40fache Vergrößerung)

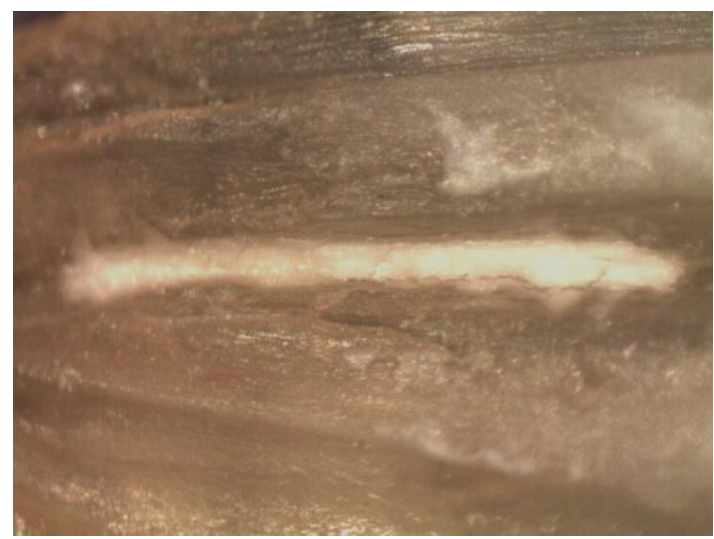

Abb. 16: Score 4 (40fache Vergrößerung)

\subsection{Statistische Auswertung}

Anhand der doppelten Auswertung beider Untersucher wurden die intraindividuelle und die interindividuelle Reliabilität überprüft und Cohens Kappa-Werte berechnet. Hieraus kann eine Aussage über das Maß der Standardisierung der Bewertung der Proben gemacht werden. 
Da von einer hohen Reproduzierbarkeit ausgegangen wurde, konnten die verschiedenen Untersuchungen (durch verschiedene und gleiche Reader) als Messwiederholungen modelliert werden). Es wurden also alle vier Auswertungen in die statistische Auswertung einbezogen.

Zur Berechnung der Daten wurde ein nichtparametrisches Analyseverfahren verwendet (Brunner et al. 2002).

Weiterhin wurden Post-Hoc-Paarvergleiche der Spültechniken in Abhängigkeit der Lage der Kavität berechnet. Die Ergebnisse der Versuche werden nach diesem Schema für das koronale und apikale Drittel getrennt untersucht. Das Signifikanzniveau wird auf $\alpha=0,05$ festgelegt.

Die statistische Auswertung erfolgte mit Statistika 9.0, das Erstellen der Graphen und Tabellen mit Statistika 9.0 und Microsoft Excel 2007. 


\section{Ergebnisse}

\subsection{Reproduzierbarkeit der Ergebnisse}

\subsubsection{Intraindividuelle Reliabilität}

Anhand der doppelten Auswertung durch beide Untersucher wurden die interindividuelle und die intraindividuelle Reliabilität geprüft. Hierfür wurden Cohens Kappa-Werte bestimmt. Anhand dieser Werte kann eine Aussage über das Maß der Standardisierung der Bewertung der Proben getroffen werden. Tabelle 1 zeigt die Übereinstimmungen der Score-Werte beider Auswertungen des ersten Untersuchers, Tabelle 2 den errechneten Kappa-Koeffizienten. Tabelle 3 und 4 zeigen die entsprechenden Daten für den zweiten Untersucher. Der Kappa-Koeffizient für Reader 1 beträgt 0,9489, der für Reader 2 beträgt 0,9341. Beide Werte sind größer als 0,8. Es kann daher von einer guten Reproduzierbarkeit bezüglich des Scoresystems ausgegangen werden.

\subsubsection{Untersucher 1}

\begin{tabular}{|c|c|c|c|c|c|}
\hline Auswertung 1 & \multicolumn{5}{|c|}{ Auswertung 2 } \\
\hline $\begin{array}{c}\text { Absolute } \\
\text { Häufigkeiten }\end{array}$ & Score 0 & Score 1 & Score 2 & Score 3 & Summe \\
\hline Score 0 & 22 & 0 & 0 & 0 & 22 \\
\hline Score 1 & 1 & 26 & 0 & 0 & 27 \\
\hline Score 2 & 0 & 0 & 71 & 3 & 74 \\
\hline Score 3 & 0 & 0 & 3 & 74 & 77 \\
\hline Summe & 23 & 26 & 74 & 77 & 200 \\
\hline
\end{tabular}

Tab. 1: Übereinstimmung der Scores beider Auswertungen für Untersucher 1

\begin{tabular}{|l|c|}
\hline \multicolumn{2}{|c|}{ Einfacher Kappa-Koeffizient } \\
\hline Kappa & 0.9489 \\
\hline 95\% Untere Konf.grenze & 0.9115 \\
\hline 95\% Obere Konf.grenze & 0.9863 \\
\hline
\end{tabular}

Tab. 2: Kappa-Koeffizient für Untersucher 1 


\subsubsection{Untersucher 2}

\begin{tabular}{|c|c|c|c|c|c|}
\hline Auswertung 1 & \multicolumn{5}{|c|}{ Auswertung 2 } \\
\hline $\begin{array}{c}\text { Absolute } \\
\text { Häufigkeiten }\end{array}$ & Score 0 & Score 1 & Score 2 & Score 3 & Summe \\
\hline Score 0 & 21 & 0 & 0 & 0 & 21 \\
\hline Score 1 & 1 & 26 & 0 & 0 & 27 \\
\hline Score 2 & 1 & 0 & 69 & 3 & 73 \\
\hline Score 3 & 0 & 0 & 4 & 75 & 79 \\
\hline Summe & 23 & 26 & 73 & 78 & 200 \\
\hline
\end{tabular}

Tab. 3: Übereinstimmung der Scores beider Auswertungen für Untersucher 2

\begin{tabular}{|l|l|}
\hline \multicolumn{2}{|c|}{ Einfacher Kappa-Koeffizient } \\
\hline Kappa & 0.9341 \\
\hline 95\% Untere Konf.grenze & 0.8919 \\
\hline 95\% Obere Konf.grenze & 0.9764 \\
\hline
\end{tabular}

Tab. 4: Kappa-Koeffizient für Untersucher 2

\subsubsection{Interindividuelle Reliabilität}

Beim Interreader-Vergleich der zwei Auswertungen liegt der Kappa-Koeffizient im schlechtesten Fall bei 0,8829 (Vergleich von Reader 1 bei Auswertung 2 mit Reader 2 bei Auswertung 1), sodass auch hier von einer guten Reproduzierbarkeit ausgegangen werden kann. Während der gesamten Auswertung betrug die Differenz innerhalb und zwischen den beiden Readern für eine Probe nie mehr als einen Score-Wert.

\subsection{Ergebnisse des Hauptversuches}

Aufgrund der errechneten Reliabilitäten kann von einer hohen Reproduzierbarkeit der Ergebnisse ausgegangen werden (s. 5.1). Die verschiedenen Auswertungen (durch verschiedene und gleiche Reader) wurden daher alle berücksichtigt und als Messwiederholungen modelliert. Da mit einem Score-System ausgewertet wurde, konnte nicht von einer Normalverteilung der Daten ausgegangen werden, sodass ein nichtpara- 
metrisches Analyseverfahren verwendet wurde (Brunner et al. 2002). Das Signifikanzniveau wurde auf $\alpha \leq 0,05$ festgelegt.

Dabei zeigte sich ein signifikanter Einzeleffekt der Spültechnik ( $p<0,000001)$. Der Einzeleffekt der Lage der Grube (Zahnhälfte) ist nicht signifikant ( $p=0,22469)$.

Zwischen der verwendeten Spültechnik (Gruppe 1-5) und der Lage der Grube (koronal/apikal) lässt sich eine signifikante Interaktion ( $p=0.01358)$ nachweisen (Tab. 5). Das heißt, der Einfluss, den die Spültechnik auf den erzielten Grad der Sauberkeit hat, hängt von der Lage der Kavität ab. Dies weist auf unterschiedliche Reinigungseffekte der einzelnen Spültechniken in den verschiedenen Wurzelkanaldritteln hin. Daher erfolgt im Folgenden eine nach Zahnhälften (apikale und koronale Gruben) getrennte Auswertung. Da die Analyse explorativen Charakters ist, wurde bei den Post-Hoc Paarvergleichen keine Adjustierung bezüglich des multiplen Niveaus vorgenommen.

\begin{tabular}{||l||c||}
\hline & $p$-Wert \\
\hline \hline Gruppe (verwendete Spültechnik) & 0.00000 \\
\hline \hline Zahnhälfte (Lage der Kavität) & 0.22469 \\
\hline \hline Interaktion & 0.01358 \\
\hline
\end{tabular}

Tab. 5: Interaktion zwischen Spültechnik und Lage der Kavität 


\subsubsection{Zahnhälfte 1 (apikale Gruben)}

\section{Paarvergleiche}

\begin{tabular}{||c||c|}
\hline $\begin{array}{c}\text { Paarvergleich } \\
\text { (Gruppe) }\end{array}$ & p-Wert \\
\hline \hline $1 * 2$ & 0.01855 \\
\hline \hline $1 * 3$ & 0.34565 \\
\hline \hline $1 * 4$ & 0.00000 \\
\hline \hline $1 * 5$ & 0.53297 \\
\hline \hline $2 * 3$ & 0.16486 \\
\hline \hline $2 * 4$ & 0.00000 \\
\hline \hline $2 * 5$ & 0.00021 \\
\hline \hline $3 * 4$ & 0.00000 \\
\hline \hline 25 & 0.07257 \\
\hline \hline
\end{tabular}

Tab. 6: Paarvergleiche der Spültechniken für das apikale Drittel

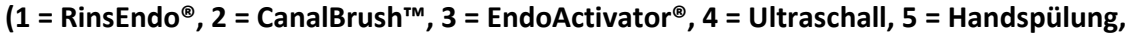
rote Markierung: signifikant, blaue Markierung: nicht signifikant)

Die Ergebnisse der Paarvergleiche für die Gruben im apikalen Kanaldrittel sind in Tabelle 6 mit den entsprechenden p-Werten aufgeführt. Sie zeigen, dass die Reinigung mit Ultraschallaktivierung (Gruppe 4) allen anderen Gruppen signifikant überlegen war. Die Spülung per Hand (Gruppe 5), mit RinsEndo ${ }^{\circledR}$ (Gruppe 1) und mit dem EndoActivator ${ }^{\circledR}$ (Gruppe 3) lieferten die schlechtesten Ergebnisse. Zwischen diesen drei Gruppen gab es keinen signifikanten Unterschied. Lediglich die CanalBrush ${ }^{\mathrm{TM}}$ (Gruppe 2) war der Handspülung $(p=0,00021)$ und RinsEndo ${ }^{\circledast}(p=0,01855)$ im apikalen Kanaldrittel bezüglich der Reinigungswirkung signifikant überlegen.

In Tabelle 7 sind die absoluten Score-Häufigkeiten aller vier Auswertungen für die apikalen Gruben aufgeführt. Diese sind als relative Häufigkeiten in Abbildung 17 in einem Säulendiagramm dargestellt. 


\begin{tabular}{|c||c|c|c|c|c||c|}
\hline & $\begin{array}{c}1 \\
\text { RinsEndo }\end{array}$ & $\begin{array}{c}2 \\
\text { CanalBrush }^{\mathrm{TM}}\end{array}$ & $\begin{array}{c}3 \\
\text { EndoActivator }^{\circledR}\end{array}$ & $\begin{array}{c}4 \\
\text { Ultraschall }\end{array}$ & $\begin{array}{c}5 \\
\text { Handspülung }\end{array}$ & Summe \\
\hline \hline Score 0 & 4 & 0 & 4 & 57 & 0 & 65 \\
\hline Score 1 & 8 & 16 & 8 & 18 & 0 & 50 \\
\hline Score 2 & 16 & 48 & 32 & 5 & 28 & 129 \\
\hline Score 3 & 52 & 16 & 36 & 0 & 52 & 156 \\
\hline \hline Summe & 80 & 80 & 80 & 80 & 80 & 400 \\
\hline
\end{tabular}

Tab. 7: Absolute Häufigkeiten der Score-Werte für die apikalen Gruben aller vier Auswertungen

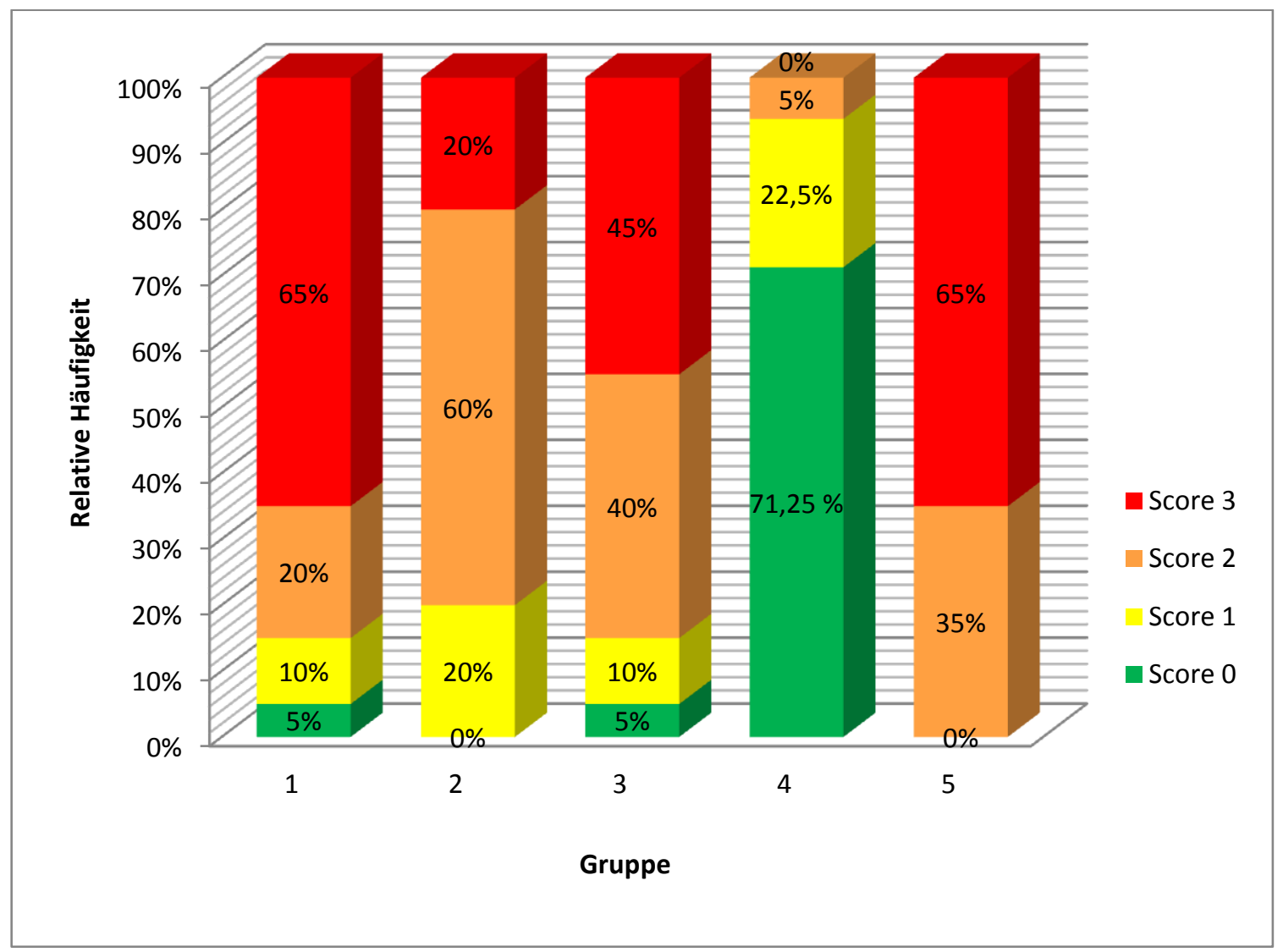

Abb. 17: Relative Häufigkeiten der Score-Werte im apikalen Drittel (Zahnhälfte 1) aller Spültechniken

(Score $\mathbf{0}=$ die Kavität ist leer, Score 1 = weniger als die Hälfte der Kavität ist mit Kalziumhydroxid gefüllt, Score $\mathbf{2}$ = mehr als die Hälfte der Kavität ist mit Kalziumhydroxid gefüllt, Score $\mathbf{3}=$ die Kavität ist vollständig mit Kalziumhydroxid gefüllt)

Aus Tabelle 7 und Abbildung 17 wird deutlich, dass mit der CanalBrush ${ }^{\mathrm{TM}}$ und der Handspülung nie eine komplette Kalziumhydroxidentfernung (Score $0=$ die Kavität ist leer) aus der apikalen Grube erreicht werden konnte. Das RinsEndo ${ }^{\circledR}$ und der EndoActivator ${ }^{\circledR}$ erreichten dies jeweils in wenigen Fällen (5\%), bei der Verwendung von Ultraschall konnte in $71,25 \%$ eine vollständige Kalziumhydroxidentfernung erreicht werden. Mit der Handspülung wurde ebenfalls nie Score 1 (weniger als die Hälfte der 
Kavität ist mit Kalziumhydroxid gefüllt) erreicht. Mit RinsEndo ${ }^{\circledast}$ und dem EndoActivator ${ }^{\circledast}$ wurde Score 1 in nur 10\% der Fälle erreicht, mit der CanalBrush ${ }^{\mathrm{TM}}$ in 20\%, mit Ultraschall in $22,5 \%$. Mehr als die Hälfte der Kavität (Score 2) war bei Ultraschall nur in $5 \%$ mit Kalziumhydroxid gefüllt, bei RinsEndo ${ }^{\circledR}$ in $20 \%$, bei der Handspülung in $35 \%$, bei EndoActivator $^{\circledR}$ in $40 \%$, bei CanalBrush ${ }^{\mathrm{TM}}$ in $60 \%$. Score 3 (die Kavität ist vollständig mit Kalziumhydroxid gefüllt) wurde bei der Verwendung von Ultraschall nie vergeben, bei CanalBrush $^{\mathrm{TM}}$ in $20 \%$ der Proben, bei EndoActivator ${ }^{\circledR}$ in $45 \%$, und bei der Verwendung von RinsEndo ${ }^{\circledR}$ ebenso oft wie bei der Handspülung (65\%).

\section{Box-Plot Hälfte 1}

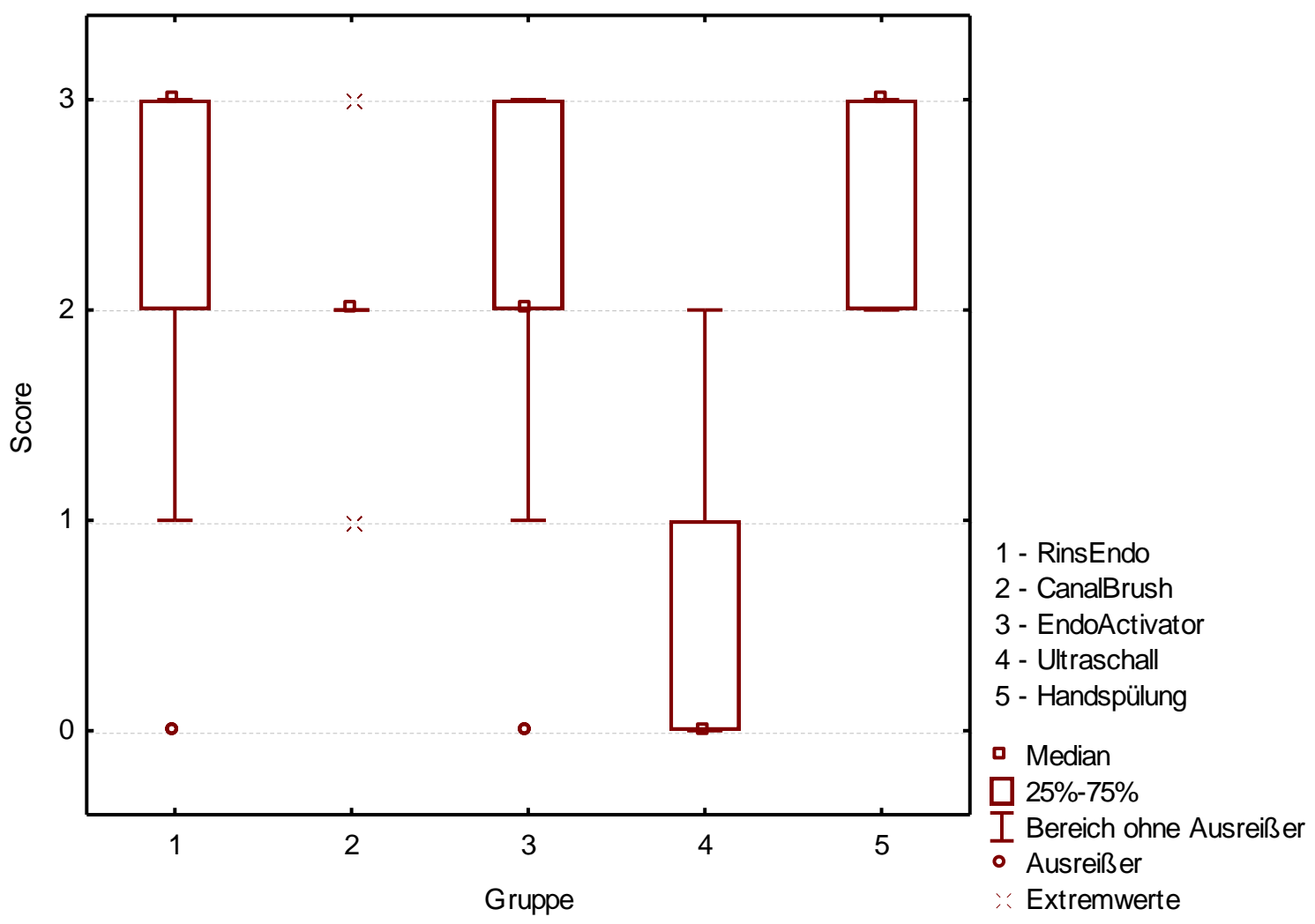

Abb. 18: Box-Plot für die apikalen Gruben (Zahnhälfte 1)

Der zugehörige Box-Plot (Abb. 18) veranschaulicht die Ergebnisse nochmals graphisch. Die Mediane des RinsEndo ${ }^{\circledast}$ (Gruppe 1) und der Handspülung (Gruppe 5) liegen bei Score 3, die der CanalBrush ${ }^{\text {TM }}$ (Gruppe 2) und des EndoActivators ${ }^{\circledR}$ (Gruppe 3) bei Score 2 und die der Ultraschall-Spülung (Gruppe 4) bei Score 0. Im Vergleich zur Handspülung wurde bei RinsEndo ${ }^{\circledast}$ in wenigen Fällen Score 1 erreicht und in seltenen Ausnahmen Score 0. Mit der CanalBrush $^{\text {TM }}$ wurde recht konstant Score 2 erreicht, mit einzelnen Ausreißern bei Score 3 
und Score 1. Der EndoActivator ${ }^{\circledR}$ erreichte wie RinsEndo $^{\circledR}$ in wenigen Fällen Score 1 und in seltenen Ausnahmen Score 2, meistens Score 2 und 3. Die Ultraschall-Spülung erreichte hauptsächlich Score 0 und 1, in wenigen Fällen Score 2.

\subsubsection{Zahnhälfte 2 (koronale Gruben)}

Paarvergleiche

\begin{tabular}{||c||c||}
\hline \hline $\begin{array}{c}\text { Paarvergleiche } \\
\text { (Gruppe) }\end{array}$ & p-Wert \\
\hline \hline $1 * 2$ & 0.63893 \\
\hline \hline $1 * 3$ & 0.05951 \\
\hline \hline $1 * 4$ & 0.00009 \\
\hline \hline $1 * 5$ & 0.04103 \\
\hline \hline $2 * 3$ & 0.07824 \\
\hline \hline $2 * 4$ & 0.00003 \\
\hline \hline $2 * 5$ & 0.00112 \\
\hline \hline $3 * 4$ & 0.01469 \\
\hline \hline $3 * 5$ & 0.00000 \\
\hline \hline $4 * 5$ & 0.00000 \\
\hline \hline
\end{tabular}

Tab. 8: Paarvergleiche der Spültechniken für das koronale Drittel (1 = RinsEndo ${ }^{\circledR}, 2$ = CanalBrush $^{\mathrm{TM}}, 3$ = EndoActivator ${ }^{\circledR}, 4$ = Ultraschall, 5 = Handspülung, rote Markierung: signifikant, blaue Markierung: nicht signifikant)

Die Ergebnisse der Paarvergleiche für die Gruben im koronalen Kanaldrittel sind in Tabelle 8 zur Übersicht mit p-Werten dargestellt. Sie unterscheiden sich von den Ergebnissen des apikalen Kanaldrittels. Die Ultraschallaktivierung (Gruppe 4) erzielte auch hier die beste Reinigungswirkung und war allen anderen Spültechniken signifikant überlegen. Die Handspülung (Gruppe 5) zeigte im koronalen Drittel die schlechteste Reinigungswirkung und war allen Gruppen signifikant unterlegen. Die Reinigungswirkung des RinsEndo ${ }^{\circledR}$ (Gruppe 1), der CanalBrush ${ }^{\mathrm{TM}}$ (Gruppe 2) und des EndoActivators ${ }^{\circledR}$ (Gruppe 3) zeigten untereinander keine signifikanten Unterschiede. 
Tabelle 9 zeigt die absoluten Score-Häufigkeiten aller vier Auswertungen für die koronalen Gruben. Die zugehörige graphische Darstellung in Form eines Säulendiagramms mit relativen Häufigkeiten findet man in Abbildung 19. Der zugehörige BoxPlot (Abb. 20) veranschaulicht die Ergebnisse nochmals.

\begin{tabular}{|c|c|c|c|c|c|c|}
\hline & $\begin{array}{c}1 \\
\text { RinsEndo }\end{array}$ & $\begin{array}{c}2 \\
\text { CanalBrush }^{\mathrm{TM}}\end{array}$ & $\begin{array}{c}3 \\
\text { EndoActivator }^{\circledR}\end{array}$ & $\begin{array}{c}4 \\
\text { Ultraschall }\end{array}$ & $\begin{array}{c}5 \\
\text { Handspülung }\end{array}$ & Summe \\
\hline Score 0 & 0 & 0 & 0 & 24 & 0 & 24 \\
\hline Score 1 & 16 & 0 & 16 & 24 & 0 & 56 \\
\hline Score 2 & 20 & 54 & 49 & 24 & 18 & 165 \\
\hline Score 3 & 44 & 26 & 15 & 8 & 62 & 155 \\
\hline Summe & 80 & 80 & 80 & 80 & 80 & 400 \\
\hline
\end{tabular}

Tab. 9: Absolute Häufigkeiten der Score-Werte für die apikalen Gruben aller Auswertungen

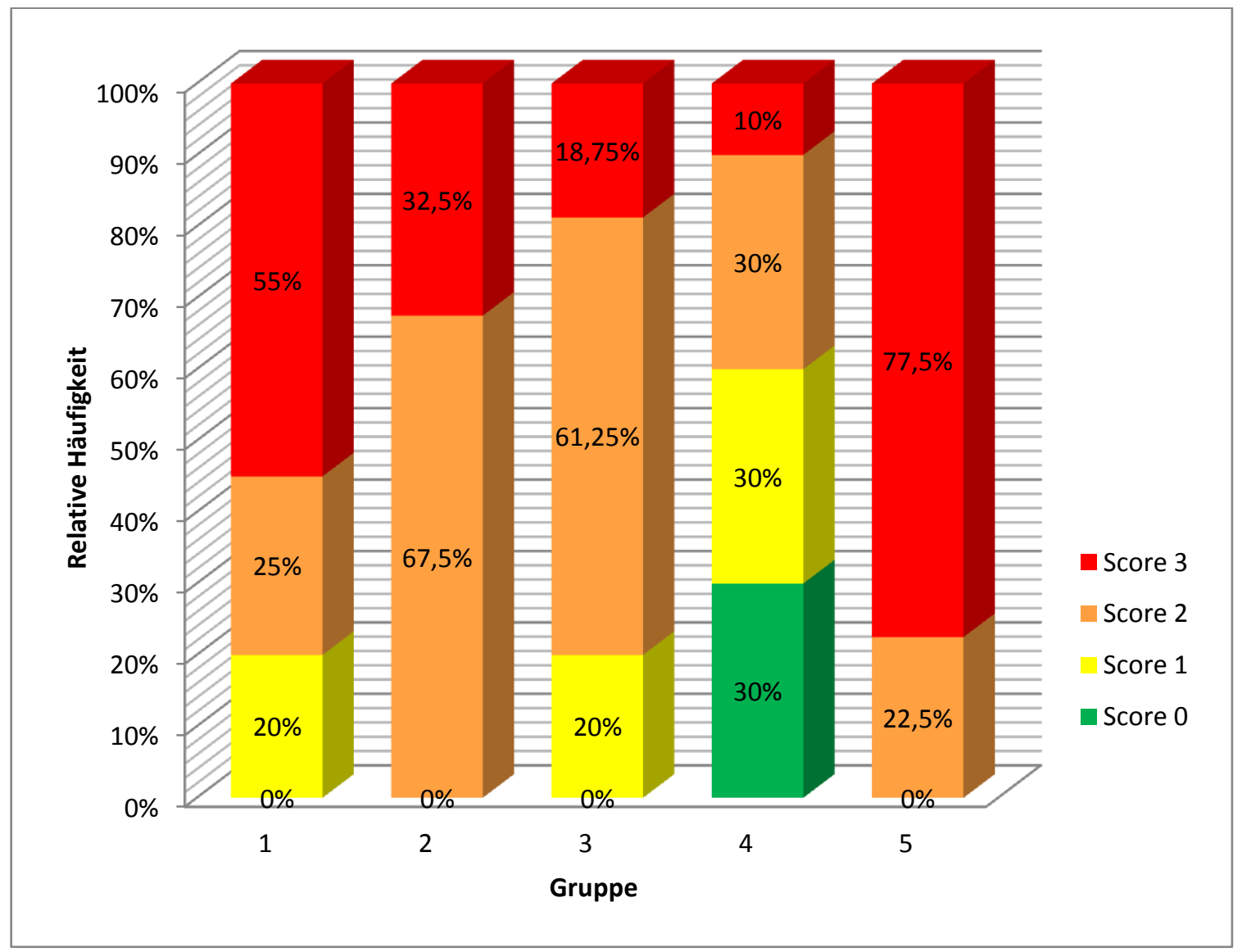

Abb. 19: Relative Häufigkeiten der Score-Werte im koronalen Drittel (Zahnhälfte 2) aller Spültechniken (Score $\mathbf{0}$ = die Kavität ist leer, Score $\mathbf{1}$ = weniger als die Hälfte der Kavität ist mit Kalziumhydroxid gefüllt, Score $\mathbf{2}$ = mehr als die Hälfte der Kavität ist mit Kalziumhydroxid gefüllt, Score $\mathbf{3}=$ die Kavität ist vollständig mit Kalziumhydroxid gefüllt) 
Im Vergleich zu Tabelle 7 und Abbildung 17, die die Ergebnisse der apikalen Gruben darstellen, wird aus Tabelle 9 und Abbildung 19 deutlich, dass die koronalen Gruben insgesamt schlechter gereinigt wurden. Vier von fünf Spültechniken erreichten in keinem Fall eine komplette Reinigung der Grube (Score 1), lediglich mit Ultraschall konnte dies bei $30 \%$ der Proben erreicht werden. Mit der CanalBrush ${ }^{\text {TM }}$ und der Handspülung konnte ebenfalls Score 1 (= weniger als die Hälfte der Kavität ist mit Kalziumhydroxid gefüllt) nicht erreicht werden. Mehr als die Hälfte der Kavität (Score 2) war nach Handspülung in 22,5\%, nach RinsEndo ${ }^{\circledR}$ in $25 \%$ und nach Ultraschall in $30 \%$ der Fälle mit Kalziumhydroxid gefüllt. Nach der Anwendung der CanalBrush ${ }^{\text {TM }}$ (67,5\%) und des EndoActivators ${ }^{\circledR}(61,25 \%)$ war Score 2 jeweils das häufigste Ergebnis. Eine vollständig mit Kalziumhydroxid gefüllte Kavität (Score 3) wurde nach dem Spülvorgang im koronalen Drittel bei allen getesteten Spültechniken detektiert. Hierbei betrug der Anteil bei Ultraschall nur $10 \%$, bei EndoActivator $^{\circledR} 18,75 \%$, bei CanalBrush ${ }^{\mathrm{TM}} 32,5 \%$, bei RinsEndo ${ }^{\circledR} 55 \%$. Am Schlechtesten schnitt auch hier die Handspülung ab (77,5\%).

In der graphische Darstellung im Box-Plot stimmen die Mediane bei vier Spültechniken mit denen von Zahnhälfte 1 überein, lediglich der der Ultraschallspülung liegt statt bei Score 0 bei Score 1. Mit der Handspülung wurde in den meisten Fällen Score 3 erreicht, nur in äußerst wenigen Ausnahmen Score 2. Die graphische Darstellung für RinsEndo ${ }^{\circledR}$ entspricht der von Zahnhälfte 1. Nur Score 0 wurde bei der Reinigung der koronalen Gruben nie erreicht. Die CanalBrush $^{\mathrm{TM}}$ erreichte Score-Werte von 2 und 3, der EndoActivator ${ }^{\circledR}$ recht konstant Score 2 mit sehr wenigen Ausreißern bei Score 1 und 3. Bei der Ultraschallspülung wurden alle Score-Werte erreicht, hauptsächlich jedoch Score 0, 1 und 2. 
Box-Plot Hälfte 2

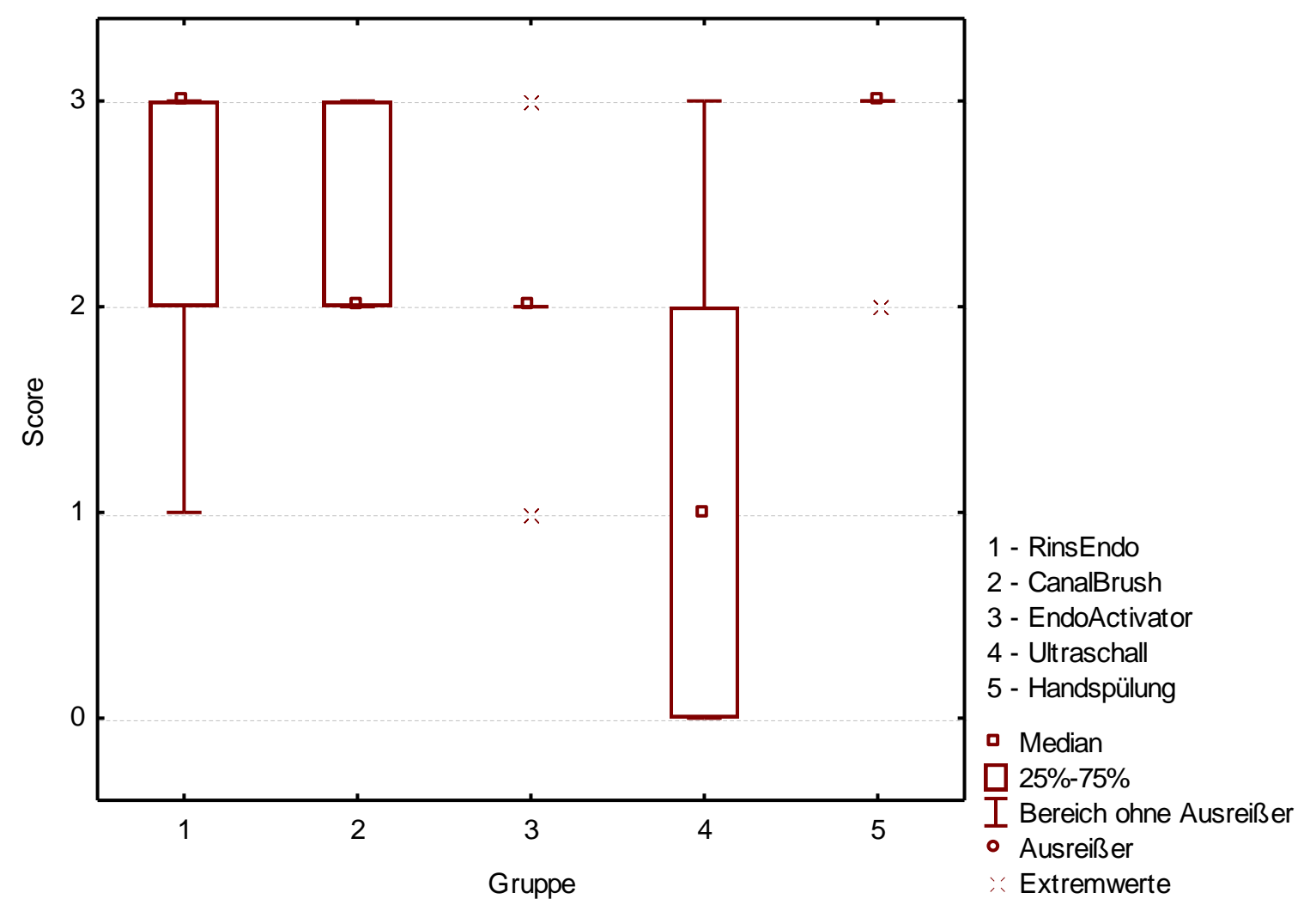

Abb. 20: Box-Plot für die koronalen Gruben (Zahnhälfte 2) 


\section{Diskussion}

Zur Bewertung des Erfolges verschiedener Wurzelkanalbehandlungsprotokolle haben klinische Langzeitstudien die höchste Aussagekraft. Allerdings ist dabei die Differenzierung bezüglich des Nutzens einzelner Zwischenschritte auf den Behandlungserfolg sehr begrenzt. Ebenso sollten vor der Einführung neuer Verfahren in den bewährten Behandlungsablauf neben der nachgewiesenen Wirksamkeit auch andere Faktoren, wie z.B. der Patientenschutz, die Arbeitssicherheit und die Handhabung der verwendeten Techniken berücksichtigt werden. Daher sind In-vitro-Studien für die Überprüfung neuer Spültechniken eine geeignete Herangehensweise, die Ergebnisse sind jedoch nicht direkt auf die In-vivo-Situation übertragbar.

\subsection{Diskussion der Methode}

Das Untersuchungsdesign dieser Studie lehnt sich an die Versuchsanordnung von Lee et al. (2004a) an. Es scheint gut geeignet zu sein, die Entfernbarkeit unterschiedlicher Substanzen aus dem Wurzelkanal zu überprüfen. Bisher wurden vor allem die Entfernung von Debris (Lee et al. 2004a; van der Sluis et al. 2005b) und Kalziumhydroxid (van der Sluis et al. 2005a, b; 2007b) aus den Kavitäten untersucht. Zusätzlich zu der bei Lee et al. (2004a) in einer Wurzelhälfte apikal gelegenen Kavität wurde wie bei Rödig et al. (2010d) in der gegenüberliegenden Zahnhälfte im koronalen Wurzelkanaldrittel ebenfalls eine Kavität künstlich konstruiert (Gruben-Modell). In anderen Studien wurde die Sauberkeit der gesamten Wurzelkanalwand untersucht (Lambrianidis et al. 1999; 2006; Kenee et al. 2006; Huang et al. 2008; McGill et al. 2008). Ein Vorteil des Gruben-Modells ist die standardisierte Größe und Lokalisation der Gruben unabhängig von der übrigen Wurzelkanalanatomie. So kann eine gute Eingrenzung des Untersuchungsgebietes gewährleistet werden. Allerdings lässt dieses Untersuchungsdesign keine Beurteilung der Effektivität der Spültechnik über den gesamten Wurzelkanal zu.

Die Versuche wurden in vitro durchgeführt, wobei durch die Verwendung natürlicher Zähne möglichst praxisnahe Bedingungen geschaffen wurden. Anders als bei der Verwendung von Kunstharzblöcken, wie sie z.B. in der Studie von van der Sluis et al. (2005a) verwendet wurden, ist hier das natürliche Wurzeldentin mit seiner tubulären Struktur vorhanden. Es muss berücksichtigt werden, dass Dentin eine inhibitorische 
Wirkung auf medikamentöse Einlagen haben kann. Dies betrifft allerdings nachgewiesenermaßen die antibakterielle Wirkung (Haapasalo HK et al. 2000; Portenier et al. 2001). Ebenso wurde der Einfluss des Dentins auf die Wirksamkeit von Spüllösungen bestätigt (Haapasalo M et al. 2010). Balvedi et al. (2010) geht von einer primär mechanischen Interaktion zwischen Kalziumhydroxid und Dentin aus, da trotz unterschiedlicher Oberflächenspannung der verschiedenen Kalziumhydroxid-Trägermedien kein Einfluss auf die Effektivität der Kalziumhydroxidentfernung festgestellt werden konnte.

Die künstlich im Wurzelkanaldentin angelegten Kavitäten sollen Unregelmäßigkeiten der Wurzelkanalsystemanatomie simulieren. Vor allem Randbereiche in ovalen Kanälen bzw. vorhandene Einziehungen können mechanisch mit herkömmlichen Präparationstechniken und Instrumenten mit rundem Querschnitt schlecht gereinigt werden. Trotzdem können auch diese künstlich angelegten Gruben nicht die Komplexität eines natürlichen Wurzelkanals wiederspiegeln. Es könnte leichter sein, Kalziumhydroxid aus den standardisierten Gruben zu entfernen als aus natürlich vorkommenden Isthmen und ovalen Ausläufern. So könnte das Gruben-Modell in einer zu guten Bewertung bezüglich der Entfernbarkeit von Kalziumhydroxid resultieren, wenn man die Ergebnisse auf die Invivo-Situation überträgt. Andererseits kann geschlussfolgert werden, dass besser zugängliche Bereiche ebenfalls gereinigt werden, wenn die Gruben gereinigt werden können. Bedacht werden muss hierbei, dass in der Grube befindliches Kalziumhydroxid nur über eine Fläche angreifbar ist, während das auf der Wurzelkanalinnenfläche angelagerte Medikament von fünf Seiten für Flüssigkeitsströmungen zu erreichen ist.

Durch das Füllen der Gruben mit Kalziumhydroxid unter dem Mikroskop und die röntgenologische Kontrolle der Kalziumhydroxideinlage im gesamten Wurzelkanal mit eventueller Korrektur bei unvollständiger Füllung oder Blasenbildung konnte ausgeschlossen werden, dass die Kavitäten nicht vollständig gefüllt wurden. Durch den Verschluss der apikalen Öffnung mit Klebewachs und das Einbetten der zusammengesetzten Zähne mit Silikonmasse in Plastikröhrchen wurde der Extrusion der Spülflüssigkeit und somit einer inadäquaten Spülung des koronalen Wurzelkanaldrittels vorgebeugt (Teixeira et al. 2005). 
Zweck der Studie war es, die bestmögliche Spültechnik für die Entfernung von Kalziumhydroxid zu ermitteln. Daher sollte der Einfluss verschiedener Spülflüssigkeiten ausgeblendet werden. Das chemische Lösungspotential vieler bekannter Spülflüssigkeiten wurde durch die Verwendung von destilliertem Wasser bei Raumtemperatur unterbunden. Aqua dest. ist nicht ausreichend in der Lage, anorganische Substanzen wie Kalzium aufzulösen (Margelos et al. 1997; Kenee et al. 2006). Laut Guerisoli et al. (1898) sind die Fließeigenschaften von Wasser und $\mathrm{NaOCl}$ vergleichbar. Die Menge der Spülflüssigkeit und die zeitliche Dauer des Spülvorgangs wurden sowohl für die Präparation der gesamten Wurzelkanäle als auch für den Hauptversuch standardisiert. So wurde zur Kalziumhydroxidentfernung jeder Zahn mit insgesamt 19,2 ml Aqua dest. bei einer ungefähren Fließrate von $6,4 \mathrm{ml}$ pro Minute gespült. Dies gleicht der Flüssigkeitsmenge, die in anderen Studien verwendet wurde, übertrifft aber das in der täglichen Praxis übliche Spülvolumen (Baumgartner et al. 1984).

Vor der Hauptuntersuchung wurden digitale Bilder der angelegten Kavitäten angefertigt, um später einen Vergleich mit denen der gereinigten Kavitäten zu ermöglichen. Ebenfalls sollte eine Identifikation der Lage der Kavität (koronal oder apikal) durch den jeweiligen Untersucher verhindert werden. Da jedoch bei der alleinigen Auswertung der Bilder der dreidimensionale Charakter schwer erkennbar war und nur die oberflächlichste Schicht des Kalziumhydroxids berücksichtigt worden wäre, wurde die Analyse primär unter dem Mikroskop vorgenommen, wobei die digitalen Bilder zu Hilfe genommen werden konnten. Die Bewertung fand unter standardisierten Lichtbedingungen an einem Mikroskop statt. Auch die digitalen Bilder wurden an ein und demselben Bildschirm betrachtet.

Das verwendete Score-System wurde von Lee et al. (2004a) beschrieben und seitdem von mehreren Autoren übernommen (van der Sluis et al. 2005a, b; Rödig et al. 2010d). Mit dem Score-System werden die Materialrückstände in vier Grade eingeteilt. Dies ist genauer als eine reine ja/nein Entscheidung. Eine Einteilung mit noch mehr Graduierungen hätte wiederum in einer höheren Fehlerrate der Untersucher durch mehrere sich überschneidende Bewertungsbereiche resultieren können. Trotzdem kann eine subjektive Zuordnung der Untersucher zu bevorzugten Scores nie vollständig ausgeschlossen werden. Um die Fehlerquote der Untersucher zu überprüfen, wurden vor Beginn der eigentlichen Ergebnisauswertung die intraindividuelle und interindividuelle 
Reliabilitäten errechnet. Die ermittelten Kappa-Koeffizienten, die im schlechtesten Fall 0.8829 betrugen $(>0,8)$, sprechen für die Reproduzierbarkeit der Ergebnisse mit Hilfe des angewandten Score-Systems. Ebenfalls konnte bei der statistischen Berechnung der Ergebnisse weder eine Wechselwirkung der Untersucher mit einer Spültechnik noch mit der Lage der Kavität gefunden werden. Es ist daher davon auszugehen, dass keine durch die Individualität der zwei Untersucher bedingte Beeinträchtigung der Ergebnisse vorliegt. Aufgrund der Abstufung der Ergebnisse in Scores ist die Verwendung des Mittelwertes als Lagemaß aus statistischer Sicht nicht korrekt, da dieser nur für quantitative, nicht aber für ordinal skalierte Merkmale berechnet werden darf. Es wurden daher multiple Paarvergleiche angewandt, ein Verfahren, das eine $\mathrm{p}$-Wert Korrektur beinhaltet (Bortz und Lienert 2008). In einigen Veröffentlichungen wurden bei der statistischen Auswertung diese Regeln nicht berücksichtigt. Dies führt zu einer eingeschränkten Vergleichbarkeit der veröffentlichten Ergebnisse.

Die Anzahl der Proben pro Gruppe, die in dieser Studie bei $n=20$ lag, korreliert mit der vieler veröffentlichter Studien (de Gregorio et al. 2010; Rödig et al. 2010b; Wiseman et al. 2011).

\subsection{Diskussion der Ergebnisse}

Keine der verwendeten Spültechniken konnte die Kalziumhydroxideinlage vollständig entfernen. Die Ergebnisse zeigen, dass eine Aktivierung der Spülflüssigkeit die Entfernung von Kalziumhydroxid aus dem Wurzelkanal verbessert.

Die Ultraschall-aktivierte-Spülung war sowohl apikal als auch koronal signifikant effektiver bezüglich der Kalziumhydroxidentfernung als alle anderen Spültechniken. Die Spülung per Hand bewirkte die schlechteste Reinigung. Dies stimmt mit vielen Ergebnissen anderer Studien überein. Die Spülergebnisse aller Spültechniken waren für die apikalen Gruben bezüglich der Sauberkeit besser als für die koronalen Gruben.

\subsubsection{Reinigungswirkung des RinsEndo ${ }^{\circledR}$}

Mit dem RinsEndo ${ }^{\circledR}$ wurden die apikalen Gruben ähnlich wie die koronalen Gruben nur mäßig von Kalziumhydroxid gereinigt. Apikal war in 85\% der Fälle mehr als die Hälfte der Kavität oder die komplette Kavität mit Kalziumhydroxid gefüllt, koronal in $80 \%$ der Fälle. 
Lediglich die apikale Grube konnte in 5\% der Proben komplett von Kalziumhydroxid befreit werden. Im Vergleich zu den anderen Spültechniken konnte das RinsEndo ${ }^{\circledR}$ die apikalen Gruben signifikant schlechter reinigen als CanalBrush ${ }^{\text {TM }}(p=0,01855)$ und Ultraschall $(p<0,00001)$, der Unterschied zum EndoActivator ${ }^{\circledR}(p=0,34565)$ und der Handspülung ( $p=0,53297)$ war nicht signifikant, die Resultate waren aber tendenziell schlechter. Die koronalen Gruben wurden mit RinsEndo ${ }^{\circledR}$ signifikant besser gereinigt als mit der Handspülung $(p=0.04103)$, signifikant schlechter als mit der Ultraschallaktivierung $(p=0,00009)$. Keine signifikanten Unterschiede traten im Vergleich zur CanalBrush ${ }^{\text {тM }}$ $(p=0,63893)$ und dem EndoActivator ${ }^{\circledast}(p=0,05951)$ auf, wobei hier wie bei der apikalen Kavität das RinsEndo ${ }^{\circledR}$ tendenziell schlechter abschnitt.

In der Literatur sind zurzeit keine Studien zum direkten Vergleich der Kalziumhydroxidentfernung aus Kavitäten verfügbar. Eine Studie, in der Debris aus apikalen Gruben entfernt wurde, konnte mit RinsEndo ${ }^{\circledR}$ signifikant bessere Ergebnisse im Vergleich zur Handspülung erreichen, unabhängig von der Aufbereitungsgröße der Wurzelkanäle (Rödig et al. 2010c). Der Unterschied zur vorliegenden Studie lag in der Verwendung von $\mathrm{NaOCl}$ als Spüllösung. Ebenfalls wurde mit mehr Flüssigkeitsvolumen gespült (30 ml statt $19 \mathrm{ml}$ ). Ein weiterer Einfluss könnte das bessere Lösungspotential des künstlich erzeugten Debris gewesen sein, das im Gegensatz zum Kalziumhydroxid der vorliegenden Studie nicht erst nach einer Woche wieder entfernt wurde. Allerdings war auch in dieser Studie die passive Ultraschallspülung dem RinsEndo ${ }^{\circledR}$ (mit Ausnahme der Wurzelkanalpräparation bis zur Größe von 30/.02) signifikant überlegen (Rödig et al. 2010c). Studien, die die Reinigungswirkung an der gesamten Kanalwand in Kombination mit chemisch wirksamen Spüllösungen untersuchten, konnten für das RinsEndo ${ }^{\circledR}$ gegenüber der Handspülung eine signifikant überlegene Reinigungswirkung bezüglich der Entfernung pulpalen Gewebes (Braun et al. 2005) und von Biofilmen (McGill et al. 2008) nachweisen. Möglicherweise machen sich die erhöhten Scherkräfte, verursacht durch den höheren Druck der Flüssigkeitsapplikation, an geraden Wurzelkanalwänden deutlicher bemerkbar als in Wurzelkanaleinziehungen. Mit Hilfe einer sehr einfachen Methode, der vertikalen Aufund Abbewegung eines gut passenden Guttapercha-Points, konnte jedoch signifikant mehr Biofilm entfernt werden als mit RinsEndo ${ }^{\circledR}$ (McGill et al. 2008). Vermutlich wird hiermit ein effektiver hydrodynamischer Effekt produziert, der die Entfernung bzw. den Austausch entsprechender Reagenzien signifikant verbessern kann. 
Die Entfernung von Debris aus gekrümmten Kanälen war mit RinsEndo ${ }^{\circledR}$ im mittleren Kanaldrittel signifikant, im apikalen tendenziell und im koronalen Drittel nicht der Handspülung überlegen. Die Schmierschicht entfernte RinsEndo ${ }^{\circledR}$ in gleicher Menge wie die Handspülung (Muselmani et al. 2005b). In gekrümmten Kanälen konnte die Schmierschicht mit RinsEndo ${ }^{\circledR}$ im mittleren Kanaldrittel besser entfernt werden als mit Handspülung, im apikalen Drittel gleichwertig. Apikal schnitten der EndoActivator ${ }^{\circledR}$ und die Guttapercha-Stift-Aktivierung besser ab.

Unabhängig von der Reinigungswirkung, die zusammenfassend für das RinsEndo ${ }^{\circledR}$ System als nicht überzeugend bewertet werden kann, sollten auch die Nachteile bzw. Nebeneffekte des Systems berücksichtigt werden. So wurde bei der Spülung mit RinsEndo ${ }^{\circledR}$ in der Studie von Hauser et al. (2007) in 80\% der Proben Spülflüssigkeit apikal extrudiert, bei manueller Spülung in nur 12\%. Desai und van Himel (2009) bestätigen diese Tendenz der Extrusion für Systeme, die mit positivem Druck arbeiten.

Eine Extrusion hätte bei der klinischen Anwendung von $\mathrm{NaOCl}$ häufig Gewebenekrosen zur Folge (Hülsmann und Hahn 2000), die wiederum in heftigen Schmerzen, Schwellungen, Hämatomen und teilweise Parästhesien resultieren können (Ehrich et al. 1993; Bowden et al. 2006; Mehdipour et al. 2007; Kleier et al. 2008). Daher sollte vor allem bei Zähnen mit weitem Foramen apicale, apikalen Resorptionen und bei Revisionen nach Überinstrumentierung und nach Wurzelspitzenresektion auf die Anwendung von RinsEndo ${ }^{\circledR}$ verzichtet werden. Ebenfalls fiel bei der Anwendung auf, dass trotz eines Spritzschutzes häufig Spülflüssigkeit seitlich entweicht und unkontrolliert in die Umgebung spritzt. Dies hätte z.B. bei der Verwendung ätzender Flüssigkeiten verheerende Folgen für das Behandlungsteam und den Patienten. Desweiteren sind die lauten Geräusche bei der Benutzung des Systems ebenfalls wenig anwender- und patientenfreundlich.

\subsubsection{Reinigungswirkung der CanalBrush ${ }^{\mathrm{TM}}$}

Die CanalBrush ${ }^{\text {TM }}$ reinigte die apikalen Gruben signifikant besser als RinsEndo ${ }^{\circledR}(p=$ $0,01855)$ und die Handspülung $(p=0,00021)$. Gleichwertig war die Reinigungswirkung mit dem EndoActivator ${ }^{\circledR}(p=0,16486)$, wobei die CanalBrush ${ }^{\text {TM }}$ nur in $20 \%$ der Fälle Score 3 (mehr als die Hälfte der Kavität mit Kalziumhydroxid gefüllt) hinterließ, der 
EndoActivator $^{\circledast}$ in $45 \%$ der Fälle. Signifikant unterlegen war sie der Ultraschallspülung $(p<0,00001)$. Insgesamt wurde in den apikalen Gruben mit der CanalBrush ${ }^{\mathrm{TM}}$ eine höhere Sauberkeit erreicht als in den koronalen. Dort konnten signifikante Unterschiede nur zur Handspülung $(p=0,00112)$ und zur Ultraschallspülung $(p=0,00003)$ festgestellt werden. Während in wenigen Fällen für die apikalen Gruben Score 1 erreicht wurde (20\%), konnten die koronalen Gruben ausschließlich mit Score 2 und 3 bewertet werden. Sowohl koronal als auch apikal wurde hauptsächlich Score 2 erreicht, das heißt eine mäßige Reinigungswirkung mit relativ vielen Kalziumhydroxidrückständen. Die Studienlage bezüglich der Entfernung von medikamentösen Einlagen, Debris oder "smear layer" mithilfe der CanalBrush ${ }^{\mathrm{TM}}$ ist dürftig. Aufgrund der sehr heterogenen Studiendesigns können nur ansatzweise Vergleiche vorgenommen werden.

Garip et al. (2010) untersuchten die Entfernung der "smear layer" von der Wurzelkanalwandoberfläche gerader Kanäle. Sie konnten im koronalen und mittleren Kanaldrittel bei der zusätzlichen Anwendung der CanalBrush ${ }^{\text {TM }}$ von 30 Sekunden im Vergleich zur EDTA-Abschlussspülung eine geringfügig, aber nicht signifikant bessere Reinigungswirkung feststellen. Im apikalen Kanaldrittel gab es keine Unterschiede. Diese Ergebnisse widersprechen denen der vorliegenden Untersuchung. Ein Grund für diesen Widerspruch könnte die unterschiedlich lange Aktivierungszeit (30 s statt $3 \mathrm{~min}$ ) sein, aber auch der Unterschied im Bewertungsdesign. So untersuchten Garip et al. (2010) die Reinigung der Wurzelkanaloberfläche und nicht die von Kavitäten. Ebenfalls wurde EDTA als Spülmedium verwendet, dessen Austausch koronal höher ist als apikal und somit schon alleine eine Auflösung der Schmierschicht hervorruft. Taşdemir et al. (2011) entfernten Kalziumhydroxid aus Wurzelkanälen und werteten nach prozentual bedeckter Gesamtwurzeloberfläche aus. Der 30-sekündige Einsatz der CanalBrush ${ }^{\text {TM }}$ zusätzlich zur $\mathrm{NaOCl}$-Spülung erzielte signifikant sauberere Kanäle als die alleinige Handspülung mit $\mathrm{NaOCl}$ oder EDTA. Der Vergleich zur Ultraschallaktivierung fiel nicht signifikant aus. Hier wurde wiederum nur die Tendenz deutlich, dass eine aktivierte Spülung mehr Kalziumhydroxidreste entfernt, ohne dass eine Differenzierung zwischen verschiedenen Kanalabschnitten zu erkennen gewesen wäre. In einer anderen Studie wurde der Bürstchenansatz bei Aktivierung mit einer Schallzahnbürste bezüglich der DebrisEntfernung untersucht (Salman et al. 2010). Bei dem Einsatz auf Arbeitslänge konnten signifikant sauberere apikale Kanaldrittel erreicht werden. Bezüglich der "smear layer“- 
Entfernung war dieser Versuchsaufbau der Spülung mit EDTA per Hand zwar tendenziell, aber nicht signifikant überlegen.

Die Anwendung der CanalBrush ${ }^{\mathrm{TM}}$ ist sehr einfach und unkompliziert. Allerdings darf nicht außer Acht gelassen werden, dass das verwendete Polypropylen nicht röntgenopak ist und im Falle einer Fraktur des Bürstchens oder einzelner lateraler Borstenhaare diese röntgenologisch nicht sichtbar werden. Wie auch in Studien von Plotino et al. (2009) und Garip et al. (2010) beschrieben, wurden bei der Anwendung in diesen Versuchen in bis zur ISO-Größe 50 präparierten geraden Wurzelkanälen bei Einsatz auf um $2 \mathrm{~mm}$ verkürzter Arbeitslänge bzw. in bis 40/.04 präparierten Kanälen bei dem Einsatz auf voller Arbeitslänge (Salman et al. 2010) weder Bürstenfrakturen noch das Abbrechen einzelner Bürstenhaare beobachtet. Allerdings kam es zu Deformationen der Bürstenhaare in Abhängigkeit von der Verwendungszeit.

In weniger weit präparierten oder gekrümmten Wurzelkanälen könnte die Friktion zwischen der Bürste und Kanalunregelmäßigkeiten ein Abreißen der Borsten zur Folge haben, die auch bei der Anwendung eines OP-Mikroskops nicht zwangsweise zu erkennen wären.

\subsubsection{Reinigungswirkung des EndoActivator ${ }^{\circledR}$}

Der EndoActivator ${ }^{\circledast}$, der als Schall-betriebenes Aktivierungsgerät eingesetzt wurde, reinigte im Gegensatz zu allen anderen Spültechniken apikal schlechter als koronal. Im Vergleich zur Ultraschallanwendung konnte sowohl in den apikal $(p<0,00001)$ als auch den koronal $(p=0,01469)$ gelegenen Kavitäten eine signifikant schlechtere Reinigungswirkung festgestellt werden. Während im Vergleich zu RinsEndo ${ }^{\circledR}$ und zur Handspülung zwar eine bessere, im Vergleich zur CanalBrush ${ }^{\mathrm{TM}}$ eine schlechtere Reinigung der apikalen Gruben, jedoch ohne Signifikanz festgestellt werden konnte, reinigte der EndoActivator ${ }^{\circledR}$ die koronalen Gruben signifikant besser als die Handspülung $(p<0,00001)$ und tendenziell besser als die CanalBrush ${ }^{\mathrm{TM}}$ und RinsEndo ${ }^{\circledR}$. Auffällig ist, dass die apikalen Gruben in 5\% der Fälle komplett gereinigt wurden (Score 0), während dies bei den koronalen Gruben nie erreicht wurde. Diese Tatsache könnte aus der Platzierung des Ansatzes mit entsprechender Auslenkungsrichtung im Kanal resultieren. Sollte der Tip 
gerade auf die Kavität hin ausgelenkt worden sein, wird der Reinigungseffekt aufgrund der Auslenkung der Spülflüssigkeit eine höhere Reinigungswirkung erreicht haben.

Vergleichende Daten zur Entfernbarkeit von Kalziumhydroxid aus weitlumigen Kanälen bzw. aus lateralen Ausläufern liegen bisher nicht vor. Studien, die die Entfernung der „Smear layers“ auf der Wurzelkanaloberfläche überprüften, konnten ebenfalls mithilfe des EndoActivators ${ }^{\circledR}$ in den koronalen Kanalanteilen eine bessere Sauberkeit erreichen als in den apikal gelegenen. Bei Uroz-Torres et al. (2010) war der Unterschied bei 1-minütiger Aktivierung des EndoActivators ${ }^{\circledR}$ im Vergleich zur Handspülung jedoch nicht signifikant. Allerdings wurde hier nur 1 Minute aktiviert gespült, möglicherweise fällt daher der Unterschied nicht so deutlich aus. Bei Rödig et al. (2010b) reinigte der EndoActivator ${ }^{\circledR}$ koronal sogar signifikant besser als Ultraschall und CanalBrush ${ }^{\mathrm{TM}}$, apikal konnten keine Unterschiede festgestellt werden. Da Rödig et al. (2010b) gekrümmte Kanäle untersuchten, sind die Ergebnisse jedoch nur bedingt vergleichbar.

Zwei Studien untersuchten den EndoActivator ${ }^{\circledR}$ bezüglich der Debris-Entfernung. Klyn et al. (2010) konnten keine signifikanten Unterschiede bei 30-sekündiger Aktivierung zwischen Ultraschall, Handspülung und EndoActivator ${ }^{\circledast}$ bezüglich der Reinigung von Wurzelkanalwand und Isthmen in Unterkiefermolaren feststellen. Rödig et al. (2010b) konnten in gekrümmten Kanälen bei 1 Minute Aktivierungszeit keine signifikanten Unterschiede zwischen Ultraschall, EndoActivator ${ }^{\circledR}$ und CanalBrush $^{\mathrm{TM}}$ feststellen. Jiang et al. (2010a) versuchten, das Phänomen der besseren Reinigungswirkung in den koronalen Kanalanteilen zu erklären. Sie gehen davon aus, dass es mit der physikalischen Bewegung des Sonic-Ansatzes erklärt werden kann. Dessen Oszillationsamplitude am Ende der Spitze beträgt ungefähr einen Millimeter, während der Durchmesser des Wurzelkanals apikal nur $\leq 0,5 \mathrm{~mm}$ beträgt. Dies deutet auf einen intensiven Wandkontakt zwischen dem Ansatz (Tip) und dem Wurzelkanal hin. Dadurch wird die freie Schwingung der Schallspitze verhindert und somit der effiziente Flüssigkeitsstrom bzw. die Aktivierung der Flüssigkeit reduziert (Jiang et al. 2010a). Wenn man den Ergebnissen des „high-speedimaging-experiments" von Jiang et al. (2010a) glaubt, scheint die Größe des SonicAnsatzes keinen Einfluss auf die Oszillationsamplitude zu haben und somit auch keinen Einfluss auf die Kontaktzeit zwischen Ansatz und Wurzelkanalwand. Allerdings ist dies 
bisher die einzige Studie, die unterschiedliche Ansatzgrößen in ihren Eigenschaften und Resultaten überprüfte.

In der Studie von Jiang et al. (2010a) konnten andere Frequenzen für den EndoActivator ${ }^{\circledR}$ identifiziert werden als die vom Hersteller angegebenen. Bei $2000 \mathrm{cpm}$ beträgt diese 160 +/- 5 statt $33 \mathrm{~Hz}$, bei 6000 cpm 175 +/- $5 \mathrm{~Hz}$ statt $100 \mathrm{~Hz}$, bei $10000 \mathrm{cpm} 190$ +/- $5 \mathrm{~Hz}$ statt $166 \mathrm{~Hz}$. Ebenso konnten weder an dem Tip, noch an der Wurzelkanalwand Kavitationseffekte festgestellt werden. Dies könnte eine Erklärung für die schlechtere Reinigungswirkung gegenüber der Ultraschallspülung sein.

Zwischen Wasser und $\mathrm{NaOCl}$ konnte bei Aktivierung mit dem EndoActivator ${ }^{\circledR}$ kein Unterschied festgestellt werden, ebenso war kein Unterschied bezüglich des „acoustig streaming" zu erkennen (Jiang et al. 2010a). Es scheint bei der Anwendung des EndoActivators ${ }^{\circledR}$ daher kein synergistischer Effekt mit $\mathrm{NaOCl}$ als Spülflüssigkeit zu existieren, wie es bei der Ultraschallaktivierung der Fall ist.

Insgesamt scheint der EndoActivator ${ }^{\circledast}$ die Reinigung des Wurzelkanals, vor allem in den koronalen Kanalanteilen, zu verbessern. Aufgrund des Polymeransatzes wird die Wurzelkanaloberfläche, anders als bei einer ultraschallangetriebenen Stahlfeile, geschont und kein Wurzelkanalwanddentin abgetragen. Ebenfalls wurde die Gefahr eines Feilenbruchs bisher nicht beschrieben. Sollten die Ansätze trotzdem im Kanal frakturieren, wären sie röntgenologisch nicht darstellbar. Die Menge an apikal extrudierter Spüllösung war mit dem EndoActivator ${ }^{\circledR}$ sehr gering, bzw. nicht höher als mit der Spülung per Hand (Desai und van Himel 2009). Daher scheint es durchaus möglich, den EndoActivator ${ }^{\circledR}$ zur Unterstützung bei der Reinigung des Wurzelkanals am Patienten einzusetzen. Mit dem dünnsten verfügbaren Ansatz könnte der EndoActivator ${ }^{\circledR}$ auch schon unterstützend bei Zwischenspülungen während der Wurzelkanalpräparation ohne Gefahr einer Stufenbildung eingesetzt werden.

\subsubsection{Reinigungswirkung der PUI}

Mit der passiven ultraschallaktivierten Spülung konnten in dieser Studie die mit Abstand besten Ergebnisse erzielt werden. Sowohl die apikale als auch die koronale Kavität konnten mit Ultraschall signifikant besser gereinigt werden als mit allen anderen in der 
Studie verwendeten Spülsystemen $\left(\right.$ RinsEndo $^{\circledR}$, CanalBrush $^{\top \mathrm{M}}$, EndoActivator ${ }^{\circledR}$, Handspülung).

Die Reinigungseffektivität fiel für die apikalen Gruben besser aus als für die koronalen. Apikal konnte in $71,25 \%$ der Fälle eine komplette Kalziumhydroxidentfernung aus der Kavität erreicht werden, koronal in nur 30\% der Fälle. Ebenso wurde apikal nie Score 3 (vollständig gefüllte Kavität) erreicht und nur in 5\% der Fälle Score 2 (mehr als die Hälfte der Kavität ist gefüllt). Koronal wurde allerdings fast in der Hälfte aller Fälle (40\%) mehr als die Hälfte oder die komplette Kavität mit Kalziumhydroxid gefüllt hinterlassen.

Auf Grundlage der veröffentlichten Daten bezüglich der Reinigungsleistung mit Ultraschall entsprechen die Ergebnisse den Erwartungen. Trotz der großen Anzahl von Publikationen gibt es nur relativ wenige, die sich mit der Entfernung von Kalziumhydroxid beschäftigten. Generell bestätigt ist die effektivere Reinigungswirkung des Ultraschalls gegenüber der Handspülung hinsichtlich der Entfernung pulpaler Geweberückstände und Dentindebris (Sabins et al. 2003; Lee et al. 2004b). Bei der Ultraschallspülung könnte möglicherweise die Feilenoszillation in direkter Nähe zu Kanalunregelmäßigkeiten mehr Debris aus diesen schwer erreichbaren Stellen entfernt haben (Lumley et al. 1993; Lee et al. 2004a). Lediglich Mayer et al. (2002) konnten keinen signifikanten Unterschied zwischen PUI und der Handspülung bezüglich der Debrisentfernung feststellen. Hier wurde allerdings zwischen EDTA und $\mathrm{NaOCl}$ nicht zwischengespült - daher ist davon auszugehen, dass sich die Spüllösungen gegenseitig inhibierten.

Eine weitere Studie verwendete das gleiche Design mit apikaler und koronaler Kavität und überprüfte die Entfernung von Debris aus den Kavitäten (Rödig et al. 2010a). In Übereinstimmung mit den Resultaten der vorliegenden Arbeit reinigte PUI signifikant besser als die Spülung per Hand bei einem Spülvolumen von $20 \mathrm{ml} \mathrm{NaOCl}$, allerdings war dort der Unterschied für die Reinigungsleistung des Ultraschalls zwischen apikaler und koronaler Kavität nicht signifikant.

Bezüglich der Entfernung der "smear layer" scheint auch bei der Anwendung von Ultraschall entscheidend zu sein, welche Spülsubstanz eingesetzt wird. So konnte PUI in Kombination mit Wasser die Schmierschicht nicht entfernen (Cameron 1983). Bei der Verwendung von $\mathrm{NaOCl}$ konnte sie zum Teil vollständig (Cameron 1987), oder nur teilweise (Cheung und Stock 1993) entfernt werden. Auch mit EDTA alleine oder in 
Kombination mit $\mathrm{NaOCl}$ konnte die "smear layer" nicht komplett entfernt werden (Cameron 1995).

Ebenso konnten zahlreiche Untersuchungen zeigen, dass der Gebrauch von Ultraschall in einer signifikanten Reduktion der Anzahl von Bakterien im Kanal resultiert (Cunningham und Martin 1982; Cunningham et al. 1982b; Martin und Cunningham 1984; Sjögren und Sundqvist 1987; DeNunzio et al. 1989; Siqueira et al. 1997).

Aus mesialen Kanälen von Unterkiefermolaren entfernte Ultraschall ebenso viel Kalziumhydroxid wie die rotierende Instrumentierung mit einer Feile. Beide Techniken waren der Handspülung signifikant überlegen. Bewertet wurde hierbei die prozentuale Kalziumhydroxidbedeckung der gesamten Wurzelkanalwand (Kenee et al. 2006). Auch Wiseman et al. (2011) untersuchten mesiale Kanäle von Unterkiefermolaren. Hier konnte nach 3mal 20-sekündiger Aktivierung signifikant mehr Kalziumhydroxid aus mesialen Kanälen entfernt werden $(69,5 \%)$ als nach ebenso langer Spülung mit dem EndoActivator ${ }^{\circledR}$ (48,6\%). Taşdemir et al. (2011) untersuchte die prozentuale Kalziumhydroxidentfernung an der Wurzelkanalwand. Nach 30-sekündiger Aktivierung und insgesamt $10 \mathrm{ml} \mathrm{NaOCl}$ konnte mit Ultraschall ebenso viel Kalziumhydroxid (ca. 75\%) entfernt werden wie mit der CanalBrush $^{\text {TM }}$. In allen drei Studien ließ sich Kalziumhydroxid mit Ultraschall nicht vollständig entfernen, obwohl $\mathrm{NaOCl}$ und EDTA als Spülagenzien verwendet wurden. Allerdings war das Spülvolumen sehr eingeschränkt und betrug bei Kenee et al. (2006) 7,5 ml, bei Taşdemir et al. (2011) $10 \mathrm{ml}$. Bei einer Steigerung des Spülvolumens wäre die Ultraschallspülung voraussichtlich überlegen gewesen.

Van der Sluis et al. (2007b) benutzten das gleiche Untersuchungsdesign wie die vorliegende Studie mit einer apikal konstruierten Kavität und spülten 3 Minuten mit 50 ml $\mathrm{NaOCl}$ per Hand und je $50 \mathrm{ml} \mathrm{H}_{2} \mathrm{O}$ und $\mathrm{NaOCl}$ mit Ultraschall. $\mathrm{NaOCl}$ konnte in Kombination mit Ultraschall signifikant mehr Kalziumhydroxid entfernen als Ultraschall mit $\mathrm{H}_{2} \mathrm{O}$ und die Handspülung mit $\mathrm{NaOCl}$. Die Auswertung erfolgte ebenfalls mit dem in dieser Studie verwandten Score-System. Ein direkter Vergleich ist leider trotzdem nicht möglich, da bei van der Sluis et al. (2007b) eine prozentuale Score-Reduktion errechnet wurde. Anhand dieses Ergebnisses wird nochmals der synergistische Effekt von Ultraschall 
und $\mathrm{NaOCl}$ deutlich. Dieser könnte auch bei Rödig et al. (2010a) dazu geführt haben, dass die koronale und die apikale Kavität gleichwertig gereinigt wurden.

Aus allen verfügbaren Daten wird ersichtlich, dass ein längerer bis zu 3-minütiger Einsatz des Ultraschalls in einer Steigerung der Reinigungsleistung resultiert, wenn die Spülflüssigkeit zwischenzeitlich erneuert wird. Dieser kumulative Effekt bei mehrmaliger Applikation und Aktivierung der Spüllösung wurde für die PUI bereits nachgewiesen (van der Sluis et al. 2010) und wird auch durch diese Studie bestätigt, da 6mal 30 Sekunden mit Ultraschallaktivierung gespült wurde.

Trotz der sehr konsensuell guten Reinigungsleistung muss bei der Anwendung des Ultraschallgerätes einiges berücksichtigt werden. Es ist immer ein Risiko vorhanden, mit den Feilen die Kanalwände $z u$ berühren und somit einen schneidenden Effekt hervorzurufen, der neue „smear layer" produziert, Stufen in die Kanalinnenwand präpariert und schlimmstenfalls zu Perforationen führt. Aufgrund der hohen Gefahr des Wandkontaktes in noch nicht präparierten und in gekrümmten Kanälen ist dort Vorsicht beim Einsatz geboten. Auch das Risiko von Frakturen der schnell vibrierenden Feilen ist zu berücksichtigen.

\subsubsection{Reinigungswirkung der Handspülung}

Die Handspülung, die in dieser Studie als Kontrollgruppe fungierte, erreichte sowohl koronal als auch apikal die schlechteste Reinigungswirkung. Im koronalen Kanaldrittel war der Unterschied zu allen anderen untersuchten Spültechniken signifikant. Bezüglich der Reinigung der apikalen Kavität waren lediglich die CanalBrush $^{\text {TM }}(p=0,00021)$ und die Ultraschallanwendung $(p<0,00001)$ signifikant überlegen, RinsEndo ${ }^{\circledR}$ und der EndoActivator ${ }^{\circledR}$ schnitten nur tendenziell besser ab. Mit Hilfe der Handspülung konnte in keinem Fall eine bessere Reinigungswirkung als Score 2 erzielt werden, d.h. es blieb immer mindestens die Hälfte der Kavität mit Kalziumhydroxid gefüllt.

Auch die Handspülung erreichte im apikalen Kanalabschnitt eine bessere Reinigungswirkung als koronal, wobei diese mit einer Verschiebung von 12,5\% zwischen Score 2 und 3 nicht bedeutend ist. Ähnliche Ergebnisse wurden bei Rödig et al. (2010d) in 
der Kontrollgruppe mit $\mathrm{H}_{2} \mathrm{O}$ erzielt. Eine mögliche Erklärung für die bessere Reinigung der apikalen Kavität wären hydrodynamische Effekte, da die Spülnadel $1 \mathrm{~mm}$ kürzer als Arbeitslänge eingeführt wurde und die Öffnung am Nadelende benachbart der apikalen Grube lag. Huang et al. (2008) beschreiben ebenfalls den Benefit des physikalischen Strömungseffektes zusätzlich zu dem chemischen Effekt der Spülflüssigkeit am Nadelende, der in dieser Studie durch die Verwendung von destilliertem Wasser ausgeblendet wurde. Dieser Ansicht sind auch Boutsioukis et al. (2007), die zusätzlich die Fließrate und den Flüssigkeits-Austausch als zu beachtende Faktoren nennen, die direkten Einfluss auf den Flüssigkeitsstrom am Nadelende haben. Doch da es schwierig ist, die Fließrate während der Spülung mit der Hand, Spritze und Nadel zu standardisieren und zu kontrollieren (Boutsioukis et al. 2007), werden darüber in den meisten Studien keine Angaben gemacht. Dies wiederum verringert die Vergleichbarkeit der heterogenen Daten. Auch in anderen Studien wurde gezeigt, dass nach der Spülung per Hand große Mengen von Dentindebris in Kanalunregelmäßigkeiten und oval geformten Kanälen zurückblieben (Cunningham et al. 1982a, Wu und Wesselink 2001).

Es liegen außer der Studie von Rödig et al. (2010d) keine Daten in der verfügbaren Literatur zur Wurzelkanal-Spülung bezüglich des Vergleichs der Kalziumhydroxidentfernung aus einer koronalen und apikalen Kavität vor. In einer weiteren Studie untersuchten Rödig et al. (2010a) die Debrisentfernung mit dem gleichen Studienaufbau. Auch dort wurden die apikalen Kavitäten (signifikant) besser gereinigt.

Insgesamt ist jedoch die Entfernung von Kalziumhydroxid mit der manuellen Spülung mit Spritze und Hand mangelhaft. Durch die Verwendung chemisch wirkender Agenzien kann sie effektiviert werden (Rödig et al. 2010d). Im Vergleich zu allen anderen Arten der Aktivierung von Spülflüssigkeiten ist sie unterlegen. Es gilt daher, die Spülflüssigkeit in Bewegung zu bringen und hohe Spülvolumina zu verwenden. 


\section{Schlussfolgerung und Ausblick}

Eine vollständige Entfernung der medikamentösen Kalziumhydroxideinlage alleine durch die Wurzelkanalspülung ist auch mit aktivierten Spültechniken nicht zu erwarten.

Die Reinigungseffizienz von Ultraschall ist allen anderen überprüften Spültechniken weit überlegen, kann allerdings vor allem im koronalen Kanalabschnitt aufgrund der variablen Ergebnisse alleine als nicht ausreichend bewertet werden.

Daher erscheint es nach heutigem Stand sinnvoll, die Wurzelkanalwand nach medikamentöser Einlage nochmals mit größeren Aufbereitungsinstrumenten zu präparieren.

Die Aktivierung der Spülflüssigkeiten ist der alleinigen Handspülung in jedem Fall vorzuziehen.

Zusätzlich sollten Spüllösungen verwendet werden, die ein höheres Lösungspotential als destilliertes Wasser haben, um die chemische Spüleffektivität zu steigern.

Es sollten weitere Untersuchungen der Spültechniken in Kombination mit unterschiedlichen Spülflüssigkeiten durchgeführt werden, um mögliche synergistische oder antagonistische Effekte aufzudecken.

Ebenfalls sollte vor der Anwendung der neuen Spültechniken am Patienten die Sicherheit der Spülsysteme kritisch betrachtet und untersucht werden.

Trotz der Fülle an Studien über die Effektivität verschiedener endodontischer SpülSysteme ist in der gegenwärtigen Literatur keine gut kontrollierte klinische Studie verfügbar. Ebenfalls scheint keine evidenzbasierte Studie vorzuliegen, die versucht, die klinische Effektivität der neuen Spülgeräte mit verbesserten Behandlungserfolgen in Beziehung zu setzen (Gu et al. 2009). Daher kann keine Aussage darüber getroffen werden, ob neue Spülsysteme im klinischen Einsatz wirklich notwendig sind. Dies sollte das große Ziel zukünftiger Studien sein. 


\section{Zusammenfassung}

Ziel der Studie: Vergleich der Reinigungswirkung verschiedener neuer Spültechniken hinsichtlich der Entfernung von Kalziumhydroxid aus künstlich in Wurzelkanalhälften angelegten Kavitäten mit Differenzierung zwischen koronalen und apikalen Kanalanteilen.

Material und Methode: 110 humane alio loco extrahierte, einwurzelige mittlere und seitliche Oberkieferfrontzähne, Eckzähne und Prämolaren mit rundem Wurzelquerschnitt und gerader Wurzel wurden randomisiert in 5 Gruppen $(n=20)$ verteilt. 10 Zähne dienten den Voruntersuchungen. Die Wurzelkanäle wurden von koronal auf eine einheitliche Länge von $19 \mathrm{~mm}$ gekürzt. Die Präparation der Wurzelkanäle erfolgte mit Handinstrumenten bei einer Arbeitslänge von $18 \mathrm{~mm}$ bis zur ISO-Größe 50. Während der Präparation wurde nach jeder Instrumentengröße mit $2 \mathrm{ml} 1 \%-\mathrm{NaOCl}$ mit einer $30-$ „gauge“-NaviTip-Kanüle per Hand gespült. Die Abschlussspülung erfolgte mit $5 \mathrm{ml}$ 17\%EDTA. Die Zähne wurden längs gespalten und pro Hälfte eine definierte Kavität von $4 \mathrm{~mm}$ Länge, 0,2 mm Breite und 0,5 mm Tiefe präpariert. Dies erfolgte in einer Wurzelhälfte im Abstand von 2-6 mm, in der anderen 10-14 mm vom Apex. Die Kavitäten wurden unter mikroskopischer Kontrolle mit Kalziumhydroxidpaste gefüllt, die Zahnhälften wieder zusammengesetzt und anschließend der gesamte Wurzelkanal mit dem gleichen Präparat gefüllt und die Homogenität der Füllung röntgenologisch überprüft. Die randomisiert in 5 Gruppen aufgeteilten Zähne wurden nach 7-tägiger Lagerung bei $37{ }^{\circ} \mathrm{C}$ und $100 \%$ Luftfeuchtigkeit mit verschiedenen Spültechniken insgesamt 3 min mit 19,1ml Aqua dest. gespült: Verwendet wurden RinsEndo ${ }^{\circledR}$ (Gr. 1), CanalBrush $^{\mathrm{TM}}$ (Gr. 2), EndoActivator ${ }^{\circledR}$ (Gr. 3), Ultraschall (Gr. 4) und Handspülung (Gr. 5=Kontrolle). Die Zahnhälften wurden wieder getrennt und die restliche Kalziumhydroxidpaste in den Kavitäten mit einem vierstufigen Score-System ausgewertet. Die statistische Auswertung erfolgte mit einem nichtparametrischen Analyseverfahren. Aufgrund eines signifikanten Einzeleffekts der Spültechnik und des nicht signifikanten Einzeleffekts der Lage der Kavität wurde die Auswertung mit Post-Hoc-Paarvergleichen getrennt nach der Lage der Kavität (apikales und koronales Drittel) vorgenommen. 
Ergebnis: Keine der Spültechniken konnte das Kalziumhydroxid vollständig aus der Kavität entfernen. Ultraschall war allen anderen Spültechniken in beiden Kanaldritteln signifikant überlegen.

Schlussfolgerung: Die Aktivierung der Spülflüssigkeit mit Ultraschall ist am besten geeignet, Kalziumhydroxid aus dem Wurzelkanal zu entfernen. 


\section{Anhang}

\subsection{Abbildungsverzeichnis}

Abb. 1: Schematische Darstellung des RinsEndo ${ }^{\circledR}$-Systems der Fa. Dürr Dental

(Dürr Dental 2011)

Abb. 2: Acoustic streaming entlang der Feile in Wasser (links) und als Schema

(rechts) (aus: van der Sluis et al. 2007a, S. 418). .21

Abb. 3: CanalBrush ${ }^{\mathrm{TM}}$ 25

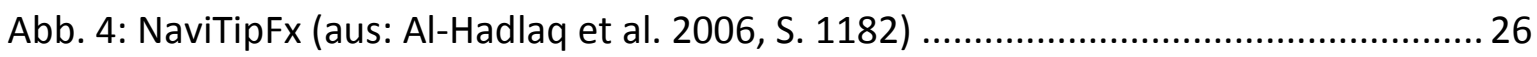

Abb. 5: EndoActivator ${ }^{\circledR}$ 27

Abb. 6: Schematische Darstellung der Kavitätenpräparation innerhalb der gespaltenen Wurzelkanäle. In einer Hälfte wurde die Kavität von $2 \mathrm{~mm}$ bis $6 \mathrm{~mm}$, in der anderen von $10 \mathrm{~mm}$ bis $14 \mathrm{~mm}$ Entfernung vom Apex präpariert

Abb. 7: Übersicht einer Zahnhälfte mit apikaler Kavität..........................................................44

Abb. 8: Vergrößerte apikale Kavität........................................................................................44

Abb. 9: Übersicht einer Zahnhälfte mit koronaler Kavität.......................................................44

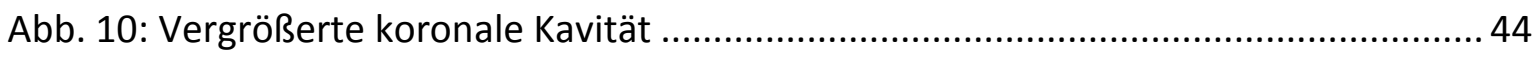

Abb. 11: Mit Kalziumhydroxid gefüllte Kavität bei 40facher Vergrößerung ....................... 45

Abb. 12: Einzelzahnaufnahme eines eingebetteten und mit Kalziumhydroxid gefüllten Zahnes

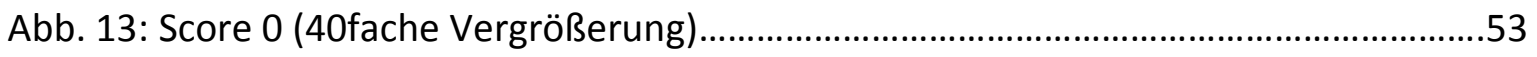

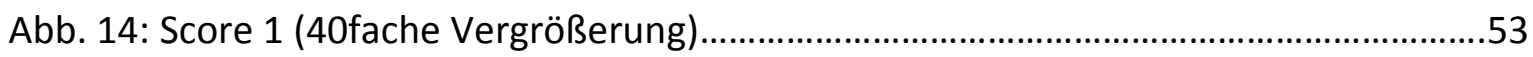

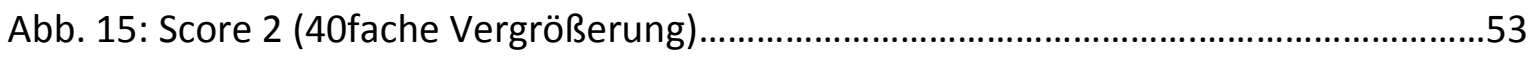

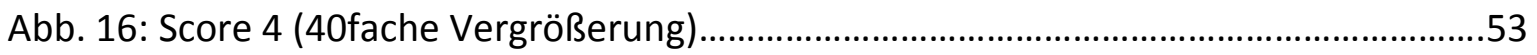

Abb. 17: Relative Häufigkeiten der Score-Werte im apikalen Drittel (Zahnhälfte 1) aller Spültechniken (Score 0 = die Kavität ist leer, Score 1 = weniger als die Hälfte der Kavität ist mit Kalziumhydroxid gefüllt, Score $2=$ mehr als die Hälfte der Kavität ist mit Kalziumhydroxid gefüllt, Score 3 = die Kavität ist vollständig mit Kalziumhydroxid gefüllt)

Abb. 18: Box-Plot für die apikalen Gruben (Zahnhälfte 1) 
Abb. 19: Relative Häufigkeiten der Score-Werte im koronalen Drittel (Zahnhälfte 2) aller Spültechniken (Score 0 = die Kavität ist leer, Score $1=$ weniger als die Hälfte der Kavität ist mit Kalziumhydroxid gefüllt, Score $2=$ mehr als die Hälfte der Kavität ist mit Kalziumhydroxid gefüllt, Score 3 = die Kavität ist vollständig mit Kalziumhydroxid gefüllt) 62

Abb. 20: Box-Plot für die koronalen Gruben (Zahnhälfte 2) 64

\subsection{Tabellenverzeichnis}

Tab. 1: Übereinstimmung der Scores beider Auswertungen für Untersucher 1 ................55

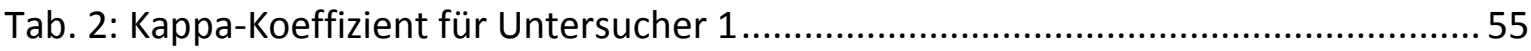

Tab. 3: Übereinstimmung der Scores beider Auswertungen für Untersucher 2 ................ 56

Tab. 4: Kappa-Koeffizient für Untersucher 2 …................................................................. 56

Tab. 5: Interaktion zwischen Spültechnik und Lage der Kavität......................................... 57

Tab. 6: Paarvergleiche der Spültechniken für das apikale Drittel $\left(1=\right.$ RinsEndo $^{\circledR}, 2=$

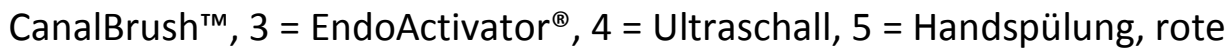
Markierung: signifikant, blaue Markierung: nicht signifikant)

Tab. 7: Absolute Häufigkeiten der Score-Werte für die apikalen Gruben aller vier Auswertungen

Tab. 8: Paarvergleiche der Spültechniken für das koronale Drittel $\left(1=\right.$ RinsEndo $^{\circledR}, 2=$

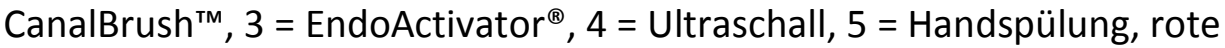
Markierung: signifikant, blaue Markierung: nicht signifikant)

Tab. 9: Absolute Häufigkeiten der Score-Werte für die apikalen Gruben aller 


\subsection{Herstellerverzeichnis / Materialliste}

Auflichtmikroskop (Motic Ergonomic Trinokular Zoom Stereo Mikroskop, Motic

Deutschland GmbH, Wetzlar, Deutschland)

CanalBrush $^{\mathrm{TM}}$ (Coltène/Whaledent, Langenau, Deutschland)

Calxyl ${ }^{\circledR}$ (OCO Präparate GmbH, Dirmstein/Pfalz, Deutschland)

Cavit $^{\circledR}$ (3M ESPE, Neuss, Deutschland)

Cervikalwachs (Geo Cervikalwachs, Renfert GmbH, Hilzingen, Deutschland)

Diamantierte Trennscheibe (Horico, Berlin, Deutschland)

Digitalkamera (Moticam 1300, Motic Deutschland GmbH, Wetzlar, Deutschland)

EndoActivator ${ }^{\circledast}$ (Densply Tulsa Dental, Tulsa, USA)

Fingerspreader (Vereinigte Dentalwerke, München

Flexitime ${ }^{\circledR}$ (Heraeus Kulzer $\mathrm{GmbH}$, Hanau, Deutschland)

Hedströmfeile (Vereinigte Dentalwerke, München, Deutschland)

Inkubator Climacell 111 (MMM Medcenter GmbH, München, Deutschland)

Klebewachs (Hartklebewachs Deiberit, Siladent Dr. Böhme \& Schöps GmbH, Goslar,

Deutschland)

NaviTip-Spülnadel (Ultradent, München, Deutschland)

Pasteinject ISO 40 (Micro-Mega, Besançon, Frankreich)

Reamer (Vereinigte Dentalwerke, München, Deutschland)

RinsEndo ${ }^{\circledR}$ (Dürr Dental, Bietigheim-Bissingen, Deutschland)

Röntgengerät: Heliodent DS (D3302) (Sirona Dental Systems GmbH, Bensheim,

Deutschland)

Silaplast (Dentax GmbH \& Co. KG, Ettlingen, Deutschland)

Ultraschallgerät (Piezon Maser 400, EMS, Nyon, Schweiz)

Wachsmesser (Aesculap, Tuttlingen, Deutschland)

Zahnbürste (Meridol, Gaba GmbH, Lörrach, Deutschland) 


\section{Literaturverzeichnis}

Abou-Rass M, Piccinino MV (1982):

The effectiveness of four clinical irrigation methods on the removal of root canal debris. Oral Surg Oral Med Oral Pathol 54, 323-328

Ahmad M (1990):

Measurements of temperature generated by ultrasonic file in vitro.

Endod Dent Traumatol $\underline{6}, 230-231$

Ahmad M, Pitt Ford TJ, Crum LA (1987):

Ultrasonic debridement of root canals: acoustic streaming and its possible role.

J Endod $\underline{13}$, 490-499

Ahmad M, Roy RA, Kamarudin AG (1992):

Observations of acoustic streaming fields around an oscillating ultrasonic file.

Endod Dent Traumatol $\underline{8}, 189-194$

Ahmad M, Pitt Ford TR, Crum LA, Walton AJ (2009):

Ultrasonic debridement of root canals: acoustic cavitation and its relevance.

Int Endod J 42, 391-398

Albrecht LJ, Baumgartner JC, Marshall JG (2004):

Evaluation of apical debris removal using various sizes and tapers of ProFile GT files.

J Endod 30, 425-428

Al-Hadlaq SM, Al-Turaiki SA, Al-Sulami U, Saad AY (2006):

Efficacy of a new brush-covered irrigation needle in removing root canal debris: a scanning electron microscopic study.

J Endod 32, 1181-1184

Al-Jadaa A, Paqué F, Attin T, Zehnder M (2009):

Necrotic pulp tissue dissolution by passive ultrasonic irrigation in simulated accessory canals: impact of canal location and angulation.

Int Endod J 42, 59-65

Andersen M, Lund A, Andreasen JO, Andreasen FM (1992):

In vitro solubility of human pulp tissue in calcium hydroxide and sodium hypochlorite.

Endod Dent Traumatol $\underline{8}, 104-108$

Archer R, Reader A, Nist R, Beck M, Meyers WJ (1992):

An in vivo evaluation of the efficacy of ultrasound after step-back preparation in mandibular molars.

J Endod 18, 549-552 
Ari H, Erdemir A, Belli S (2004):

Evaluation of the effect of endodontic irrigation solutions on the microhardness and the roughness of root canal dentin.

J Endod 30, 792-795

Athanassiadis B, Abbott PV, Walsh LJ (2007):

The use of calcium hydroxide, antibiotics and biocides as antimicrobial medicaments in endodontics.

Aust Dent J $\underline{52}$, S64-82

Badr AE, Omar N, Badria FA (2011):

A laboratory evaluation of the antibacterial and cytotoxic effect of Liquorice when used as root canal medicament.

Int Endod J 44, 51-58

Balvedi RPA, Versiani MA, Manna FF, Biffi JCG (2010):

A comparison of two techniques for the removal of calcium hydroxide from root canals. Int Endod J 43, 763-768

Barbizam JVB, Trope M, Teixeira ECN, Tanomaru-Filho M, Teixeira FB (2008):

Effect of calcium hydroxide intracanal dressing on the bond strength of a resin-based endodontic sealer.

Braz Dent J 19, 224-227

Barthel CR, Levin LG, Reisner HM, Trope M (1997):

TNF-alpha release in monocytes after exposure to calcium hydroxide treated Escherichia coli LPS.

Int Endod J 30, 155-159

Barthel CR, Georgi M, Schäfer E, Petschelt A, Flachsenberg S, Neuber T, Kockapan C, Weiger R, Hülsmann M (2006): Stellungnahme der DGZMK: Die Wurzelkanalspülung. Zahnärztl Mitt 96, 50-51

Baumgartner JC, Cuenin PR (1992):

Efficacy of several concentrations of sodium hypochlorite for root canal irrigation. J Endod 18, 605-612

Baumgartner JC, Brown CM, Mader CL, Peters DD, Shulman JD (1984):

A scanning electron microscopic evaluation of root canal debridement using saline, sodium hypochlorite, and citric acid.

J Endod 10, 525-531

Biggs JT, Benenati FW, Sabala CL (1988):

Treatment of iatrogenic root perforations with associated osseous lesions.

J Endod 14, 620-624 
Bortz J, Lienert GA:

Kurzgefasste Statistik für die klinische Forschung. Leitfaden für die verteilungsfreie Analyse kleiner Stichproben, 3.Auflage;

Springer Medizin Verlag, Heidelberg 2008

Boutsioukis C, Lambrianidis T, Kastrinakis E, Bekiaroglou P (2007):

Measurement of pressure and flow rates during irrigation of a root canal ex vivo with three endodontic needles.

Int Endod J 40, 504-513

Boutsioukis C, Lambrianidis T, Kastrinakis E (2009):

Irrigant flow within a prepared root canal using various flow rates: a Computational Fluid Dynamics study.

Int Endod J 42, 144-155

Boutsioukis C, Gogos C, Verhaagen B, Versluis M, Kastrinakis E, van der Sluis LWM (2010): The effect of apical preparation size on irrigant flow in root canals evaluated using an unsteady Computational Fluid Dynamics model.

Int Endod J 43, 874-881

Bowden JR, Ethunandan M, Brennan PA (2006):

Life-threatening airway obstruction secondary to hypochlorite extrusion during root canal treatment.

Oral Surg Oral Med Oral Pathol Oral Radiol Endod 101, 402-404

Braun A, Nolden R (1999):

Applikation eines Kalziumhydroxid-Pastenpräparates in ISO-genormte Kanallumina.

Dtsch Zahnärztl Z 노, 258-261

Braun A, Kappes D, Krause F, Jepsen S (2005):

Efficiency of a novel rinsing device for the removal of pulp tissue in vitro.

Int Endod J 38, 923 (Abstract \#19)

Brito PRR, Souza LC, Machado Oliveira JC de, Alves FRF, De-Deus G, Lopes HP, Siqueira JF (2009): Comparison of the effectiveness of three irrigation techniques in reducing intracanal Enterococcus faecalis populations: an in vitro study.

J Endod $\underline{35}, 1422-1427$

Brown JI, Doran JE (1975):

An in vitro evaluation of the particle flotation capability of various irrigating solutions.

J Calif Dent Assoc $\underline{3}, 60-63$

Brunner E, Domhof S, Langer F

Nonparametric analysis of longitudinal data in factorial experiments.

John Wiley \& Sons, New York 2002, 187-210 
Bryce G, O'Donnell D, Ready D, Ng Y, Pratten J, Gulabivala K (2009):

Contemporary root canal irrigants are able to disrupt and eradicate single- and dualspecies biofilms.

J Endod $\underline{35}, 1243-1248$

Buck RA, Cai J, Eleazer PD, Staat RH, Hurst HE (2001):

Detoxification of endotoxin by endodontic irrigants and calcium hydroxide.

J Endod 27, 325-327

Byström A, Sundqvist G (1981):

Bacteriologic evaluation of the efficacy of mechanical root canal instrumentation in endodontic therapy.

Scand J Dent Res $\underline{89}$, 321-328

Byström A, Sundqvist G (1983):

Bacteriologic evaluation of the effect of 0.5 percent sodium hypochlorite in endodontic therapy.

Oral Surg Oral Med Oral Pathol $\underline{55}, 307-312$

Byström A, Sundqvist G (1985):

The antibacterial action of sodium hypochlorite and EDTA in 60 cases of endodontic therapy.

Int Endod J 18, 35-40

Byström A, Claesson R, Sundqvist G (1985):

The antibacterial effect of camphorated paramonochlorophenol, camphorated phenol and calcium hydroxide in the treatment of infected root canals.

Endod Dent Traumatol 1, 170-175

Byström A, Happonen RP, Sjogren U, Sundqvist G (1987):

Healing of periapical lesions of pulpless teeth after endodontic treatment with controlled asepsis.

Endod Dent Traumatol $\underline{3}, 58-63$

Calt S, Serper A (1999):

Dentinal tubule penetration of root canal sealers after root canal dressing with calcium hydroxide.

J Endod 25, 431-433

Calt S, Serper A (2002):

Time-dependent effects of EDTA on dentin structures.

J Endod 28, 17-19

Cameron JA (1983):

The use of ultrasonics in the removal of the smear layer: a scanning electron microscope study.

J Endod 9 , 289-292 
Cameron JA (1987):

The synergistic relationship between ultrasound and sodium hypochlorite: a scanning electron microscope evaluation.

J Endod 13, 541-545

Cameron JA (1995):

Factors affecting the clinical efficiency of ultrasonic endodontics: a scanning electron microscopy study.

Int Endod J 28, 47-53

Caron G, Nham K, Bronnec F, Machtou P (2010):

Effectiveness of different final irrigant activation protocols on smear layer removal in curved canals.

J Endod 36, 1361-1366

Cheung GS, Stock CJ (1993):

In vitro cleaning ability of root canal irrigants with and without endosonics.

Int Endod J 26, 334-343

Chow TW (1983):

Mechanical effectiveness of root canal irrigation.

J Endod 9 , 475-479

Clegg MS, Vertucci FJ, Walker C, Belanger M, Britto LR (2006):

The effect of exposure to irrigant solutions on apical dentin biofilms in vitro.

J Endod $\underline{32}$, 434-437

Coltene whaledent (2011):

http://www.coltene.com/download.php?file_id=4133

Contardo L, Luca M de, Bevilacqua L, Breschi L, Di Lenarda R (2007):

Influence of calcium hydroxide debris on the quality of endodontic apical seal.

Minerva Stomatol $\underline{56}, 509-517$

Coolidge ED (1919):

The diagnosis and treatment of conditions resulting from diseases dental pulps.

J Am Dent Assoc 6 , 337-349

Crumpton BJ, Goodell GG, McClanahan SB (2005):

Effects on smear layer and debris removal with varying volumes of $17 \%$ REDTA after rotary instrumentation.

J Endod 31, 536-538

Cunningham WT, Martin H (1982):

A scanning electron microscope evaluation of root canal débridement with the endosonic ultrasonic synergistic system.

Oral Surg Oral Med Oral Pathol $\underline{53}, 527-531$ 
Cunningham WT, Martin H, Forrest WR (1982a):

Evaluation of root canal débridement by the endosonic ultrasonic synergistic system.

Oral Surg Oral Med Oral Pathol $\underline{53}, 401-404$

Cunningham WT, Martin H, Pelleu GB, Stoops DE (1982b):

A comparison of antimicrobial effectiveness of endosonic and hand root canal therapy.

Oral Surg Oral Med Oral Pathol 54, 238-241

Cvek M (1972):

Treatment of non-vital permanent incisors with calcium hydroxide. I. Follow-up of periapical repair and apical closure of immature roots.

Odontol Revy 23, 27-44

Cvek M (1974):

Treatment of non-vital permanent incisors with calcium hydroxide. IV. Periodontal healing and closure of the root canal in the coronal fragment of teeth with intra-alveolar fracture and vital apical fragment. A follow-up.

Odontol Revy $\underline{25}$, 239-246

Cvek M (1978):

A clinical report on partial pulpotomy and capping with calcium hydroxide in permanent incisors with complicated crown fracture.

J Endod 4, 232-237

Dalton BC, Orstavik D, Phillips C, Pettiette M, Trope M (1998):

Bacterial reduction with nickel-titanium rotary instrumentation.

J Endod 24, 763-767

De Gregorio C, Estevez R, Cisneros R, Paranjpe A, Cohenca N (2010):

Efficacy of different irrigation and activation systems on the penetration of sodium hypochlorite into simulated lateral canals and up to working length: an in vitro study.

J Endod $\underline{36}, 1216-1221$

DeNunzio MS, Hicks ML, Pelleu GB, Kingman A, Sauber JJ (1989):

Bacteriological comparison of ultrasonic and hand instrumentation of root canals in dogs.

J Endod 15, 290-293

De Oliveira LD, Jorge AOC, Carvalho CAT, Koga-Ito CY, Valera MC (2007):

In vitro effects of endodontic irrigants on endotoxins in root canals.

Oral Surg Oral Med Oral Pathol Oral Radiol Endod 104, 135-142

Desai P, van Himel (2009):

Comparative safety of various intracanal irrigation systems.

J Endod $\underline{35}$, 545-549

Deveaux E, Dufour D, Boniface B (2000):

Five methods of calcium hydroxide intracanal placement: an in vitro evaluation.

Oral Surg Oral Med Oral Pathol Oral Radiol Endod 89, 349-355 
Distel JW, Hatton JF, Gillespie MJ (2002):

Biofilm formation in medicated root canals.

J Endod 28, 689-693

Drake DR, Wiemann AH, Rivera EM, Walton RE (1994):

Bacterial retention in canal walls in vitro: effect of smear layer.

J Endod 20, 78-82

Dumsha TC, Gutmann JL (1985):

Clinical techniques for the placement of calcium hydroxide.

Compend Contin Educ Dent $\underline{6}$, 482-3, 486, 488-9

Dürr Dental (2011):

http://www.duerrdental.de/index.php?id=483\&doclds=935\&lng=DEU

Ehrich DG, Brian JD, Walker WA (1993):

Sodium hypochlorite accident: inadvertent injection into the maxillary sinus.

J Endod 19, 180-182

Estrela C, Sydney GB, Bammann LL, Felippe Júnior O (1995a):

Mechanism of action of calcium and hydroxyl ions of calcium hydroxide on tissue and bacteria.

Braz Dent J $\underline{6}$, 85-90

Estrela C, Sydney GB, Pesce HF, Felippe Júnior O (1995b):

Dentinal diffusion of hydroxyl ions of various calcium hydroxide pastes.

Braz Dent J $\underline{6}, 5-9$

Evans M, Davies JK, Sundqvist G, Figdor D (2002):

Mechanisms involved in the resistance of Enterococcus faecalis to calcium hydroxide. Int Endod J 35, 221-228

Fabricius L, Dahlén G, Holm SE, Möller AJ (1982):

Influence of combinations of oral bacteria on periapical tissues of monkeys.

Scand J Dent Res 90, 200-206

Falk KW, Sedgley CM (2005):

The influence of preparation size on the mechanical efficacy of root canal irrigation in vitro.

J Endod $\underline{31}, 742-745$

Fava LR, Saunders WP (1999):

Calcium hydroxide pastes: classification and clinical indications.

Int Endod J 32, 257-282

Frank AL (1966):

Therapy for the divergent pulpless tooth by continued apical formation.

J Am Dent Assoc 72, 87-93 
Fuks AB, Bielak S, Chosak A (1982):

Clinical and radiographic assessment of direct pulp capping and pulpotomy in young permanent teeth.

Pediatr Dent $\underline{4}, 240-244$

Fuks AB, Cosack A, Klein H, Eidelman E (1987):

Partial pulpotomy as a treatment alternative for exposed pulps in crown-fractured permanent incisors.

Endod Dent Traumatol $\underline{3}, 100-102$

Fukumoto Y, Kikuchi I, Yoshioka T, Kobayashi C, Suda H (2006):

An ex vivo evaluation of a new root canal irrigation technique with intracanal aspiration. Int Endod J 39, 93-99

Garip Y, Sazak H, Gunday M, Hatipoglu S (2010):

Evaluation of smear layer removal after use of a canal brush: an SEM study.

Oral Surg Oral Med Oral Pathol Oral Radiol Endod 110, e62-66

Gilbert B (1983):

Endodontic treatment of the open apex.

Quintessence Int 14, 293-299

Goldberg F, Alfie D, Roitman M (2004):

Evaluation of the incidence of transportation after placement and removal of calcium hydroxide.

J Endod 30, 646-648

Gomes BP, Ferraz CC, Vianna ME, Berber VB, Teixeira FB, Souza-Filho FJ (2001):

In vitro antimicrobial activity of several concentrations of sodium hypochlorite and chlorhexidine gluconate in the elimination of Enterococcus faecalis.

Int Endod J 34, 424-428

Grossmann LI (1943):

Irrigation of root canals.

J Am Dent Assoc 30, 1915-1917

Gu L, Kim JR, Ling J, Choi KK, Pashley DH, Tay FR (2009):

Review of contemporary irrigant agitation techniques and devices.

J Endod 35, 791-804

Guerisoli DMZ, Silva RS, Pécora JD (1898):

Evaluation of some physico-chemical properties of different concentrations of sodium hypochlorite solutions.

Braz Endod J 3 , 21-23 
Gulabivala K:

Biologische und klinische Grundlagen der Wurzelkanalbehandlung; in: Endodontie, hrsg. von Stock CJ, Walker RT, u.a.;

Elsevier Urban \& Fischer, München, 2005, 3-66

Gulabivala K, Stock CJ:

Wurzelkanalpräparation; in: Endodontie, hrsg. v. Stock CJ, Walker RT, u.a.;

Elsevier Urban \& Fischer, München, 2005, 135-171

Gulabivala K, Patel B, Evans GE, Ng YL (2005):

Effects of mechanical and chemical procedures on root canal surfaces.

Endod Topics 10, 103-122

Gulla R, Riitano G, Riitano F (1990):

Studio dell'anatomia endocanalre mediante sezioni longitudinali, stampi e diafanizzazione.; Study of canal anatomy using longitudinal sections, castings and diaphanizationÉU.

Giornale di endodonzia $\underline{4}, 11-16$

Gutarts R, Nusstein J, Reader A, Beck M (2005):

In vivo debridement efficacy of ultrasonic irrigation following hand-rotary instrumentation in human mandibular molars.

J Endod 31, 166-170

Gutiérrez JH, Jofré A, Villena F (1990):

Scanning electron microscope study on the action of endodontic irrigants on bacteria invading the dentinal tubules.

Oral Surg Oral Med Oral Pathol $\underline{69}, 491-501$

Haapasalo HK, Sirén EK, Waltimo T, Ørstavik D, Haapasalo M (2000):

Inactivation of local root canal medicaments by dentine: an in vitro study.

Int Endod J 33, 126-131

Haapasalo M, Endal U, Zandi H, Coil JM (2005):

Eradication of endodontic infection by instrumentation and irrigation solutions.

Endod Topics 10, 77-102

Haapasalo M, Shen Y, Qian W, Gao Y (2010):

Irrigation in endodontics.

Dent Clin North Am 노, 291-312

Haidet J, Reader A, Beck M, Meyers W (1989):

An in vivo comparison of the step-back technique versus a step-back/ultrasonic technique in human mandibular molars.

J Endod 15, 195-199 
Hancock HH, Sigurdsson A, Trope M, Moiseiwitsch J (2001):

Bacteria isolated after unsuccessful endodontic treatment in a North American population.

Oral Surg Oral Med Oral Pathol Oral Radiol Endod 91, 579-586

Hand RE, Smith ML, Harrison JW (1978):

Analysis of the effect of dilution on the necrotic tissue dissolution property of sodium hypochlorite.

J Endod 4 , 60-64

Hanlon RJ, Wucherpfennig AL, Green DB (1998):

Osteogenetic potential of calcium-containing biomaterials.

J Endod 24, 297 (Abstract \#31)

Harrison AJ, Chivatxaranukul P, Parashos P, Messer HH (2010):

The effect of ultrasonically activated irrigation on reduction of Enterococcus faecalis in experimentally infected root canals.

Int Endod J 43, 968-977

Harrison JW (1984):

Irrigation of the root canal system.

Dent Clin North Am 28, 797-808

Haskell EW, Stanley HR, Chellemi J, Stringfellow H (1978):

Direct pulp capping treatment: a long-term follow-up.

J Am Dent Assoc 97, 607-612

Hasselgren G, Olsson B, Cvek M (1988):

Effects of calcium hydroxide and sodium hypochlorite on the dissolution of necrotic porcine muscle tissue.

J Endod 14, 125-127

Hauser V, Braun A, Frentzen M (2007):

Penetration depth of a dye marker into dentine using a novel hydrodynamic system (RinsEndo).

Int Endod J 40, 644-652

Heistein S (2007):

RinsEndo - des Kaisers neue Kleider oder ein "Must-have"?

Zahnheilkd Management Kultur 23, 418-419

Heithersay GS (1970):

Stimulation of root formation in incompletely developed pulpless teeth.

Oral Surg Oral Med Oral Pathol $\underline{29}, 620-630$

Heithersay GS (1975):

Calcium hydroxide in the treatment of pulpless teeth with associated pathology.

$\mathrm{J}$ Br Endod Soc 8 , 74-93 
Hosoya N, Kurayama H, lino F, Arai T (2004):

Effects of calcium hydroxide on physical and sealing properties of canal sealers. Int Endod J 37, 178-184

Hsieh YD, Gau CH, Kung Wu SF, Shen EC, Hsu PW, Fu E (2007):

Dynamic recording of irrigating fluid distribution in root canals using thermal image analysis.

Int Endod J 40, 11-17

Huang T, Gulabivala K, Ng Y (2008):

A bio-molecular film ex-vivo model to evaluate the influence of canal dimensions and irrigation variables on the efficacy of irrigation.

Int Endod J 41, 60-71

Huffaker SK, Safavi K, Spangberg LSW, Kaufman B (2010):

Influence of a passive sonic irrigation system on the elimination of bacteria from root canal systems: a clinical study.

J Endod 36, 1315-1318

Hülsmann M (1997):

Die Wurzelkanalspülung - Ziele, Mittel und Techniken.

Endodontie $\underline{6}, 47-62$

Hülsmann M (2006):

Die Desinfektion des endodontischen Systems.

Endodontie 15, 147-170

Hülsmann M, Hahn W (2000):

Complications during root canal irrigation-literature review and case reports. Int Endod J 33, 186-193

Hülsmann M, Schäfer E: Probleme in der Endodontie. Prävention, Identifikation und Management; hrsg. von Hülsmann M, Schäfer E;

Quintessenz Verlag, Berlin 2007

Hülsmann M, Heckendorff M, Lennon A (2003):

Chelating agents in root canal treatment: mode of action and indications for their use. Int Endod J 36, 810-830

Itoh A, Higuchi N, Minami G, Yasue T, Yoshida T, Maseki T, Nakamura H (1999): A survey of filling methods, intracanal medications, and instrument breakage. J Endod 25, 823-824

Jiang L, Verhaagen B, Versluis M, van der Sluis LWM (2010a):

Evaluation of a sonic device designed to activate irrigant in the root canal. J Endod $\underline{36}$, 143-146 
Jiang L, Verhaagen B, Versluis M, van der Sluis LWM (2010b):

Influence of the oscillation direction of an ultrasonic file on the cleaning efficacy of passive ultrasonic irrigation.

J Endod $\underline{36}, 1372-1376$

Kahn FH, Rosenberg PA, Gliksberg J (1995):

An in vitro evaluation of the irrigating characteristics of ultrasonic and subsonic handpieces and irrigating needles and probes.

J Endod 21, 277-280

Kakehashi S, Stanley HR, Fitzgerald RJ (1965):

The effects of surgical exposures of dental pulps in germ-free and conventional laboratory rats.

Oral Surg Oral Med Oral Pathol 20, 340-349

Kantz WE, Henry CA (1974):

Isolation and classification of anaerobic bacteria from intact pulp chambers of non-vital teeth in man.

Arch Oral Biol 19, 91-96

Katebzadeh N, Hupp J, Trope M (1999):

Histological periapical repair after obturation of infected root canals in dogs.

J Endod 25, 364-368

Katebzadeh N, Sigurdsson A, Trope M (2000):

Radiographic evaluation of periapical healing after obturation of infected root canals: an in vivo study.

Int Endod J 33, 60-66

Kayaoglu G, Erten H, Bodrumlu E, Ørstavik D (2009):

The resistance of collagen-associated, planktonic cells of Enterococcus faecalis to calcium hydroxide.

J Endod $\underline{35}, 46-49$

Keir DM, Senia ES, Montgomery S (1990):

Effectiveness of a brush in removing postinstrumentation canal debris.

J Endod 16, 323-327

Kenee DM, Allemang JD, Johnson JD, Hellstein J, Nichol BK (2006):

A quantitative assessment of efficacy of various calcium hydroxide removal techniques.

J Endod 32, 563-565

Khademi A, Yazdizadeh M, Feizianfard M (2006):

Determination of the minimum instrumentation size for penetration of irrigants to the apical third of root canal systems.

J Endod $\underline{32}, 417-420$ 
Kim SK, Kim YO (2002):

Influence of calcium hydroxide intracanal medication on apical seal.

Int Endod J 35, 623-628

Kleier DJ, Averbach RE, Kawulok TC (1985):

Efficient calcium hydroxide placement within the root canal.

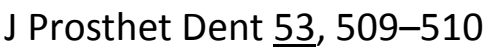

Kleier DJ, Averbach RE, Mehdipour O (2008):

The sodium hypochlorite accident: experience of diplomates of the American Board of Endodontics.

J Endod 34, 1346-1350

Klyn SL, Kirkpatrick TC, Rutledge RE (2010):

In vitro comparisons of debris removal of the EndoActivator system, the $\mathrm{F}$ file, ultrasonic irrigation, and $\mathrm{NaOCl}$ irrigation alone after hand-rotary instrumentation in human mandibular molars.

J Endod $\underline{36}, 1367-1371$

Koçkapan C (1995):

Die Bedeutung der Schmierschicht bei der Wurzelkanalbehandlung.

Endodontie 4, 33-48

Koçkapan C (2003):

Curriculum Endodontie. Spülen der Wurzelkanäle,

Quintessenz-Verlags GmbH, Berlin 2003, 349-373.

Komabayashi T, D'souza RN, Dechow PC, Safavi KE, Spångberg LSW (2009):

Particle size and shape of calcium hydroxide.

J Endod 35, 284-287

Kuga MC, Tanomaru-Filho M, Faria G, Só MVR, Galletti T, Bavello JRS (2010):

Calcium hydroxide intracanal dressing removal with different rotary instruments and irrigating solutions: a scanning electron microscopy study.

Braz Dent J 21, 310-314

Lambrianidis T, Margelos J, Beltes P (1999):

Removal efficiency of calcium hydroxide dressing from the root canal.

J Endod 25, 85-88

Lambrianidis T, Kosti E, Boutsioukis C, Mazinis M (2006):

Removal efficacy of various calcium hydroxide/chlorhexidine medicaments from the root canal.

Int Endod J 39, 55-61 
Lana MA, Ribeiro-Sobrinho AP, Stehling R, Garcia GD, Silva BK, Hamdan JS, Nicoli JR, Carvalho MA, Farias LM de (2001):

Microorganisms isolated from root canals presenting necrotic pulp and their drug susceptibility in vitro.

Oral Microbiol Immunol 16, 100-105

Law A, Messer H (2004):

An evidence-based analysis of the antibacterial effectiveness of intracanal medicaments. J Endod 30, 689-694

Lee S, Wu M, Wesselink PR (2004a):

The effectiveness of syringe irrigation and ultrasonics to remove debris from simulated irregularities within prepared root canal walls.

Int Endod J 37, 672-678

Lee S, Wu M, Wesselink PR (2004b):

The efficacy of ultrasonic irrigation to remove artificially placed dentine debris from different-sized simulated plastic root canals.

Int Endod J 37, 607-612

Löst C, Wesselink PR, Winkler R (1992):

Grundlagen und Prinzipien der modernen Endodontie.

Endodontie 1, 7-18

Lumley PJ, Walmsley AD (1992):

Effect of precurving on the performance of endosonic $\mathrm{K}$ files.

J Endod 18, 232-236

Lumley PJ, Walmsley AD, Laird WR (1991):

Streaming patterns produced around endosonic files.

Int Endod J 24, 290-297

Lumley PJ, Walmsley AD, Walton RE, Rippin JW (1993):

Cleaning of oval canals using ultrasonic or sonic instrumentation.

J Endod 19, 453-457

Lumley PJ, Adams N, Tomson P:

Practical clinical endodontics. Edinburg, 1.Auflage;

Churchill Livingstone, New York 2006

Lussi A, Nussbächer U, Grosrey J (1993):

A novel noninstrumented technique for cleansing the root canal system.

J Endod 19, 549-553

Manogue M, Patel S, Walker RT:

The principles of endodontics.

Oxford University Press, New York 2005 
Marending M, Zehnder M (2007):

Beeinflussung der mechanischen Dentineigenschaften durch die chemische Wurzelkanalaufbereitung.

Endodontie 16, 333-346

Margelos J, Eliades G, Verdelis C, Palaghias G (1997):

Interaction of calcium hydroxide with zinc oxide-eugenol type sealers: a potential clinical problem.

J Endod $\underline{23}, 43-48$

Martin H, Cunningham W (1984):

Endosonic endodontics: the ultrasonic synergistic system.

Int Dent J 34, 198-203

Mayer BE, Peters OA, Barbakow F (2002):

Effects of rotary instruments and ultrasonic irrigation on debris and smear layer scores: a scanning electron microscopic study.

Int Endod J 35, 582-589

McGill S, Gulabivala K, Mordan N, Ng Y (2008):

The efficacy of dynamic irrigation using a commercially available system (RinsEndo) determined by removal of a collagen 'bio-molecular film' from an ex vivo model.

Int Endod J 41, 602-608

Mehdipour O, Kleier DJ, Averbach RE (2007):

Anatomy of sodium hypochlorite accidents.

Compend Contin Educ Dent 28, 544-6, 548, 550

Meyer W (1970):

Die Anatomie der Wurzelkanäle, dargestellt an mikroskopischen

Rekonstruktionsmodellen.

Dtsch Zahnärztl Z 25, 1064-1077

Molander A, Reit C, Dahlén G, Kvist T (1998):

Microbiological status of root-filled teeth with apical periodontitis.

Int Endod J 31, 1-7

Molander A, Reit C, Dahlén G (1999):

The antimicrobial effect of calcium hydroxide in root canals pretreated with $5 \%$ iodine potassium iodide.

Endod Dent Traumatol 15, 205-209

Moser JB, Heuer MA (1982):

Forces and efficacy in endodontic irrigation systems.

Oral Surg Oral Med Oral Pathol $\underline{53}, 425-428$

Muschol A, Speer U: Medizinische Mikrobiologie.

Mediskript, München: 1978 
Muselmani B: Rasterelektronenmikroskopische Untersuchung zur Qualität der Aufbereitung und Reinigung des Wurzelkanals. Med. Diss. Universität Jena 2007 online verfügbar unter http://d-nb.info/987843028/00 / http://nbnresolving.de/urn:nbn:de:gbv:27-20080229-112357-5

Muselmani B, Kneist S, Glockmann E (2005a):

REM-Untersuchung zur Reinigungswirkung von RinsEndo - Eine In-vitro (Pilot) Studie [Abstract]. Berlin: Gemeinsame Tagung der wissenschaftlichen Gesellschaften der ZMK/Deutscher Zahnärztetag.

Muselmani B, Kneist S, Glockmann E (2005b): Antimicrobial effectiveness of hydrodynamic and conventional rinsing in root canal [Abstract]. Amsterdam: The Joint Meeting of the Continental European (CED) and Scandinavian (NOF) Divisions of the International Association of Dental Research (IADR).

Naenni N, Thoma K, Zehnder M (2004):

Soft tissue dissolution capacity of currently used and potential endodontic irrigants. J Endod 30 , 785-787

Nair PNR, Henry S, Cano V, Vera J (2005):

Microbial status of apical root canal system of human mandibular first molars with primary apical periodontitis after "one-visit" endodontic treatment.

Oral Surg Oral Med Oral Pathol Oral Radiol Endod 99, 231-252

Nandini S, Velmurugan N, Kandaswamy D (2006): Removal efficiency of calcium hydroxide intracanal medicament with two calcium chelators: volumetric analysis using spiral CT, an in vitro study. J Endod 32, 1097-1101

Nelson-Filho P, Leonardo MR, Silva LAB, Assed S (2002):

Radiographic evaluation of the effect of endotoxin (LPS) plus calcium hydroxide on apical and periapical tissues of dogs.

J Endod 28, 694-696

Nerwich A, Figdor D, Messer HH (1993):

$\mathrm{pH}$ changes in root dentin over a 4-week period following root canal dressing with calcium hydroxide.

J Endod 19, 302-306

Nguy D, Sedgley C (2006):

The influence of canal curvature on the mechanical efficacy of root canal irrigation in vitro using real-time imaging of bioluminescent bacteria.

J Endod 32, 1077-1080

Nielsen BA, Craig Baumgartner J (2007):

Comparison of the EndoVac system to needle irrigation of root canals.

J Endod 33, 611-615 
Niu W, Yoshioka T, Kobayashi C, Suda H (2002):

A scanning electron microscopic study of dentinal erosion by final irrigation with EDTA and $\mathrm{NaOCl}$ solutions.

Int Endod J 35, 934-939

Oguntebi BR (1994):

Dentine tubule infection and endodontic therapy implications.

Int Endod J 27, 218-222

Ørstavik D (2003):

Die Wurzelkanaldesinfektion - Eine Übersicht über Auffassungen und jüngste

Entwicklungen.

Endodontie 12, 343-352

Ørstavik D, Haapasalo M (1990):

Disinfection by endodontic irrigants and dressings of experimentally infected dentinal tubules.

Endod Dent Traumatol $\underline{6}, 142-149$

Ørstavik D, Kerekes K, Molven O (1991):

Effects of extensive apical reaming and calcium hydroxide dressing on bacterial infection during treatment of apical periodontitis: a pilot study.

Int Endod J 24, 1-7

Oztan MD, Akman A, Dalat D (2002):

Intracanal placement of calcium hydroxide: a comparison of two different mixtures and carriers.

Oral Surg Oral Med Oral Pathol Oral Radiol Endod $\underline{94}$, 93-97

Paqué F, Ganahl D, Peters OA (2009):

Effects of root canal preparation on apical geometry assessed by micro-computed tomography.

J Endod $\underline{35}, 1056-1059$

Paragliola R, Franco V, Fabiani C, Mazzoni A, Nato F, Tay FR, Breschi L, Grandini S (2010):

Final rinse optimization: influence of different agitation protocols.

J Endod $\underline{36}$, 282-285

Pasqualini D, Cuffini AM, Scotti N, Mandras N, Scalas D, Pera F, Berutti E (2010):

Comparative evaluation of the antimicrobial efficacy of a $5 \%$ sodium hypochlorite subsonic-activated solution.

J Endod $\underline{36}, 1358-1360$

Pesse AV, Warrier GR, Dhir VK (2005):

An experimental study of the gas entrapment process in closed-end microchannels. Int J Heat Mass Tran 48, 5150-5165 
Peters Cl, Koka RS, Highsmith S, Peters OA (2005):

Calcium hydroxide dressings using different preparation and application modes: density and dissolution by simulated tissue pressure.

Int Endod J 38, 889-895

Peters LB, van Winkelhoff AJ, Buijs JF, Wesselink PR (2002a):

Effects of instrumentation, irrigation and dressing with calcium hydroxide on infection in pulpless teeth with periapical bone lesions.

Int Endod J $\underline{35}, 13-21$

Peters LB, Wesselink PR, van Winkelhoff AJ (2002b):

Combinations of bacterial species in endodontic infections.

Int Endod J 35, 698-702

Peters OA (2004):

Current challenges and concepts in the preparation of root canal systems: a review.

J Endod 30, 559-567

Pinheiro ET, Gomes BPFA, Ferraz CCR, Sousa ELR, Teixeira FB, Souza-Filho FJ (2003a):

Microorganisms from canals of root-filled teeth with periapical lesions.

Int Endod J 36, 1-11

Pinheiro ET, Gomes BPFA, Ferraz CCR, Teixeira FB, Zaia AA, Souza Filho FJ (2003b):

Evaluation of root canal microorganisms isolated from teeth with endodontic failure and their antimicrobial susceptibility.

Oral Microbiol Immunol $\underline{18}, 100-103$

Plotino G, Grande NM, Melo MC, Bahia MG, Somma F (2009):

Mechanical properties and dimensional characterisation of Roeko CanalBrush.

Int Endod J 42, 1159, Abstract R112

Portenier I, Haapasalo HK, Rye A, Waltimo T, Ørstavik D, Haapasalo M (2001):

Inactivation of root canal medicaments by dentine, hydroxylapatite and bovine serum albumin.

Int Endod J 34, 184-188

Portenier I, Haapasalo HK, Orstavik D, Yamauchi M, Haapasalo M (2002):

Inactivation of the antibacterial activity of iodine potassium iodide and chlorhexidine digluconate against Enterococcus faecalis by dentin, dentin matrix, type-I collagen, and heat-killed microbial whole cells.

J Endod 28, 634-637

Preiswerk G (1901):

Die Pulpa-Amputation, eine klinische, pathohistologische und bakteriologische Studie.

Österr-Ung Vjschr Zahnhkd 17, 145-220 
Pschyrembel:

Klinisches Wörterbuch, 262. neu bearb. Auflage;

de Gruyter, Berlin 2010

Radcliffe CE, Potouridou L, Qureshi R, Habahbeh N, Qualtrough A, Worthington H, Drucker DB (2004):

Antimicrobial activity of varying concentrations of sodium hypochlorite on the endodontic microorganisms Actinomyces israelii, A. naeslundii, Candida albicans and Enterococcus faecalis.

Int Endod J 37, 438-446

Ram Z (1977):

Effectiveness of root canal irrigation.

Oral Surg Oral Med Oral Pathol 44, 306-312

Riitano F (1981):

Root anatomy and endodontic instrumentation.

Riv Ital Stomatol $\underline{50}$, 689-701

Rivera EM, Williams K (1994):

Placement of calcium hydroxide in simulated canals: comparison of glycerin versus water. J Endod 20, 445-448

Rödig T (2010):

Literatur-Rundschau. Neuartige Systeme zur Applikation und Aktivierung von Spülflüssigkeiten.

Endodontie 19, 187-195

Rödig T, Hülsmann M (2006):

Literatur-Rundschau. Applikation und Entfernung der medikamentösen Einlage.

Endodontie 15, 379-385

Rödig T, Bozkurt M, Konietschke F, Hülsmann M (2010a):

Comparison of the Vibringe system with syringe and passive ultrasonic irrigation in removing debris from simulated root canal irregularities.

J Endod 36, 1410-1413

Rödig T, Döllmann S, Konietschke F, Drebenstedt S, Hülsmann M (2010b):

Effectiveness of different irrigant agitation techniques on debris and smear layer removal in curved root canals: a scanning electron microscopy study.

J Endod $\underline{36}, 1983-1987$

Rödig T, Sedghi M, Konietschke F, Lange K, Ziebolz D, Hülsmann M (2010c):

Efficacy of syringe irrigation, RinsEndo and passive ultrasonic irrigation in removing debris from irregularities in root canals with different apical sizes.

Int Endod J 43, 581-589 
Rödig T, Vogel S, Zapf A, Hülsmann M (2010d):

Efficacy of different irrigants in the removal of calcium hydroxide from root canals. Int Endod J 43, 519-527

Roy RA, Ahmad M, Crum LA (1994):

Physical mechanisms governing the hydrodynamic response of an oscillating ultrasonic file.

Int Endod J 27, 197-207

Ruddle CJ (2007):

Hydrodynamic disinfection: tsunami endodontics.

Dent Today 26, 110-117

Sabins RA, Johnson JD, Hellstein JW (2003):

A comparison of the cleaning efficacy of short-term sonic and ultrasonic passive irrigation after hand instrumentation in molar root canals.

J Endod 29, 674-678

Safavi KE, Nichols FC (1993):

Effect of calcium hydroxide on bacterial lipopolysaccharide.

J Endod $\underline{19}$, 76-78

Saif S, Carey CM, Tordik PA, McClanahan SB (2008):

Effect of irrigants and cementum injury on diffusion of hydroxyl ions through the dentinal tubules.

J Endod $\underline{34}, 50-52$

Saleh AA, Ettman WM (1999):

Effect of endodontic irrigation solutions on microhardness of root canal dentine.

J Dent 27, 43-46

Salgado RJC, Moura-Netto C, Yamazaki AK, Cardoso LN, Moura AAM de, Prokopowitsch I (2009):

Comparison of different irrigants on calcium hydroxide medication removal: microscopic cleanliness evaluation.

Oral Surg Oral Med Oral Pathol Oral Radiol Endod 107, 580-584

Salman MI, Baumann MA, Hellmich M, Roggendorf MJ, Termaat S (2010):

SEM evaluation of root canal debridement with Sonicare CanalBrush irrigation.

Int Endod J 43, 363-369

Sathorn C, Parashos P, Messer H (2007):

Antibacterial efficacy of calcium hydroxide intracanal dressing: a systematic review and meta-analysis.

Int Endod J 40, 2-10 
Schoeffel GJ (2007):

The EndoVac method of endodontic irrigation: safety first.

Dent Today 26, 92, 94, 96 passim

Schoeffel GJ (2008):

The EndoVac method of endodontic irrigation, part 2--efficacy.

Dent Today 27, 82, 84, 86-87

Schröder U (1985):

Effects of calcium hydroxide-containing pulp-capping agents on pulp cell migration, proliferation, and differentiation.

J Dent Res 64, 541-548

Sciaky I, Pisanti S (1960):

Localization of calcium placed over amputated pulps in dogs' teeth.

J Dent Res 39, 1128-1132

Sedgley C, Applegate B, Nagel A, Hall D (2004):

Real-time imaging and quantification of bioluminescent bacteria in root canals in vitro. J Endod 30, 893-898

Sedgley C, Nagel A, Hall D, Applegate B (2005):

Influence of irrigant needle depth in removing bioluminescent bacteria inoculated into instrumented root canals using real-time imaging in vitro.

Int Endod J 38, 97-104

Sen BH, Piskin B, Demirci T (1995a):

Observation of bacteria and fungi in infected root canals and dentinal tubules by SEM.

Endod Dent Traumatol 11, 6-9

Sen BH, Wesselink PR, Türkün M (1995b):

The smear layer: a phenomenon in root canal therapy.

Int Endod J 28, 141-148

Sen BH, Safavi KE, Spångberg LS (1997):

Growth patterns of Candida albicans in relation to radicular dentin.

Oral Surg Oral Med Oral Pathol Oral Radiol Endod $\underline{84}$, 68-73

Sena NT, Gomes BPFA, Vianna ME, Berber VB, Zaia AA, Ferraz CCR, Souza-Filho FJ (2006): In vitro antimicrobial activity of sodium hypochlorite and chlorhexidine against selected single-species biofilms.

Int Endod J 39, 878-885

Shahravan A, Haghdoost A, Adl A, Rahimi H, Shadifar F (2007):

Effect of smear layer on sealing ability of canal obturation: a systematic review and metaanalysis.

J Endod 33, 96-105 
Shen Y, Stojicic S, Qian W, Olsen I, Haapasalo M (2010):

The synergistic antimicrobial effect by mechanical agitation and two chlorhexidine preparations on biofilm bacteria.

J Endod 36, 100-104

Shuping GB, Orstavik D, Sigurdsson A, Trope M (2000):

Reduction of intracanal bacteria using nickel-titanium rotary instrumentation and various medications.

J Endod 26, 751-755

Sigurdsson A, Stancill R, Madison S (1992):

Intracanal placement of $\mathrm{Ca}(\mathrm{OH}) 2$ : a comparison of techniques.

J Endod 18, 367-370

Siqueira JF, Lopes HP (1999):

Mechanisms of antimicrobial activity of calcium hydroxide: a critical review.

Int Endod J 32, 361-369

Siqueira JF, Lopes HP (2002):

Kalziumhydroxid als antimikrobielle Einlage in der Endodontie - Wirkungsmechanismen, Vorteile und Grenzen.

Endodontie 11, 222-347

Siqueira JF, Rôças IN (2008):

Clinical implications and microbiology of bacterial persistence after treatment procedures.

J Endod 34, 1291-1301.e3

Siqueira JF, Machado AG, Silveira RM, Lopes HP, Uzeda M de (1997):

Evaluation of the effectiveness of sodium hypochlorite used with three irrigation methods in the elimination of Enterococcus faecalis from the root canal, in vitro.

Int Endod J 30, 279-282

Siqueira JF, Batista MM, Fraga RC, Uzeda M de (1998):

Antibacterial effects of endodontic irrigants on black-pigmented gram-negative anaerobes and facultative bacteria.

J Endod 24, 414-416

Siqueira JF, Lima KC, Magalhães FA, Lopes HP, Uzeda M de (1999):

Mechanical reduction of the bacterial population in the root canal by three instrumentation techniques.

J Endod 25, 332-335

Siqueira JF, Rôças IN, Favieri A, Lima KC (2000):

Chemomechanical reduction of the bacterial population in the root canal after instrumentation and irrigation with $1 \%, 2.5 \%$, and $5.25 \%$ sodium hypochlorite.

J Endod 26, 331-334 
Siqueira JF, Magalhães KM, Rôças IN (2007a):

Bacterial reduction in infected root canals treated with $2.5 \% \mathrm{NaOCl}$ as an irrigant and calcium hydroxide/camphorated paramonochlorophenol paste as an intracanal dressing. J Endod $\underline{33}, 667-672$

Siqueira JF, Paiva SSM, Rôças IN (2007b):

Reduction in the cultivable bacterial populations in infected root canals by a chlorhexidine-based antimicrobial protocol.

J Endod $\underline{33}, 541-547$

Siqueira JF, Rôças IN, Paiva SSM, Guimarães-Pinto T, Magalhães KM, Lima KC (2007c):

Bacteriologic investigation of the effects of sodium hypochlorite and chlorhexidine during the endodontic treatment of teeth with apical periodontitis.

Oral Surg Oral Med Oral Pathol Oral Radiol Endod 104, 122-130

Sirtes G, Waltimo T, Schaetzle M, Zehnder M (2005):

The effects of temperature on sodium hypochlorite short-term stability, pulp dissolution capacity, and antimicrobial efficacy.

J Endod 31, 669-671

Sjögren U, Sundqvist G (1987):

Bacteriologic evaluation of ultrasonic root canal instrumentation.

Oral Surg Oral Med Oral Pathol $\underline{63}, 366-370$

Sjögren U, Hagglund B, Sundqvist G, Wing K (1990):

Factors affecting the long-term results of endodontic treatment.

J Endod 16, 498-504

Sjögren U, Figdor D, Spångberg L, Sundqvist G (1991):

The antimicrobial effect of calcium hydroxide as a short-term intracanal dressing.

Int Endod J 24, 119-125

Sjögren U, Figdor D, Persson S, Sundqvist G (1997):

Influence of infection at the time of root filling on the outcome of endodontic treatment of teeth with apical periodontitis.

Int Endod J 30, 297-306

Spångberg L, Langeland K (1973):

Biologic effects of dental materials. 1. Toxicity of root canal filling materials on HeLa cells in vitro.

Oral Surg Oral Med Oral Pathol $\underline{35}, 402-414$

Spångberg L, Rutberg M, Rydinge $E$ (1979):

Biologic effects of endodontic antimicrobial agents.

J Endod ㅁ, 166-175 
Spielman Al (2007):

The Birth of the Most Important 18th Century Dental Text: Pierre Fauchard's Le

Chirurgien Dentist.

J Dent Res 86, 922-926

Spratt DA, Pratten J, Wilson M, Gulabivala K (2001):

An in vitro evaluation of the antimicrobial efficacy of irrigants on biofilms of root canal isolates.

Int Endod J 34, 300-307

Staehle HJ, Thomä C, Müller HP (1997):

Comparative in vitro investigation of different methods for temporary root canal filling with aqueous suspensions of calcium hydroxide.

Endod Dent Traumatol 13, 106-112

Stock CJ (1991):

Current status of the use of ultrasound in endodontics.

Int Dent J 41, 175-182

Strindberg LZ (1956):

The dependence of the results of pulp therapy on certain factors. An analytic study based on radiographic and clinical follow-up examinations.

Acta Odontol Scand 14, 1-175

Su Y, Wang C, Ye L (2011):

Healing rate and post-obturation pain of single- versus multiple-visit endodontic treatment for infected root canals: a systematic review.

J Endod 37, 125-132

Sundqvist G (1992):

Associations between microbial species in dental root canal infections.

Oral Microbiol Immunol $\underline{7}, 257-262$

Sundqvist G (1994):

Taxonomy, ecology, and pathogenicity of the root canal flora.

Oral Surg Oral Med Oral Pathol $\underline{78}, 522-530$

Sundqvist G, Johansson E, Sjögren U (1989):

Prevalence of black-pigmented bacteroides species in root canal infections.

J Endod 15, 13-19

Sundqvist G, Figdor D, Persson S, Sjögren U (1998):

Microbiologic analysis of teeth with failed endodontic treatment and the outcome of conservative re-treatment.

Oral Surg Oral Med Oral Pathol Oral Radiol Endod $\underline{85}$, 86-93 
Svec TA, Harrison JW (1977):

Chemomechanical removal of pulpal and dentinal debris with sodium hypochlorite and hydrogen peroxide vs normal saline solution.

J Endod $\underline{3}, 49-53$

Svensäter G, Bergenholtz G (2004):

Biofilms in endodontic infections.

Endod Topics $\underline{9}$, 27-36

Tanomaru JMG, Leonardo MR, Tanomaru Filho M, Bonetti Filho I, Silva LAB (2003):

Effect of different irrigation solutions and calcium hydroxide on bacterial LPS.

Int Endod J 36, 733-739

Taşdemir T, Celik D, Er K, Yildirim T, Ceyhanli KT, Yeşilyurt C (2011):

Efficacy of several techniques for the removal of calcium hydroxide medicament from root canals.

Int Endod J 44, 505-509

Teixeira CS, Felippe MCS, Felippe WT (2005):

The effect of application time of EDTA and $\mathrm{NaOCl}$ on intracanal smear layer removal: an SEM analysis.

Int Endod J 38, 285-290

Teplitsky P (1986):

McSpadden compactor. Vertical condensation technique to deliver calcium hydroxide.

J Can Dent Assoc 52, 779-781

Tidmarsh BG (1979):

Accidental perforation of the roots of teeth.

J Oral Rehabil $\underline{6}$, 235-240

Torabinejad M, Handysides R, Khademi AA, Bakland LK (2002):

Clinical implications of the smear layer in endodontics: a review.

Oral Surg Oral Med Oral Pathol Oral Radiol Endod 94, 658-666

Torres CP, Apicella MJ, Yancich PP, Parker MH (2004):

Intracanal placement of calcium hydroxide: a comparison of techniques, revisited.

J Endod 30, 225-227

Townsend C, Maki J (2009):

An in vitro comparison of new irrigation and agitation techniques to ultrasonic agitation in removing bacteria from a simulated root canal.

J Endod 35, 1040-1043

Tronstad L, Mjör IA (1972):

Capping of the inflamed pulp.

Oral Surg Oral Med Oral Pathol 34, 477-485 
Tronstad L, Andreasen JO, Hasselgren G, Kristerson L, Riis I (1981):

$\mathrm{PH}$ changes in dental tissues after root canal filling with calcium hydroxide.

J Endod ㄱ, 17-21

Tronstad L, Barnett F, Schwartzben L, Frasca P (1985):

Effectiveness and safety of a sonic vibratory endodontic instrument.

Endod Dent Traumatol 1, 69-76

Trope M, Delano EO, Orstavik D (1999):

Endodontic treatment of teeth with apical periodontitis: single vs. multivisit treatment.

J Endod 25, 345-350

Türkün M, Cengiz T (1997):

The effects of sodium hypochlorite and calcium hydroxide on tissue dissolution and root canal cleanliness.

Int Endod J 30, 335-342

Uroz-Torres D, González-Rodríguez MP, Ferrer-Luque CM (2010):

Effectiveness of the EndoActivator System in removing the smear layer after root canal instrumentation.

J Endod 36, 308-311

Usman N, Baumgartner JC, Marshall JG (2004):

Influence of instrument size on root canal debridement.

J Endod 30, 110-112

Van der Sluis LWM (2006):

Die passive Ultraschallspülung des Wurzelkanalsystems.

Endodontie 15, 177-185

Van der Sluis LWM, Wu MK, Wesselink PR (2005a):

A comparison between a smooth wire and a K-file in removing artificially placed dentine debris from root canals in resin blocks during ultrasonic irrigation.

Int Endod J 38, 593-596

Van der Sluis LWM, Wu MK, Wesselink PR (2005b):

The efficacy of ultrasonic irrigation to remove artificially placed dentine debris from human root canals prepared using instruments of varying taper.

Int Endod J 38, 764-768

Van der Sluis LWM, Gambarini G, Wu MK, Wesselink PR (2006):

The influence of volume, type of irrigant and flushing method on removing artificially placed dentine debris from the apical root canal during passive ultrasonic irrigation. Int Endod J 39, 472-476

Van der Sluis LWM, Versluis M, Wu MK, Wesselink PR (2007a):

Passive ultrasonic irrigation of the root canal: a review of the literature.

Int Endod J 40, 415-426 
Van der Sluis LWM, Wu MK, Wesselink PR (2007b):

The evaluation of removal of calcium hydroxide paste from an artificial standardized groove in the apical root canal using different irrigation methodologies.

Int Endod J 40, 52-57

Van der Sluis LWM, Vogels MPJM, Verhaagen B, Macedo R, Wesselink PR (2010):

Study on the influence of refreshment/activation cycles and irrigants on mechanical cleaning efficiency during ultrasonic activation of the irrigant.

J Endod 36, 737-740

Vivan RR, Bortolo MV, Duarte MA, Moraes IG, Tanomaru-Filho M, Bramante CM (2010): Scanning electron microscopy analysis of RinsEndo system and conventional irrigation for debris removal.

Braz Dent J 21, 305-309

Wadachi R, Araki K, Suda H (1998):

Effect of calcium hydroxide on the dissolution of soft tissue on the root canal wall.

J Endod 24, 326-330

Walmsley AD (1987):

Ultrasound and root canal treatment: the need for scientific evaluation.

Int Endod J 20, 105-111

Walmsley AD, Lumley PJ, Laird WR (1989):

Oscillatory pattern of sonically powered endodontic files.

Int Endod J 22, 125-132

Walters MJ, Baumgartner JC, Marshall JG (2002):

Efficacy of irrigation with rotary instrumentation.

J Endod 28, 837-839

Waltimo T, Ørstavik D, Sirén EK, Haapasalo M (1999):

In vitro susceptibility of Candida albicans to four disinfectants and their combinations.

Int Endod J 32, 421-429

Waltimo T, Ørstavik D, Meurman JH, Samaranayake LP, Haapasalo M (2000):

In vitro susceptibility of Candida albicans isolates from apical and marginal periodontitis to common antifungal agents.

Oral Microbiol Immunol 15, 245-248

Waltimo T, Trope M, Haapasalo M, Ørstavik D (2005):

Clinical efficacy of treatment procedures in endodontic infection control and one year

follow-up of periapical healing.

J Endod $\underline{31}$, 863-866

Webber RT, Schwiebert KA, Cathey GM (1981):

A technique for placement of calcium hydroxide in the root canal system.

J Am Dent Assoc 103, 417-421 
Weise M, Roggendorf MJ, Ebert J, Petschelt A, Frankenberger R (2007):

Four methods for cleaning simulated lateral extensions of curved root canals - a SEM evaluation.

Int Endod J 40, 979-1000, ( Abstract \# R2.39)

Wiggins S, Ottino JM (2004):

Foundations of chaotic mixing.

Philos Transact A Math Phys Eng Sci 362, 937-970

Wiseman A, Cox TC, Paranjpe A, Flake NM, Cohenca N, Johnson JD (2011):

Efficacy of sonic and ultrasonic activation for removal of calcium hydroxide from mesial canals of mandibular molars: a microtomographic study.

J Endod 37, 235-238

Witton R, Henthorn K, Ethunandan M, Harmer S, Brennan PA (2005):

Neurological complications following extrusion of sodium hypochlorite solution during root canal treatment.

Int Endod J $\underline{38}$, 843-848

Wu MK, Wesselink PR (1995):

Efficacy of three techniques in cleaning the apical portion of curved root canals.

Oral Surg Oral Med Oral Pathol Oral Radiol Endod 79, 492-496

Wu MK, Wesselink PR (2001):

A primary observation on the preparation and obturation of oval canals.

Int Endod J 34, 137-141

Wu MK, van der Sluis LWM, Wesselink PR (2003):

The capability of two hand instrumentation techniques to remove the inner layer of dentine in oval canals.

Int Endod J 36, 218-224

Yamada RS, Armas A, Goldman M, Lin PS (1983):

A scanning electron microscopic comparison of a high volume final flush with several irrigating solutions: Part 3.

J Endod $\underline{9}, 137-142$

Zehnder M (2006):

Root canal irrigants.

J Endod 32, 389-398

Zehnder M, Lehnert B, Schönenberger K, Waltimo T (2003):

Irrigants and intracanal medicaments in endodontics.

Schweiz Monatsschr Zahnmed 113, 756-763

Zeltner M, Peters OA, Paqué F (2009):

Temperature changes during ultrasonic irrigation with different inserts and modes of activation.

J Endod $\underline{35}, 573-577$ 


\section{Danksagung}

Mein besonderer Dank gilt meinem Doktorvater Herrn Prof. Dr. med. dent. Michael Hülsmann, kommissarischer Direktor der Abteilung Präventive Zahnmedizin, Parodontologie und Kariologie der Universitätsmedizin Göttingen für die freundliche Vergabe des Themas sowie die zuverlässige und engagierte Betreuung und die immerwährende Motivation.

Für die kompetente Beratung und die statistische Auswertung der Daten danke ich Frau Katharina Lange aus der Abteilung Medizinische Statistik der Universitätsmedizin Göttingen.

Ebenfalls möchte ich mich an dieser Stelle bei Allen bedanken, die mich auf diesem Weg unterstützt und begleitet haben. Ein herzliches Dankeschön gilt Moritz Schroeder für die vielen gemeinsamen Stunden während der praktischen Versuche. 